\title{
Work: Marxist and Systems-Theoretical Approaches
}

Using Marxist and systems theory as guides, this book offers an entry point to the current debate on the role of economy in modern society, the change in work organizations and the effect of the economy on the individual. It explores the concepts of 'work society', 'industrial society' and 'capitalist society' to explain the conditions of society as a whole, and not just the conditions of businesses, making particular use of the category of 'work'. The first systematic theoretical comparison of Marxism and systems theory, it provides a brief overview of the central debates concerning work society and the controversies surrounding organizations in capitalism. As such, it will appeal to social scientists and social theorists with interests in the sociology of work, industry and organizations.

Stefan Kühl is Professor of Sociology at the University of Bielefeld, Germany, and a senior consultant for Metaplan - a consulting firm based in Princeton, Versailles, Hamburg, Shanghai and Singapore. He is the author of Organizations: A Systems Approach; When the Monkeys Run the Zoo: The Pitfalls of Flat Hierarchies; The Sudoku Effect: Universities in the Vicious Circle of Bureaucracy; The Nazi Connection: Eugenics, American Racism, and German National Socialism; For the Betterment of the Race: The Rise and Fall of the International Movement for Eugenics and Racial Hygiene; and Ordinary Organizations: Why Normal Men Carried Out the Holocaust. 


\section{Routledge Studies in Social and Political Thought}

137 Common Sense as a Paradigm of Thought

An Analysis of Social Interaction

Tim Delaney

138 The Intellectual Origins of Modernity

David Ohana

\section{Political Fraternity}

Democracy beyond Freedom and Equality

Angel Puyol

140 Nationalism, Inequality and England's Political Predicament

Charles Leddy-Owen

141 Politics through the Iliad and the Odyssey

Hobbes writes Homer

Andrea Catanzaro

\section{Social Change in a Material World}

Theodore R. Schatzki

\section{Hubris and Progress}

A Future Born of Presumption

Carlo Bordoni

144 Work: Marxist and Systems-Theoretical Approaches Stefan Kühl

For a full list of titles in this series, please visit www.routledge.com/series/ RSSPT 


\title{
Work: Marxist and Systems-Theoretical Approaches
}

\author{
Stefan Kühl
}

\author{
Routledge \\ 甯 Taylor \& Francis Group \\ LONDON AND NEW YORK
}


First published in English 2019 by Routledge

by Routledge

2 Park Square, Milton Park, Abingdon, Oxon OX14 4RN

and by Routledge

52 Vanderbilt Avenue, New York, NY 10017

Routledge is an imprint of the Taylor \& Francis Group, an informa business

(C) 2019 Stefan Kühl

The right of Stefan Kühl to be identified as author of this work has been asserted by him in accordance with sections 77 and 78 of the Copyright, Designs and Patents Act 1988.

Translated by Andrés Crump

All rights reserved. No part of this book may be reprinted or reproduced or utilised in any form or by any electronic, mechanical, or other means, now known or hereafter invented, including photocopying and recording, or in any information storage or retrieval system, without permission in writing from the publishers.

Trademark notice: Product or corporate names may be trademarks or registered trademarks, and are used only for identification and explanation without intent to infringe.

Published in German by Springer VS 2017

British Library Cataloguing-in-Publication Data

A catalogue record for this book is available from the British Library

Library of Congress Cataloging-in-Publication Data

A catalog record has been requested for this book

ISBN: 978-0-367-14449-4 (hbk)

ISBN: 978-0-429-03209-7 (ebk)

Typeset in Times New Roman

by codeMantra 
Translation from the German language edition: Work by Stefan Kühl Copyright (C) Springer VS 2017. Springer VS is part of Springer Science + Business Media. All Rights Reserved. 



\section{Contents}

1 Work-theoretical perspectives 1

The explanation of society over the key category of work 3

Beyond the limitation of mid-range theories-Marxism and

systems theory as grand theories 5

The focus on three debates 7

2 Primacy of economy vs. functional differentiation: the debate on the form of modern society

2.1 The basic Marxian idea: from capitalist economy to capitalist society 10

2.2 The societal theory debate: from Pre-Fordism to Fordism to Post-Fordism 17

2.3 The systems-theoretical approach of functional differentiation: capitalist economy instead of capitalist society 26

3 Business vs. organization: subsumising the company to the logic of profit maximization or stressing the self-logic of the organization

3.1 Marx's basic notion: the increase of absolute and relative surplus value 36

3.2 The debate: Taylorist vs. Holistic forms of work 41

3.3 The approach of systems theory: the inherent rationale of the organization 53

4 Worker consciousness vs. worker essence as a role: class as a binding link between society and the individual

4.1 The Marxian rationale: the imprint of work and the class concept 71 


\section{viii Contents}

4.2 The debate: formation and differentiation of class consciousness 77

4.3 The approach of a theory of functional differentiation: roles 87

5 In favor of a renaissance of grand theories

Regarding the 'critical potential' of sociology 97

References

Index 


\section{Work-theoretical perspectives}

Work is an enigmatic term. Intuitively, one supposes what it means. However, upon closer inspection, it becomes apparent just how difficult it is to determine what can and can't be defined as work (see already, e.g., Cummings/ Srivastva 1977; Ransome 1996). It might be uncontroversial to say that a person 'works' when they are remunerated for their activities at a factory, a retirement home or an association. But what if their activities are not remunerated at all? Of course, one wouldn't say that an entrepreneur managing their own company is not 'working'; but what if they have someone else manage the company, and the entrepreneur retreats to the position of chairman of the supervisory board? When a paid tutor at a university teaches the intricacies of variance analysis to their fellow students, one would presume that they are 'working'; but what if they're performing this service as an act of friendship?

One could simplify things and refer to all human activities as work (regarding the difficulty thereof, see, e.g., Applebaum 1992; Karlsson 2004; Budd 2011). For instance, adults who wrap their kids in diapers, take them to kindergarten or read to them at bedtime would be performing 'childrearing work'; cleaning up, grocery shopping and cooking would obviously also count as 'housework'. The same would go for someone who is politically or artistically active, or someone who is committed to volunteer work; according to this broad definition, they would also be 'working'. Someone in conversation with their partner would be performing 'relationship work', and if feelings are involved, one could speak of additional 'emotional work' taking place. Furthermore, one who tries to come to terms with a breakup after failed 'relationship work' would be performing 'mourning work', just as one who is processing this long after the separation would be performing 'remembrance work'. Whatever we do, we would be performing work-as long as we are able to make these activities appear as work to ourselves and others (see Liessmann 2000: 86f).

Or one could exclusively attempt to define as work the activities which are understood as a burden. The 'burdensome character' of work (Marcuse 1973) would be understood as a feature - if not a central feature — of work. For example, digging in the beds of your allotment garden in your spare 


\section{Work-theoretical perspectives}

time would be considered to be a leisurely activity, but if you're doing this to ensure your survival as a subsistence farmer, then it would be considered as work. Likewise, if you play with your children, or with those of friends or family, just for fun, this would be seen as a leisurely activity; do this as a kindergarten teacher's or day-care worker's burdensome task, it would be seen as work. Ultimately, our relationship to an activity would determine whether it was work or not.

However, the question is still: How exactly can we clarify to ourselves and others that we are working and not simply pursuing pleasure? All attempts to recognize household activities - such as raising children, taking care of family members or preparing meals - as paid work have been unsuccessful. Financial remuneration continues to be the decisive criterion to define something as work (see Waring 1999). Payment signalizes that an activity is of value to someone; in this way, it is possible to negotiate labor power in the same way as commodities and capital.

The possibility and-even more importantly — the necessity to offer and sell one's own labor power in the labor markets formed itself comprehensively with the emergence of the capitalist economic system (see Polanyi 1977: p. 94). In the transitional period from a feudal society to a capitalist society, there were still various groups for which the provision of remunerated activities in the labor market did not play a central role. Small farmers, homeworkers and artisans who lived on the countryside had various sources that contributed to their livelihood. Indeed, they sold their products and services, but to a considerable extent, they lived from the products that they themselves farmed and manufactured. Similarly, the artisans and wageworkers that lived in the cities would lease a small piece of land and grow food for their own needs in order to maintain partial independence. The small garden allotments that can still be found in many cities today are remnants of these economic survival strategies (see Crouch/Ward 1997; Willes 2014). House personnel, servants and unmarried artisan journeymen generally had no access to such a piece of land. However, as they were integrated in the household of their employers, remunerated work was not of central significance to them either. The most important foundations for their existence were 'room and board', which they obtained 'for free' from their employers. Remuneration in form of money played a tangential role (see Kocka 1983: p. 40, 1990: p. 109). Vestiges of this originally once widely spread form of work can be found in the case of au pairs, who work for a limited time and are integrated in the household of a family for low remuneration (see Búriková/Miller 2010).

It wasn't until the establishment of wage labor that work became a commodity quantifiable by money. It became possible to compare under monetary considerations the activities of a soldier with that of a weaver or an agricultural worker. In businesses, it became possible to calculate the cost of labor powers similarly to that of raw material and capitals, and these various cost factors could be correlated as a result. It was possible to calculate 
whether it was more affordable to execute a task by introducing new automatized production methods or with the extensive application of labor powers. And, quite central - from the moment that work services became quantifiable with dollars, marks or francs - they became negotiable in the markets, similarly to products or capital (for the observational function of markets, see Luhmann 1988a: p. 95).

The last century is characterized by the efforts to have more and more activities recognized as paid labor. The women's movement in particular stood for the valuing of household, child-rearing and caretaking work through monetary remuneration (seminally, see Oakley 1985, 1990). Conservative circles embraced this idea within a certain scope by demanding that women be paid a so-called 'stove premium' if, instead of handing over their children to a day care center, they raised them at home. There were also further considerations to value volunteer, citizen and individual work by remunerating it in some way (see Bungum/Kvande 2013). And the kinds of payment that were considered were not only monetary, but in the form of tax benefits, access to college placement or state services as well (see Beck 1999; Georgeou 2012).

Ultimately, this struggle for recognition by being monetarily valued has resulted in increasingly more activities being subjected to commodification. Commodification, according to the definition of the social sciences, is when more things are valued monetarily and therefore become tradable in the market. Just as works of art (Velthuis 2005), the adoption of children (Zelizer 1985), human sperm and egg cells (Almeling 2007), organs (Healy 2006), educational services (Kühl 2014) or environmental damage (Fourcade 2011) are labeled with price tags, the value of more and more human activities would also be increasingly calculated in dollars, euros or yens (Budd 2011: 43ff.).

It is uncontroversial that the rise of paid work and the correlated emergence of labor markets represent a central feature of modern economy (see Castel 1995). However, one of the core questions of social sciences is how decisive this process of offering and selling of labor power on the market is - not only for the economy but also for modern society as a whole.

\section{The explanation of society over the key category of work}

Underneath contemporary sociological analyses — such as those of work society, industrial society, service society or capitalist society-hides the thought that work is the central category needed to explain modern society. With the acknowledgment of such time diagnoses, the idea of using the key category of work to describe not only the relations in companies, administrations or hospitals, but also those in society as a whole became dominant (cf. Offe 1985: 129ff.). This is correlated with the fact that the emergence of sociology as a scientific school of thought coincided with the height of industrialization and the formation of capitalism (cf. Dahrendorf 1962: 7ff.). 


\section{Work-theoretical perspectives}

In this way, the sociologist Claude-Henri de Saint-Simon-active in the late 18th and early 19th centuries - compared the French society with a large factory in "Du système industriel" (1964), one of the very first sociological monographs. His concept of enterprise industriel does not only describe a business; it describes society as well. Herbert Spencer, the evolutionary theorist who lived in the 19th century (1969), described the development from a military to an industrial society in which the businesslike exchange of services would become a commonplace dominant social relationship.

Sociologists had a clear theoretical preference for Marxism for a long time-after all, there is scarcely another theory that bestows work with such significance in the explanation of society. Work, as Friedrich Engels put it (1962: p. 444), is "the primary basic condition for all human existence, and this to such an extent that, in a sense, we have to say that labour created man himself". At the latest after the upheavals in the universities in the late 1960s and early 1970s, the majority of sociologists interested in work looked to Marx's theory of history and society. All paths seemed to lead to Marx, who'd offered a "comprehensive theoretical interpretation at the highest intellectual level of all, which one wanted to research" (Bahrdt 1982: p. 14; see also Strangleman 2016: p. 22). Regarding the key category of 'work', the sociologists that looked to Marx had convincing connections to the sociological theory of society, to the theory of business and to theories on the individual. Specifically, as class relation with Marx reflected the relation between capital and work, it was possible to more or less tie with the same theory the entire spectrum of societal relations, the tensions in businesses and the behavior of individuals using the concept of 'classes'.

However, since the 1990s at least, Marxism seemed to lose ground as a central point of reference for large sections of social science. Whether this quiet retreat from Marx was owed to the general "theory-fatigue" of old sociology warriors, a dissatisfaction with aspects of Marx's theory or political sobriety in the face of the failure of state socialism, the increasing abstinence of societal theory in large sections of work and industrial sociology, of work science and of economic science, was undeniable. Fundamental papers on the development of capitalist economy seldom serve as exceptions at the moment. New rationalization strategies in companies are described without categorizing profit maximization strategies within the frame of a basic Marxist interpretation. Research on work ethic is hardly ever linked to the once popular research into class consciousness anymore.

The Marxist roots of social scientists who were interested in work reached so deep that most of them dared approach other fundamentally differently structured concepts of societal theory only to a limited extent. Predominantly, the trend seems to be to either use as basis medium-range theories such as micropolitics, principal-agent theory or new institutionalism, or to completely refrain from any theoretical approach. Most sociological analyses are characterized by a conspicuous theoretical modesty. If at all, the theories that are used have an aspiration for explanations which are limited 
to a fraction of the social field. Salvation is sought in theories that are no longer aimed at society as a whole, but only at a small aspect of 'the social'. More and more, empirical researchers are stacked together without the increasing knowledge that would lead to the formation of a comprehensive theory (Luhmann 1984: p. 7).

\section{Beyond the limitation of mid-range theories-Marxism and systems theory as grand theories}

Against this trend of extensive renunciation of the linkage between work and industrial-sociological research, work and economic scientific research and comprehensive societal theoretical approaches, the focus of this book aims to reconstruct the central debate on work from the perspective of the two grand theories which are particularly interesting at the moment: Marxism and systems theory. The intention here is not to put forward a binding definition of work (see, e.g., Provis 2009; Voß 2010 or Budd 2013 for the difficulties hereof) and subsequently to show how these grand theories work their way into it, but rather to show how these two theories position themselves in regard to the central controversies related to work.

The claim of these two grand theories is their ability to explain not just individual, but all aspects of the social. One speaks of a 'grand theory' when the theory is able to explain the stability and change of societies; when they can determine the relationship between economy, politics, law, education, science, religion, mass media and sport; when they can shed light on the functionality of organizations, be they companies, schools, universities, churches or television stations; and when they can explain such elementary social forms as grocery shopping, the exchange of affection at an office party or bullying in the classroom.

There certainly isn't an existing analysis from the perspective of a grand theory for every single social phenomenon, but it must be fundamentally possible to describe every social phenomenon with its resources. One needs time to navigate such varying subjects as global social inequality, the decline of physical violence in modern cities, the increasing legal equality of women and men in organizations, the priority rules of waiting in line for your turn or the role conflict of talk show hosts from a theoretical perspective. The claim of a grand theory, however, consists of a theoretically consistent — as well as appropriately empirical-description of these different phenomena within their definition; otherwise, it wouldn't be considered a grand theory.

It is not easy to discern which social science theories are to be understood as mid-range theories and which as grand theories. There are theories-for instance, the rational choice theory - which began as mid-range theories, but went on to develop the claim of being theories for the explanation of all social phenomena. Furthermore, there are theories-for example, the conflict theory of Ralf Dahrendorf (1957) or Randall Collins (2010) from which, despite containing comprehensive claims to an explanation of 
modern society, only a highly disputed theory of conflict of interest on a societal level has remained.

And yet, the test with which one can determine the range of a theory is relatively simple: One simply takes a theory which has been successfully used for the analysis of a social phenomenon and applies it to something else. If the theory is not suitable to explain the other social phenomenon, then we are dealing with a 'mid-range theory'. Quite often, followers of a theory reveal this by aggressively explaining that, for instance, 'their' theory of micropolitics, of resource mobilization or of hegemonic masculinity are well suitable to describe some other social phenomena, but others cannot be represented, or only imprecisely.

In order to avoid any misunderstanding: It is impossible to use mid-range theories in a multifaceted manner. To name one example, the theory of new institutionalism can be used to explain why certain management patterns have established themselves in organizations worldwide (see Bromley/Meyer 2015). With practice theory - to name another example-one can easily analyze why a specific habit develops in the upper class (see Bourdieu 1979). However, if one has further-reaching sociotheoretical aspirations, explanations of individual aspects of the social do not suffice; one must instead have the aspiration to explain all aspects of social phenomena.

At the latest since the beginning of the 20th century, there have been two fundamentally different sociotheoretical perspectives in the social sciences: One is more focused on class dominance; the other one on work distribution between societal subsets which are equal in rank. Simply put, while Marxism sees class differences - that is, the differentiation between top and bottom characterized by the relations of productions - as the primary criterion of modern society, systems theory explains society from the tension-laden interaction between societal subsystems such as economy, politics, science and religion.

In light of these considerations, however, one should not overlook the fact that neither does Marxism possess a monopoly over explanations of society on the basis of class antagonism, nor is systems theory the only theory that addresses the interaction between societal function systems. Even if the concept of 'class' is primarily associated with the Marxist definition of ownership of means of production, there are other 'class theories'-for instance, those of Ferdinand Tönnies or Pierre Bourdieu. For Tönnies, the struggle for economic, political and morally intellectual predominance was always a struggle between the classes (Tönnies 2010); and while Bourdieu in no way denies the significance of economic capital for class formation, he considers the significance of cultural and social capital similarly important (Bourdieu 1979). The theory of functional differentiation is identified today with Niklas Luhmann's systems theory, although its foundation can be traced back to the sociologists Émile Durkheim and Max Weber, active at the end of the 19 th century, beginning of the 20th. Durkheim compares modern societies with higher organisms in which each organ fulfills a special function for 
the 'greater whole'. In modern society, there is a formation of 'organic solidarity', as the different 'organs' are reliant on each other precisely because of their distribution of work (cf. Durkheim 1988: 236ff.). Weber also argues that various 'value spheres' such as science, finance, law, politic and art find themselves in conflict with each other (cf. Weber 1990: 536ff.).

The different formations of Marxist theory on the one hand, and systems theory on the other, result in the different observations of phenomena such as the influence of financial lobbies in politics, law or science; the conflicts between work unions and employers; the organization of work in businesses; the cooperative relations between companies, public administrations and universities; and the class identity of the proletariat. Whereas Marx's theory instruments demand that political, legal or scientific analysis refer to the economic relations and consider the rationale of organizations and individuals in connection to those economic relations, the theory of functional differentiation not only emphasizes the diversity of societal subsets but also focuses on both an organization's and a person's own rationale as systems.

\section{The focus on three debates}

In the following, I'll present the three central debates in which Marxist theory delivered well-known templates with its understanding of work, and which are therefore well suited to work out the difference to systems theory. In outdated terminology, one would speak of an analysis on a macro-level of society, the mid-level of the organization and the micro-level of the thinking and acting of the individual (for further usage of this outdated terminology see, e.g., Scott 2001: 83ff.).

The initial focus is set on the reconstruction of whole societal developments. How is the conflict between capital and work regulated legally? Which moderating functions are taken on by politics in this analysis? The classical Marxist theory determines the functionality of law or politics, respectively, from the conditions of production. The economy is not a societal subset among many, but rather the one that has the relevant influence on how society functions as a whole. 'Capitalism' therefore not only characterizes the functionality of the financial system but of society in general. Systems theory on the other hand-just as other theories of functional differentiation-emphasizes the distinction of various societal subsets such as politics, law or finance, which carry out important functions for each other without presuming the dominance of one societal subset over another.

A second focus is given to the business as the place where, at least during a high phase of industrialization, the central production processes occur: the organization. The classical Marxist theory understands the structures of cooperation, rule and control in organizations as a part of a conflict between antagonistic camps characterized by objective interests. On the one 


\section{Work-theoretical perspectives}

hand, we have those who have access to external labor power because of their capital; on the other hand, we have those that have nothing to sell but their labor power. Systems theory admits that conflicts occur in organizations between capital owners and workers, yet it maintains that these are often overlapped with other conflicts such as those between different departments, or between different groups of profession; it emphasizes the obstinacy of organizations - of companies, as well as universities, public administrations and hospitals. While in Marxist theory the analysis of organizations is mostly derived from societal production conditions, the obstinacy of organizations - of companies, as well as universities, public administrations and hospitals - is analyzed by systems theory. In systems theory, it is asserted that the economic, legal, political and mass media environment plays an important role for organizations. However, this theory focuses more on understanding organizations as social systems that distinguish themselves from their environment by means of membership rules, goal formulations and hierarchies.

The third focus is set on the experiences, behavioral reactions and ways of thinking of people characterized by the relations of production. With the term 'class', the theoretical approaches characterized by Marxism possess a category which on the one hand seems to be clearly defined by the relations between work and capital, and on the other hand makes it possible to comprehend the relationship between society and the individual. In this sense, it is consistent that an important strand of research has dealt with the formation of class consciousness of the working population. By contrast, systems theory relies strongly on the term of 'role' when determining the relation of society and individual. From this theoretical perspective, the individual appears as a role bearer whose role repertoire may also include the role of the class-conscious proletarian, but merely as one role among many.

The central perspective lies on contemporaneous societal processes that initially developed in Europe and America in the last century, and subsequently spread around the world. However, it should not be ruled out that it is also possible to learn a great deal about work in antiquity, the Middle Ages or early modernity from Marxist or systems theoretical understanding (for a concise historical overview, see Conze 1972; Applebaum 1992 or Jochum 2010). Nonetheless, the central debates on the change of work were carried out in the past centuries. 


\title{
2 Primacy of economy vs. functional differentiation
}

\author{
The debate on the form of \\ modern society
}

In contemporary sociological analyses of our times, there is often the thesis of an 'economization' of society. Each decision made in society is ultimately presented as an economic one. The choice of a field of study, a job, a lane on the highway or a sexual partner is presented as an individual's utility-based decision. There are tendencies that come from economic sciences that present the 'economic calculation' of each decision as ultimately rational.

Neoliberal approaches assume that societies reach the highest possible increase in prosperity for all if one allows economic criteria to rule in all fields and maintains the self-regulating (by prices) dynamic of the market forces undistorted by political intervention. This approach, which can be traced back to the early ideas of the economist Léon Walras, proclaims that the markets of work, finance, products, as well as friendships and marriage can be held in balance if one grants the invisible hand of the market free reign (cf., e.g., Friedman 1997).

Critics of neoliberalism reflect this view as a last resort. They complain that the planet then becomes a playing field for one driving force: profit. The 'neurotic lucre', the 'temptation of profit' brings 'the whole territory under its rule' (cf. Forrester 2001: p. 7 and p. 26). What is being criticized is the development toward a 'McKinsey Society', in which, just as with the globally active corporate consulting companies, a 'dictatorship of efficiency' dominates. This leads to a 'total economization of society', in which all subsets are consequently explained within the economic rationale (cf. Kurbjuweit 2003: p. 11).

Political incompatibility of these positions notwithstanding, both offer suggestions in which society is defined by the economy. Society appears as a 'work society', 'industrial society', 'postindustrial society', 'a society of service provision', 'knowledge society', 'market society', 'class society', or a 'capitalist society'.

In sociology, Karl Marx has an unparalleled position as a theorist with regard to the definition of society within economic relations. Even if political economists such as David Ricardo and Adam Smith had previously attempted to define societies by their economic functionality, it was Marx who, in the 19th century, was the first to develop a societal analysis based on the definition of the productive forces and the relationships of production. 


\subsection{The basic Marxian idea: from capitalist economy to capitalist society}

Salient new developments trigger a description of the whole society with reference to these very developments. A soon as it is possible to differentiate the work sphere as an independent section thanks to the driving force of capital utilization and the technical-organizational development, and work distribution becomes the central principle of an industrial assembly line, it stands to reason to describe society as a 'work society' or an 'industrial society'. If its knowledge - and no longer the capital tied to large industrial businesses - which is seen as the main lever for societal value increase, it stands to reason to use the term 'knowledge society'. If the risks associated with genetic or nuclear technology are keeping the whole world on its toes, these developments could then be described with the term 'risk society'.

The strength of this time diagnosis lies in its ability to precisely focus on what is new in society by using the postulate of a comprehensive societal description of the transitional phenomenon. However, the risk lies in relating all dimensions of society to this transitional phenomenon, which leads to an overgeneralization of developmental trends (cf. Savage 2009). Retrospectively, Karl Marx's ideas can be precisely observed in relation to this field of conflict: They arose at a time of transition from a corporate society characterized by agriculture to an industrial society. Today, one can either observe Marx as a time diagnostician who developed an overarching societal theory from a transitional phenomenon of modern society - that of the differentiation of the capitalist economy — or highlight the resilience of his economic analyses beyond any transient or limited time diagnosis. In sociological research, one tends to do the latter.

\section{The rationale of the economy: from use value to the exchange value of commodities}

In his definition of capitalism, Karl Marx assumes an analysis of commodities. Commodities are useful because they serve to satisfy human needs. According to Marx, they have a 'use value'. People in the Stone Age, which Adam Smith introduced to the political economy, used bearskin because they could use it to protect themselves against the cold of the Ice Age. Knights in the Middle Ages profited from a horse because it allowed them to move more quickly from one place to another. A raspberry sorbet has a use value for a stockbroker because it relieves their hunger and tickles their palate. We attribute a use value to something we perceive as necessary, useful or pleasant (cf. Marx 1959a: 67ff.).

As the commodities possessed by someone else are always more interesting than those we possess ourselves, exchange processes are implemented. One is less interested in the use value of one's own commodities than that of 
our peers. Consequently, it is advantageous for both to exchange the commodities. It is possible to exchange commodities directly: "Give me your bearskin and you can have my horse". These direct exchange processes took place in early societies. However, they can also be observed during moments of crisis in modern societies; for instance, during long civil wars or strong inflationary periods. Still, it generally makes sense to utilize a medium between actions of exchange, for instance, money. One no longer exchanges 'a bearskin for a horse', but instead 'a bearskin for 250 euros' and 'a horse for 250 euros'. In this way, it is not only possible to take advantage of spontaneous exchange possibilities but also to wait for someone else to appear later with another, more appealing 'use value' compared to that of the current buyer of one's commodities (cf. Sweezy 1972: 41f.).

The immediate form of the circulation of commodities, according to Marx's definition, is the conversion of commodities to money (you get 250 euros for the bearskin) and the reconversion of money to commodities (you can buy a tuna sandwich for 10 euros) (cf. Marx 1961b: p. 70; Marx 1962a: p. 161). At the center lies the use value: "I'll trade you this bearskin for your organic strawberries so I can make some jam". Money is simply a medium so that we can exchange commodities (see Graeber 2011 for a critique thereof). The exchange of equally valuable products with the help of the medium of money is what Marx meant when he described the original form of the exchange of commodities in the premodern societies with the formula 》C-M-Cu (Commodities-Money-Commodities). Money becomes an exchange equivalent with which it is possible to purchase all other commodities. It is the most common among all commodities.

So where is the issue here? Marx postulates that commodities always have a double dimension. They not only have a use value, but an 'exchange value' as well. One can use the bearskin as a garment, but it can also be sold for gold. You can ride a horse, but you can also sell it at the horse market. You can spread the organic strawberry jam on toast for breakfast, or you can sell it in the market. Commodities are not only an object with a use value, but an object with a price, with an exchange value as well.

The formation of capitalism - and here Marx acts as a contemporary sociological analyst of his time-leads to the interest of the use value falling behind in comparison to the exchange value. One no longer kills the bear in order to use its fur for warmth; rather, it is done because it can be exchanged for a large sum of money at the market. One doesn't make organic strawberry jam because you or your neighbors may like it; you make it because it has a higher exchange value in the market than regular jam. The point of the exchange of commodities essentially shifted: It isn't about satisfying needs anymore, that is, about the use value, but rather about the maximization of money. In capitalism, the circulation of money becomes 'the goal itself'. Instead of ' $\mathrm{C}-\mathrm{M}-\mathrm{C}$ ', the dominating rationale is now ' $\mathrm{M}-\mathrm{C}-\mathrm{M}$ ' (Money-Commodities-Money) (cf. Marx 1962a: p. 167; see also Marx 1961b: p. 105). 


\section{Economical Primacy \& functional differentiation}

A capitalist, according to Marx, is a financial dealer who assumes the following orientation regarding the multiplication of money:

His person, or rather his pocket, is the point from which the money starts and to which it returns. Only in so far as the appropriation of ever more and more wealth in the abstract becomes the sole motive of his operations, does he function as a capitalist.

(Marx 1962a: 167f.)

Whereas for the independent manufacturer and the worker it is still about selling their product or labor power in order to buy what is necessary for life, for the capitalist it is about buying raw materials, product and labor power in order to later sell it in such a way that they have more money than before. In short: The independent manufacturer and the worker sell in order to buy; the capitalist buys in order to sell.

This process is excessive and unlimited. One can always use more money-an observation already put forward by Aristoteles. Capitalism, according to Marx, is characterized by the "restless never-ending process of profit-making" (Marx 1962a: 167f.). One would like to sell the individual parts, purchased at 250 euros, for 300 euros - or even better, 350 euros. The goal of the capitalist is that the second ' $\mathrm{M}$ ' in the ' $\mathrm{M}-\mathrm{C}-\mathrm{M}$ ' process be bigger than the first ' $M$ '. Instead of a simple ' $\mathrm{M}-\mathrm{C}-\mathrm{M}$ ', they want an ' $\mathrm{M}-\mathrm{C}-\mathrm{M}^{*}$ ' (Money-Commodities - more Money). The process of making more money out of money-and in turn utilizing that money for the multiplication of money — was named 'accumulation of capital' by Marx (cf. Marx 1962a: 605ff.).

But how is this done? How does the capitalist manage to earn more money than they originally spent in the purchase of a commodity?

\section{The commodity of labor power: the formation of the labor power entrepreneur and his exploitation}

The relation in which various commodities can be exchanged is determined by the labor power and the exact work time therein. That a horse costs 250 euros and a bearskin costs 250 euros, that is, that they can be exchanged at a relation of 1:1 (and not 1:5), is due to the fact that one needs the same amount of average time to raise a horse as is needed to produce a bearskin. The value of a commodity is determined by the work time put in it. More precisely: From the average work time necessary for its production. Marx speaks here of the societally necessary 'work time'.

How is then the value of labor power determined? According to Marx, labor power is a "completely normal commodity". It also has a use value and an exchange value, just as the bearskin does. Its use value lies in what one can do with it, that is, which activities the worker can perform in a given time, the value they can add to specific materials. The exchange value 
of work is determined - just as with that of any other commodity - by the work time required for its production. But what exactly is this work time necessary for its production? To produce work time it is first necessary to produce workers, that is, children must be born and raised. They must have at least sufficient clothing, food and accommodations so that they can live and be able to work. These so-called 'reproduction costs' of work determine the exchange value of work: The work of one day is worth as much as how many resources are needed to keep a worker alive for one day of their life.

The nub of the matter is then-and this is the core of Marx's theory of capitalism - that the use value of work is greater than its exchange value. That the value that a worker adds to the material that they work on a day of work is of greater value than the cost of production or maintenance of its labor power for one day. This is why the capitalist applies a surplus value - the difference between the exchange value of work, that is, what the work costs the capitalist, and the use value of work, that is, the profit value the capitalist draws from the work of the worker. The value increase added to the material by the worker 'belongs' to the capitalist because they are the use value of the labor power, and as the capitalist buys the labor power, let's say, for one day, the value use belongs to them in this time.

More critically, the only possibility for the capitalist to make more money from money consists of organizing work in such a way that they can create more value with the labor power of their workers than they spend for the wages of the workers. In the production of commodities organized by them, the capitalist - according to this highly simplified depiction-does not give back all the value which is produced to the labor powers as actual producers; instead, the capitalist keeps a part of the produced value for themselves. For the worker, this means that they don't only work for their livelihood and for the time necessary for the reproduction of their labor power, they are also forced to work more in order to create a surplus value (the 's' in political economy) for the capitalist in the surplus time.

However, this 'principle of exploitation' is concealed by a simple mechanism. The wage appears as the price that the capitalist pays the worker for the work performed. If this were truly so, and the capitalist really paid the worker the value the worker produced, the capitalist would have no chance to appropriate the surplus value of the work. The wage, according to Marx, does not reflect the value of work, but rather the value of labor power. In other words, the capitalist purchases the work capacity of a worker for a specific time. How much surplus value the capitalist is able to gain from this labor power depends on their skill.

At first sight, the 'commodity labor power' is no different with regard to its use value and its exchange value from a commodity such as bearskin or jam (cf. Marx/Engels 1958b: p. 468). The capitalist, as the purchaser of the commodity of labor power, must be interested in both the use value as well as the exchange value. Transforming the use value of work - that is, the work itself - into the object so that the needs of people are satisfied is something 
that the capitalist obviously can't ignore; it is of no use to them if things are produced which are not needed. At the same time, the exchange value of work plays an important role - that is, the amount of money for which the labor power is exchanged. The capitalist must be interested in the abstract exchange for which they can buy labor power, as this value is crucial to whether or not they'll be able to make a profit. The purchased labor power is implemented for the production of cooking pots, plowshares or razor blades as long as the capitalist deems it necessary in order to attain the highest surplus value. If, however, they find that they can make more profit if their workers produce harvesters, tanks and peace buttons instead, the labor power purchased by them will then be implemented accordingly (cf. also Geiger 1929: p. 688).

To offer their labor power as a commodity, the 'double freedom' of the wage worker is called for. On the one hand, with the formation of capitalism, the worker is able to attain 'freedom' and break from the slave-like, domineering, corporative and traditional chains of the premodern era, and in this way attain the complete 'freedom' of their work capacity; as a 'free wage worker' they are the sole owners of their labor power and have therefore an exclusive right of disposal over it. On the other hand, they are also 'free' from all materials required for the production, and therefore obliged to offer the capital owner their labor power - that is, sell their labor power (cf. Marx 1962a: p. 183; see Berger 1995 for details; see Castel 1995 for historical development).

When people join a company in order to earn their livelihood, they act as free owners of their labor power, which they can offer for purchase. The contract that they make with their 'employer' is a 'simple' purchase contract between the buyer and the seller. It depends on the quality of the labor power offered, the condition of the labor market and the respective negotiating skills of the buyer and seller whether the worker gets a good 'cut' of the deal or not (cf. Marx 1962a: 190ff.).

In short, with the establishment of the wageworker principle, workers became 'entrepreneurs of themselves' who could - had to-offer labor power on a free market. The 'labor power entrepreneur' came to be in the moment in which humans could freely make use of their labor power, which only they possess, and not - as is suggested in certain areas of sociology today-when the strong managerial involvement of employees began to dissolve 20-30 years ago (cf. Voß/Pongratz 1998; see the clarification with Kühl 2002: 81ff.).

However, as a result, whether workers can get by with their earnings or not was no longer the problem of the buyer of the labor power commodity. A customer at the Middle Eastern bazaar might ignore the vendor's complaint that, at the agreed upon price, not only the vendor but also the vendor's whole family will also starve. Similarly, the capitalist as buyer of the labor power commodity ignores the worker's complaints of not being able to make ends meets with his wage. According to Peter Decker and Konrad Hecker (2002: p. 17), the modern proletariat owes its 'politico-economical birth' to the 'conceivably most successful combination of necessity and freedom'; 
in the establishment - safeguarded by the Rechtsstaat (lit. legal state or state of law) — of the civil private property, the means of production are essentially omitted. The modern proletariat, not accountable to anyone (not even to the capitalist) and nonetheless secured by the Rechtsstaat and equipped with the sole right of disposal of their own labor power and lifespan, becomes the object of desire for the capitalist proprietors. Proletarians find their chance of livelihood in the labor market by making themselves freely available to the capital, albeit by necessity.

\section{The step toward societal analysis: regarding the economic base and political superstructure}

One could label the transition from ' $\mathrm{C}-\mathrm{M}-\mathrm{C}$ ' to ' $\mathrm{M}-\mathrm{C}-\mathrm{M}$ ' as a differentiation of the economic systems in modern society as a result of the formation of the labor power entrepreneur and the interest of the capitalist in the proliferation of money. Most social scientists would agree with Marx that the private property of means of production, the expansion-targeting business of acquisitions, the wage labor as a dominant form of acquisitive work and the transformation of all produced goods and services - as well as the labor power in marketable commodities necessary for it-are central characteristics of the capitalist economy (compare Aron 1964; Weber 1976; Polanyi 1977; Collins 1990).

But Marx did not leave it at the description of this differentiation of economy. His priority was not to describe capitalist economy, but rather capitalist society. According to Marx, "In all forms of society there is one specific kind of production which predominates over the rest, whose relations thus assign rank and influence to the others". "Capital is the alldominating economic power of bourgeois society". Therefore, it must form "the starting-point and the finishing-point" of the examination (cf. Marx 1961a: 637f.). In capitalism, society is 'appropriated' by the economy in an even more pervasive way than in feudalism. According to Karl Marx and Friedrich Engels, "The bourgeoisie cannot exist without constantly revolutionizing the relations of production, and with them the whole relations of society" (Marx/Engels 1958b: p. 465).

Simply put, in his societal theory, Marx surmises a primate of the economy. The economic 'base', according to the common Marxist short formula, determines the 'superstructure' (Marx 1961b: p. 8). In their early works, Marx and Engels still conceived of politics and jurisprudence as an urgent instrument of the capital in order to continue the economic exploitation of the worker. From this perspective, jurisprudence was "but the will of a class made into law" for Marx and Engels; politics is "merely the organized power of one class for oppressing another" (Marx/Engels 1958b: p. 477).

Later, Marx and Engels would continuously modify this image strongly: Marx, especially in the blueprints of 'Critique of Political Economy' and in his analysis of the French state under Louis Napoleon; Engels, especially 
in his thoughts on the origin of family, private property and the state. Even before developing a coherent theory of state, it is quite clear that both Karl Marx and Friedrich Engels saw politics and jurisprudence as autonomous authorities that assume a stabilizing function of 'regulators' of the class struggle. Jurisprudence and politics find themselves in a 'dual position'. On the one hand, they represent the power relations between capital and work; on the other, they take the function of a regulator of the class struggle across the classes. From this perspective, the state is always two things: Rechtsstaat (legal state) and Klassenstaat (class state).

Regarding jurisprudence: The formation of a legal sphere is important because capitalism is based on the voluntary transaction between autonomous legal entities and overcomes the relationship of servitude still dominant in feudalism. The bourgeois legal entity is the guarantor for the contractual agreement being kept between the free legal persons. If the transaction of a latex mattress for 250 euros, or one hour of labor power for eight euros has been agreed on, both sides must rely on the existence of an overarching entity where they can demand the agreement be honored. If the buyer of the mattress has no intention of paying the agreed on 250 euros, or the buyer of the labor power commodity refuses to pay the employee the sum laid down in the work contract, one can be quite certain that the Rechtsstaat will get involved with unrelenting severity (c.f., e.g., Carruthers/Ariovich 2004).

Regarding politics: The possibility that political institutions can form an 'apparent' political power that can become 'independent' is not excluded by Marx and Engels. While only the law of economic pressure seems to apply in many situations in capitalist society, political power nonetheless has the possibilities to evade the pressures of capital in moments of crisis. In this way, Marx showed which political instruments of the French state under Louis Napoleon not only managed to avoid financial breakdown, but helped advance the capitalist expansion even further (cf. Marx 1960; see also Gurland 1969: p. 55). Friedrich Engels sees the function of the state as ensuring that "these classes with conflicting economic interests might not consume themselves and society in fruitless struggle". The state represents "a power, seemingly standing above society" that would "alleviate the conflict and keep it within the bounds of 'order" (Engels 1969: p. 165; see also Jakob 1999: p. 20).

The purpose here is not to define the relation of 'base' and 'superstructure', as Marx and Engels have already done, and as it has been further developed in the social theory debates of the 20th century (see Mayer 1994: p. 172 for an overview). What is important is that a significant strain of the social sciences has been strongly influenced by the social theory project of Marxism: The definition of the relation of capitalist economy to politics and civil law. The aim consisted of, on the one hand, avoiding a merely reductionist derivation of politics and jurisprudence from capitalist conditions; on the other hand, developing the political and legal spheres, but not all too loosely coupled to the economic conditions (cf. Holloway/Piciotto 1979: p. 4). 


\subsection{The societal theory debate: from Pre-Fordism to Fordism to Post-Fordism}

In countries with a capitalist economic system, the development of productive force has obviously not led to one of the many collapses of the system predicted by many Marxists. Any of the socialist societies envisioned by Marxists seem farther than ever today. Even Marxists theorists are shying away from concepts of theory of collapse or immiseration. They advocate filing away the concepts that presuppose an inevitable collision with a crisis. They also point out that even Marx, in his later writings, did not assume an almost naturally ordained transition from a societal system characterized by the conflict between capital and work to a classless society. In contrast to the common end-of-the-world and immiseration theories of the Malthusians, the Darwinists and the utopian socialists in the 19th century, Marx believed that an improvement of the conditions of the working masses was possible through organized action, thereby considering an adaptation of capitalism possible (cf. Gurland 1969: p. 52; Sweezy 1972: 225ff.; Hirsch/Roth 1986: p. 41).

The main challenge for a social science inspired by Marxism consists of theoretically 'getting a grip on' the development of capitalism as a central structuring characteristic of modern societies. How can one explain from a Marxist perspective that capitalism manages to survive despite the continuous resurgence of crises? What 'patchwork' and what 'particular measures' manage to keep stable the contradiction of capital and work (Adorno 1969: p. 20)? The central question: Which societal structures are the ones that ensure a continuing capitalist production, and how do they come to be and how do they transform themselves (Aglietta 1979: p. 17)?

The regulation theory, which had its roots in political economy, assumes that the dynamic of capital 'sets free an enormous productive force', but that capital is at the same time a 'blind power' that cannot tame the forces it sets free. According to the assumption of the regulation theorists, the capitalist economy has the ability to set human energy in motion in such a way that it is transformed into growth. However, due to conflicting interests, it is not able to guarantee overall cohesion (cf. Aglietta 2000: p. 19).

Only the view on the formation of economic, political, legal and social manners of regulation can explain - and this is where the regulation theorists look back on the theory of hegemony of Antonio Gramsci, the Italian socialist who was active in the first half of the 20th century - why capitalism survives despite continuously reoccurring crises. The negotiations between the representative bodies of capital and work, the state entities of politic, a legal system which is largely autonomous from politics and the economy, the various educational institutions, the scientific institutions and mass media-according to the opinion of regulation theorists - all contributed to the channeling of the 'class struggle' without endangering the further accumulation of capital (cf. Aglietta 1979: p. 123; see also Lipietz 1998: p. 17; Aglietta 2000: p. 19; Jessop 2003: p. 91). 
In this way, the argumentation of the regulation theorists is very similar to the thesis of economic anthropologist Karl Polanyi. He emphasized that an unrestrained development of capitalism would lead to an 'overexploitation of the labor power', and consequently to a 'destruction of society'. The capitalist society reacted to this tendency for self-destruction with an array of self-limitations, which ultimately aim to plan, regulate and control the economy according to political criteria. According to Polanyi, the formation of capitalism is a 'double movement' of two opposing organizational tendencies. While one tendency aims for the expansion of the market organization, the goal of the other is to limit the freedom of the market in order to prevent the self-destruction of society (cf. Polanyi 1977). When a dominant manner of regulation has formed itself, according to the regulation theorists, there can be relatively stable phases of capitalism on a regular basis. Only small crises would emerge, and they would not threaten the foundational manner of regulation. Yet due to the restless pursuit of capital to always achieve more profit, investment strategies, production technologies and work organizations could change in such a way that they end up in opposition to the dominant forms of regulation. With time, structural crises would emerge, which would result in the collapse of the old manner of regulation, and consequently a new capitalist manner of regulation would establish itself.

Against this backdrop, regulation theorists worked out a four-phase model, with which the development of capitalism up to the present is explained.

\section{The formation phase of capitalism: the phase of extensive accumulation strategy}

By the middle of the 19th century, the transition from a feudal society to capitalism was largely completed in the centers of the United States and in most cities of Europe. In this early phase of developing capitalism, which followed the first industrial revolution, entrepreneurs invested their capital predominantly in the improvement of the existing production systems. Indeed, new technical developments-especially in the fields of tool machinery, steam operation and casting technology-were reached for and integrated in production, but, primarily, the companies attempted to utilize the preexisting knowledge for their business.

Until the end of the 19th century, the profit maximization strategy of the companies in the pioneering countries of the industrialization was geared toward the demand of even more performance by extending the workday of a wage laborer. Michel Anglietta describes this stance of capital geared toward wage reduction and work time extension as an 'extensive accumulation strategy' (Aglietta 1979: p. 130; see also Glick/Brenner 1999: p. 43).

Why was the investment of entrepreneurs in production technology during the early phase of developing capitalism so limited? 
According to regulation theorists, one of the main causes was the lack of demand in the consumer goods market. Until the middle of the 19th century, many workers ensured their survival through self-sustenance and not by purchasing commodities. The groups of small farmers, homeworkers and countryside artisans - and in part also the city artisans and workerspossessed or leased a small piece of land and farmed food to satisfy their own needs. This 'sustenance economy' was often more important for the worker as the merely irregular wage labor, which was limited to only a few months a year (cf. also Kocka 1983: 40ff.). This made the worker partly independent from price fluctuations at the commodity markets, but, on the other hand, also made it possible for 'the capital' to pay very low wages. The regulation theorists refer to this process - which defined the early phase of capitalism - as 'dominance of non-commodity type relations' (what is meant is the 'sustenance economy') through 'commodity type relations in the way of consumption' (i.e., the goods that one purchases with one's wage; cf. Aglietta 1979: p. 80).

\section{Mass production without mass consumption: the intensive accumulation strategy in the early Fordist phase}

At the beginning of the 20th century, mass production progressively established itself as the central strategy of the capital. The mass productioncore phenomenon of the second industrial revolution characterized by the electrification, distribution of the combustion engine and expansion of the chemical industry (cf. Friedmann 1959: 6ff.) — demanded enormous investments from capitalists in conveyor systems, machines and production technology. Regulation theorists define the strategy based on technological development and investment in machines as the 'intensive accumulation strategy' of the capital (cf. Glick/Brenner 1999: 37ff.).

The large investments in production systems could not be afforded by many companies, and consequently, in important industries, oligopolies formed - that is, a collection of a few companies that could largely divide the market among themselves. In the automobile industry, for instance, in which initially over 200 providers tumbled about, the focus on mass production led to a scarce dozen providers remaining on the market. At the beginning, Cornflakes were produced by several hundred manufacturers in the city of Battle Creek in the United States. However, the necessary investment in production technology resulted in the disappearance of a large part of these providers.

The capitalist system based on mass production is defined as 'Fordism', drawing upon the coining of Antonio Gramsci (Gramsci 1999; see also Aglietta 1979: p. 117). Henry Ford was the founder of the 'Ford' Automobile Factories and belonged to the leading forces in the introduction of the principle of mass production. Tools and workers were to be assigned according to the 'order of the preceding tasks', so that each part would travel 


\section{Economical Primacy \& functional differentiation}

the shortest possible way during the production process. Over sliding rails, assembly lines and transportation mediums, the parts in production moved in such a way that the worker could always stand in the same fixed position. Ford's aim was not just to organize the production process according to these principles; the entire value chain-from the creation of raw material to the selling of the produced commodity — was to be guided by the principle of the 'economic management', subject to the process of rationalization (Ford 1923: p. 93).

Ford developed the production concept of Frederick Taylor - the founder of 'scientific management' - even further. Taylor understood that the division of what is planned and what is controlled in the activities that are carried out was a prerequisite for an efficient production. The work process should be made independent from any manual skills and any knowledge of the worker. According to Taylor's vision, each detail of the industrial production process should be analyzed and scientifically processed. The atomistically dissected activities requiring only minimum qualifications from the workers should be, from an organizational standpoint, carried out in such a way that people and machines are interlocked like clockwork. In scientific management, the knowledge of the best execution of an activity no longer lay with the worker, but with the management (cf. Taylor 1967: 35ff.).

The great challenge for capitalism during this phase was that the mass production of consumer goods did not meet a corresponding demand. The big financial crisis at the end of the 1920 s is seen as an indication by the regulation theorists that, even though the newly developing Fordist production forms certainly brought about benefits of efficiency, they still led to a crisis, as there were no consumers who had the sufficient financial strength. The problem - to use the terminology of the regulation theorists - was in the existence of an 'intensive accumulation regime without mass consumption' (cf. Lipietz 1985: 123f.; Lipietz 1998: 38f.).

In an almost paradoxical way, according to the regulation theorists, it was first the successful struggle of the working class that contributed to an improvement of their life conditions, so that- to some extent already after the global financial crisis of the late 1920s, but especially after the Second World War-a stable market for mass consumer products developed as a result. Simply put: Not until the capitalists were forced to pay higher wages to the workers did markets emerge that made possible a new, stable development phase of capitalism (cf. Aglietta 1979: 154ff.).

\section{The phase of great Fordist compromises: mass production and mass consumerism}

The great Fordist compromise that came about after the Second World War consisted of profits generated from efficiency gains in mass production which were not only being used for investment in new machines but also 
to pay the increasing wages of workers. According to regulation theorists, these wage increases made up the base for mass consumerism in western industrial states in which, eventually, almost any employee was able to afford a small car, a washing machine or a tropical vacation (cf. Aglietta 2002: p. 13).

For regulation theorists, 'Fordism' ultimately does not only signify sliding rails, assembly lines and other forms of production based on means of transportation, but also a fundamental change of the consumer patterns of the working population. Like no other statement, a remark by Henry Ford conveys this double orientation on production and consumerism: Each one of his workers, according to Ford, should be able to afford a Tin Lizzie, the car which was manufactured in his factory. Through large-scale production with simultaneously rising wages, the automobile was to be 'democratized' (cf. Hounshell 1985).

The rising wage level in the industrial core centers stimulated a process defined by Burkart Lutz as a capitalist land-grab of the financial sector. The traditional family economy, small entrepreneurs working for their own consumption, numerous independents and networks of small service providers were increasingly ousted. The production of washing machines resulted in the disappearance of small laundromats. The industrial produced readymade meals led to more and more people cooking less frequently. In the field of mass entertainment, Microsoft's X-Box-mainly manufactured in Asia - is replacing the independent artist (cf. Lutz 1989; see also Gershuny 1978: 92ff.; Aglietta 2000: p. 339).

Which role did the state play in the formation of this stable production and consumption relation? In the tradition of Marx, regulation theorists presuppose that capital, in and of itself, does not have an interest in resolving over-production - or rather, the underconsumption crisis-by raising the wage level of the worker. First, according to the argumentation, a 'statist reformism' made possible the increase of the wage level. Three aspects can be identified as the central characteristics of 'statist reformism' (cf. Hirsch 1995: 76ff.; Lipietz 1998: p. 14).

At first, the state took accompanying measures to secure this growth dynamic with the aim of - through a Keynesian politic of demand-securing full-time employment. The increase of demand was possible because the national markets were so isolated by customs that direct investment of the state or tax relief for the employees were primarily advantageous for the national economy (cf. Lipietz 1998: p. 21).

Second, the state strove to protect employees from all too large income losses - in old age, in case of medical issues or unemployment - with social security measures. With unemployment insurance, pension plans, accident and health insurance, regulations for continuation of wages in case of illness and work disability insurance, 'indirect wages' were created that could guarantee at least limited consumerism even in the case of short or long term cessation of gainful employment. The 'reserve army of work'comprised of the unemployed whose function Marx saw in the disciplining 


\section{Economical Primacy \& functional differentiation}

of the worker found 'in bread' (Marx 1962a: p. 661) — lost in significance due to the various state regulated safe-guarding mechanisms (cf. also Habermas 1981: 530ff.).

Third, the state created the framework for a 'social partnership' between capital and work. The class conflict was set aside by the state by placing the responsibility for the financial growth in the hands of both labor market parties. As a result of the participation of work unions in the concept of the social partnership, as self-domestication of the working class came to be. Precisely the success of the work unions in the negotiation of wage increases, as well as the implementation of rights of protection, information and codetermination, led to a transformation into 'internal system actors' of even the lobbies officially aligned with the aims of the class struggle (cf. Beckenbach 1991: p. 185).

This highly standardized form of work and mass consumerism, the 'inner land-grabbing' of more and more social areas with the industrial production paradigm and the integration effect of the social state cumulated, according to some observers, in the diagnosis of a 'formed society' (Ludwig Ehrhard) or a 'programmed society' (Alain Touraine). 'People's lives' during the Fordist period were, according to Ulrich Beck, 'just as standardized as the metal sheets from which they welded cars together' (Beck 2000b: p. 39).

But the 'dream of perpetual prosperity' (Lutz 1989), the hope of a constant 'golden age' (Lipietz 1998) lasted only until the 1970s. Fordism, sooner or later, led to falling profit rates, according to the diagnosis of the regulation theorists. Management exhausted the advantages drawn from intensifying work, deconstructing the work process and introducing new machines. Additionally, the primarily state-national forms of regulation found themselves contradicting the increasing internationalization of production (cf. Aglietta 1979: p. 163; Lipietz 1998: p. 39; Hirsch 1995: 84ff.).

These crisis phenomena provided for a long time the research program for social sciences geared toward Marxism; the question that sparks the interest of Marxists: What is the shape of the capitalist society after the end of the dominant Fordist age?

\section{The contours in the Post-Fordist phase: worldwide financial markets and global value chain}

With the description of the capitalist societal system that has formed itself since the end of the 20th century, sociologists in the Marxian tradition are either inclined toward the very abstract formulation of 'Post-Fordism' or 'late Fordism' (e.g., Hirsch/Roth 1986), or, with concepts such as 'Toyotism' (Roth 1994), 'Sonyism' (Wark 1991) or 'Wintelism'-a portmanteau of 'Windows' and 'Intel'-_Borrus/Zysman 1998), they attempt to coin, as precisely as possible, a counter-concept to Fordism. While in the first concept strategy the 'post-' and the 'late' alone conveyed a certain hopelessness in determining new forms of regulation, the concept selection of 'Toyotism', 
'Sonyism' or 'Wintelism' often led to a limitation of perspective on sole production strategies of the capital. Differently to the term 'Fordism', which formulated a societal theory in the early system, the studies collected under the new concepts often ended up as 'nearly theory-abstinent' works on industrial sociology (cf. the critique of Jessop 2003: 95ff.).

Among regulation theorists, there is a general consensus that one cannot agree on which criteria are characteristic of the new forms of regulation of 'Post-Fordism', 'Toyotism', 'Sonyism' or 'Wintelism'. Regulation theorists have so far not been able to deliver a similarly precise definition to rival that of Fordism. There are only two central trends that indicate the gaining significance of global financial markets and the emergence of global value chains as crucially characteristic of 'Post-Fordism'.

Regarding the globalization of financial markets: The Fordist compromise was based on wages and price being geared nationally, and financial markets having primarily a national focus. In Fordism, the accumulated savings in a country were made widely available to companies in the country. The supporters of the Fordist financial regime were-at least in Germany, France and Italy-nationally embedded banks and insurance companies. They either themselves possessed significant stocks in industrial companies and significantly determined the company politics through supervisory boards (equity participation) or influenced the company through credit lending (outside capital provision). The banks carried the Fordist compromise - which, after the added value was generated, did not only benefit the equity owners but could also be reflected in the increased wages for the employees - for a long time. Their goal was a longterm safeguarding of capitalist accumulation. 'Joe Public' - the Fordist prototype-earned sufficient money as an employee to not only satisfy his consumer needs, but to be able to entrust his minor savings to his banks at a fixed interest rate of $4 \%$ or $5 \%$, which in turn made it possible for the bank management to provide a loan to a mid-sized company in the same region (cf. Aglietta 2000: 50ff). The Post-Fordist era is, in contrast, characterized by the globalization of the financial markets, whose supporters are no longer the banks of the Fordist age-which were connected to the companies for years and decades - but the institutional investors in all financial centers around the world. Funds, foundations, insurance companies and banks focused on investment businesses invested their own money and the money entrusted to them in the businesses that guaranteed a short term return on their investment (see also Krippner 2011). Whether this business is in Frankfurt, Chicago, New York, Singapore or Tokyo is irrelevant. This change correlates with the modified investment behavior of 'Joe Public' (see also Polillo 2009). Instead of putting their money in postal office savings books or treasury obligations, the prototype of the Post-Fordist saver now invests either directly in shares of large, high-tech and small growth companies or they purchase stocks in funds that invest the money in companies for them. Had they entrusted their money to the 


\section{Economical Primacy \& functional differentiation}

banks for a fixed interest rates during Fordism, they would now hope for high dividends and especially for a rising share price. Whenever the financial markets boom, it escalates to an 'exit capitalism' in which equity owners resell the once purchased company stocks at a highest possible 'exit profit' after a short time (cf. Kühl 2003: 9ff.). For the company, this means that they have to maintain their investors-who are interested in a quick profitable 'exit'- by permanently providing success notifications. The share profit becomes a "guiding variable for the behavior of the company" (Aglietta 2000: p. 94).

Global value chain: In Post-Fordism, the internationalization of the financial market is accompanied by a special form of international division of labor. This development is often summarized under the buzzword 'globalization'. What is new is certainly not the formation of worldwide markets. Karl Marx and Friedrich Engels had already postulated in "The Communist Manifesto" that the "modern industry" established the world market and the bourgeoisie gave "a cosmopolitan character to production and consumption in every country" through "its exploitation of the world market". "In place of the old local and national seclusion and self-sufficiency, we have intercourse in every direction, universal inter-dependence of nations" (Marx/ Engels 1958b: 464ff.). What, then, is new? Simply put, regulation theorists see the difference in the fact that, in Fordism, the production of goods (but not trade) had a primary national focus, whereas in Post-Fordism, companies and complete industries increasingly outsource the production of their commodities abroad; supported by the development of microelectronics - a core characteristic of the third industrial revolution-company-wide, systemic rationalization processes were developed. From the purchase of raw materials to the development of products and machines, to the central manufacturing steps and the final assembly, the individual steps of the value chain were increasingly distributed across different regions of the globe. The individual elements of production were, respectively, outsourced to the countries where qualification, wage prices and taxes were most affordable for the company (cf. Lipietz 1998: p. 127).

Which effects does this development have on the nation state? The nation state, according to the regulation theorists, cannot get the financial forces that were initially promoted by it under control. It progressively loses its ability to perceive the function of a regulation of capitalism. It may well be that the internationalization of the financial markets and the division of labor does not lead to a disappearance of the nation state (cf. Aglietta 2000: p. 42), but it increasingly sets in a 'social competition of undercutting'. As capital tends to act increasingly globally, while labor power continues to be very strongly domestically geared, the 'domestic competition state' focuses on 'creating affordable utilization conditions in competition with other states'. Under labels such as 'America Inc.', 'Japan Inc.' or 'Germany Inc.', nations could be perceived as capitalist companies-for instance, according to the analysis of Joachim Hirsch - that "functioning smoothly and 
efficiently" are "geared toward an economic goal" (Hirsch 1995: 103ff.). Under these conditions, it becomes more difficult - according to the opinion of regulation theorists - to maintain the Fordist wage compromise.

\section{The limits of the regulation approach: how far can a productionist theory of society reach?}

The strength of the regulatory approach can be seen in the fact that it has provided a framework that could be used to grasp the rough lines of economic change both theoretically and empirically (see, for a review, the anthologies of Amin 1994; Boyer/Saillard 2002; Jessop/Sum 2006). In the debate about whether we are dealing with Fordism, High-Fordism, Neo-Fordism, or Post-Fordism, the sociology interested in work did not lose sight of the overall economic developments. Thus, the theory of regulation contributed so significantly, so that this strand of sociology did not wither away into a mere industrial sociology.

However, the premises of this approach must not be ignored: With the diagnosis of late or neo-capitalism, Fordism or Post-Fordism, emphasis is put on the fact that the Marxian analysis is still valid, and only gradual differences existed compared to the dominant forms of economic production in Marx's lifetime. The intervention of the 'welfare state', which Marx could not have predicted, would have well led to a 'stopping' of the class conflict, but the classes might — at least presumably_-break up in a crisis at any time. In this way, it was possible to set oneself apart from the terms 'welfare state economy', 'service economy', or, later, 'knowledge economy', which asserted that society "so thoroughly determined by unimaginably-extended technology" that, by contrast, "the social relations, which once defined capitalism", that is, the formation of wage-work conditions and the emergence of the contradictions of classes, lost relevance (Adorno 1969: p. 12; see also the overview in Beckenbach et al. 1973: p. 25; Beckenbach 1991: 94f.).

In this variation of social theory, the focus is a 'productionist definition' of society. When Otto Morf (1970: 90f.) emphasizes that the political economy defines production as "a concept of the largest scope as a societally general definition", he ultimately coincides with all explanation approaches of late capitalism explicitly inspired by Marx, Fordism and Post-Fordism. By means of this productionist definition, all problems indicated in Marx's theory are reproduced: An ultimately functional department of the state from the production conditions and a tendency toward deterministic assumptions over the development paths of the capitalist economy.

The central question in this direction of societal theory is to what extent the relations of production can support a definition of the whole society. Is it possible to define society as a whole by way of the relation of capital and work? Is it possible - just as the Marxist theorists from Antonio Gramsci (1967), to Louis Althusser (1977) and Nicos Poulantzas (1973) did-to grant a relatively high level of importance to the willfulness of societal subsets like politics, 


\section{Economical Primacy \& functional differentiation}

law or science and still maintain the capitalist relations of production as the starting point of analysis? How is an opposite societal theory formed which places the willfulness of subsets at the center of its analysis and is simultaneously in the position to control the popularity of capitalist economy?

\subsection{The systems-theoretical approach of functional differentiation: capitalist economy instead of capitalist society}

With formulas such as ' $\mathrm{M}-\mathrm{C}-\mathrm{M}$ ', Marx described the differentiation of the economy and then-perhaps hastily_-generalized from the formation of the economy as an independent functional system to society as a whole. The theory of functional differentiation agrees with Marx on the thesis of the differentiation of the capitalist economy, but asserts that the economy is not the only social subset that has undergone a process of self-sufficiency. Politics, law, science, religion, health care, education, the mass media, even family and intimacy had similar processes behind them. Max Weber was certainly one of the first sociologists to look at this development (Weber 1990) with his concept of the differentiation of 'social value spheres', such as religious ethics, capitalist economy, scientific rationality and the acceptance of bureaucratic rules (cf. Weber 1990).

\section{Economy as one societal subset among many}

The differentiation of a societal subset-be it economy, politics, law or science-means that the operations of the respective functional system run according to their own logics and rules. With increasing differentiation, for example, the solution of practical problems of the economy is no longer relevant in science; rather, the scientists are more concerned with the publication of essays in prestigious magazines. The scientist is primarily interested in the opinion of their colleagues, and not the political or economic usefulness of their own research. Even with the differentiation of the economy as an independent functional system, only 'money-making for the sake of money' (see ' $\mathrm{M}-\mathrm{C}-\mathrm{M}$ ') counts. In contrast to pre-modern societies, money can no longer be used to buy souls, political offices or scientific reputation. You must pray to save souls, campaign as a candidate in political elections and publish articles accepted by professional colleagues for scientific reputation. Money can only be used to satisfy its needs for consumption-or to make more money (see ' $\mathrm{M}-\mathrm{C}-\mathrm{M}$ '). With the differentiation of love as an independent societal subset, unlike in the Middle Ages and in the early modern age, it is no longer interesting to see how a partner can fulfill economic, legal or political functions; today, on the other hand, everything revolves around 'romantic love'. The groupies who throw themselves at the world's pop and sports stars, and who are discriminated against in the mass media as 'gold diggers', serve only as a morally objectionable counterpart to 'true' romantic love. 
In the most far-reaching form of functional differentiation, societal subsets only work according to simple two-step schemes: In the economy, it is only interesting if one pays or not, and not whether the color of the skin, the gender or the political affiliation of a customer or vendor is acceptable; in the legal system, verdicts must be justified by reference to the legality or illegality of conduct. It may be that black people are more often condemned for murder than white people, that workers without a high school diploma are more likely to get a speeding ticket than a professor wearing their bourgeoisie on their sleeve-still, skin color, level of education or tenure status are not relevant arguments when questioning legality or illegality in court.

The inherent logic of the social subsystems is so strong that one is usually automatically guided by them. A student usually knows that good grades are obtained through the fulfillment of examination requirements, not by regular transfers to the bank account of their lecturer or by performing sexual favors to their professor. In educational institutions such as the university, everything revolves around learning; in business everything is about solvency. Even if money can be used to pay for tutoring with emeritus professors or to gain access to universities, and reciprocally a good education makes it more likely that one gets a good job in the financial world, all parties are well aware of the difference between money and education. The popular argument among US students that paying 20,000 US dollars per semester should earn you a good university degree can be dismissed by professors as pathological, just as the employer can dismiss the argument of applicants that claim that they alone - thanks to their impressive university degrees-deserve a higher salary.

The increasing differentiation of economy, politics, law, art or love as societal subsets, according to Luhmann's terminology (e.g., 1984), offers an 'expectation of trustworthiness'. If, during summer sales, a beach towel is offered as a supposed 'bargain', the buyer assumes that the department store-despite the favorable price-strives for profit, and not to do their potential customer a favor with a cheap towel, or to persuade them to vote for a certain political party. The management knows that the buyer in the department store is neither looking for a favor nor political self-realization, but rather a 'good deal' during the summer sales, and is thus accordingly oriented. On the other hand, a lover assumes that their partner is with them because of love, and not because they intend to persuade them to vote for a conservative party, visit a Marxist group meeting, or buy a beach towel. Mutual tenderness (a whispered 'I love you') strengthens the conviction that their partners motivating force is always love. Functional differentiation is thus not just a societal principle based on the actions of actors; it is also a principle repeatedly reproduced and confirmed in everyday communication.

If one disregards the understandable Marxist defense against the theory of functional differentiation, one can read it as a radicalization of Karl Marx (cf. Luhmann 1975e: p. 81; Luhmann 1997: p. 366). The willfulness of 


\section{Economical Primacy \& functional differentiation}

differentiated societal subsets such as religion, politics or love leads to economy not needing to worry about much more. It is only under these 'relief conditions'- and herein lies the radicalization - that capitalism can unfold its dynamic (Luhmann 1997: 724ff.). In the simplest terms, the separation of religion and economy in the modern world signifies that one can do without the not-so-profitable spiritual salvation investments, and instead put one's money in new machines. The development of a self-sufficient political system had similarly dynamic effects. With the securing of collective state power over parliaments and governments, the connection of land ownership and political influence - which is still characteristic of the pre-modern periodlost a great deal of importance. The possible sale of the often-unprofitable land ownership led to the availability of capital for more profitable investments. Not only did the formation of economy and love as two societal fields with their respective logics brought forth the phenomenon of romantic love (no longer economically or politically justified), it also gave the capitalist economy a dynamic thrust. In some African and Asian regions, it is still possible to observe the extent to which the capitalist economy is hampered by the fact that families spend large amounts of money to 'buy' a 'loving' partner for their daughter (or, less commonly, their son).

\section{Legitimate indifference as a hallmark of functionally differentiated societies}

In the early differentiation theory of Émile Durkheim and Talcott Parsons, the functional differentiation was still conceived as a large societal division of labor in which every sector, more or less adjusted with regard to each other, provided its services to society. The sociologist Durkheim-active at the end of the 19th century and the beginning of the 20th century-showed how the various disciplines develop with their respective logics in modern society, but also emphasized that, due to the interdependent nature of the societal subsets, there is an emergence of a new societal cohesion, an 'organic solidarity'. Parson, whose most important works appeared in the middle of the 20th century, points out in his theory of structural functionalism, which was primarily justified by him, that the self-preservation of a society is ensured when the systems adapt themselves to their environment, they keep their target parameters in view, the integration of the processes is assured and the values are stable (cf. Parsons 1971; Durkheim 1984).

The differentiation theory of Niklas Luhmann, which has been developing since the 1960s, has no longer anything to do with this tendency towards a harmonious society. In contrast to Durkheim's theory of the social division of labor and Parson's structural functionalism - but also to the theory of regulation or Max Weber's theory of bureaucracy - the approach of functional differentiation, represented by systems theorists, surmises a 'subintegration' of modern societies. 
The differentiation of subsystems takes place as a 'cultivation, association and finally adoption of world views'. This leads to a reality in which the subsystems, from their own perspective, comprehend society as a whole; from the perspective of the economy, society presents itself as capitalism. Science sees society as a knowledge economy or even as a science economy. For the legal system, it seems self-evident to understand society as a legal state. The media understands everything as part of a large communication society, which, of course, could not exist without mass media.

Every occurrence in modern society is interpreted differently from the logic of the respective social subsystems. Nutritional problems in Ethiopia are viewed by the economy from the point of view of whether business can be made from the import or export of grain, from the transport to Ethiopia, and distribution to the allegedly deprived population. Ethiopian politics are interested in whether it can secure its power in the country by directing aid supplies. From a scientific point of view, it is of interest whether the topic is suitable for a university qualification or even for a larger research project. The media is interested in the subject from the point of view of whether they should publish a story about a famine or report critically on the 'staged starvation'.

From this perspective, the above-mentioned complaint (or the enthusiasm) about the 'economization of society' is only one of many on the social 'Wailing Wall' (Luhmann 1997: p. 763). Just as economization can be deplored, the self-righteousness of science can be denounced, and fears can be voiced that a scientific 'expertocracy' is increasingly colonizing all spheres of life (see Illich 1979: 7ff.). Or it is the primacy of politics that is criticized because there is too little consideration for the natural logic of science, economics, sport or culture. The new Aristoteleans, who demand a return to policy, are told that the interference of politics is precisely the problem (see Kieserling 2003: 423ff.). Or it is deplored that social, economic and political relations will increasingly be subject to a legal regime. Ultimately-according to this excessive criticism-in the case of a an electoral dispute, it wouldn't be the United States wholesalers, the media moguls or even the voters who would decide who the new US president will be, but rather some courts in Florida. Or one complains about the increasing power of the media in the determination of social issues, and declares that, as a politically interested person, there is no need for the analysis of editorialists, which after a "short stint in the bestseller list...wander over to the yellowed collections of the antiquaries" (Bourdieu 2003: 10f.).

How is it that these complaints are formed? Modern society, according to the theorists of functional differentiation, is characterized by a high degree of 'legitimate indifference' between the individual subsystems (Luhmann 1965: p. 35). In modern society, the economy does not need to take into account the fact that the mass unemployment caused by it leads to a collapse of the pension or health system. If an entrepreneur, in view of the mass layoffs they have carried out, points out that they are not responsible for the welfare 


\section{Economical Primacy \& functional differentiation}

of the whole world, they play upon this legitimate indifference. In modern society, science is freed from the constraints of taking excessive consideration of religious feelings, aspects of economic usability or political utility. Naturally, science is called upon to 'respect Christian values', facilitate the production of 'useful products', and, more than ever, strengthen the 'critical potential' of the social movement; however, it is a sign of highly functional differentiation when science succeeds in making clear its legitimate indifference towards religion, economics or politics by referring to their 'freedom of research'.

This 'functional relief' (Luhmann 1975c: 145ff.) does not lead to an independence of the individual function systems from each other, but to the exact opposite. Since universities - with the exception of some old private universities in the United States and the United Kingdom-do not have their own goods which they can use to finance their researchers and educators, they are dependent on the fact that economic wealth is produced, which can then be partly redirected into science by a functioning political system. As the economy can now concentrate 'solely' on the principle of profit maximization, and - as it was in the beginning of European capitalism and, in some cases, still is in developing countries - no longer has to ensure the protection of its constant and variable capital with private armies, it is therefore strongly dependent on the functioning of the police. Since capitalist companies no longer keep their 'own judges', they are dependent on the autonomy of the legal system. If, as in Russia, politics makes use of the legal system for its own purposes, and firms can be sentenced using paper-thin reasons, the development of a self-sufficient capitalist economy is compromised as a result.

From this perspective, there is no reason to pay heed to a function system. Not only capitalist economy is dependent on a functioning political system, a thriving scientific landscape and a sophisticated legal system; the political system must also be able to rely on a functioning economic system and a stable legal system. A differentiation theorist would argue to the Marxist state theorist that, although they have correctly understood the problem of the dependence of societal subsets such as politics and law on the economy, there is no reason to limit this dependence to the economy.

\section{From the problem of exploitation to the problem of exclusion}

What are the central problems of modern societies from this perspective? Functional differentiation produces subsequent problems, which in turn cannot be easily solved by further functional differentiation: The risks of nuclear energy, genetic engineering and ecological catastrophes, and the exclusion of large parts of mankind from basic livelihood. It can be seen that the individual functional systems are overburdened with the solution to these problems, and, as a result, do not consider themselves as (solely) responsible for them. 
The central difference to a theory of society put forward by Marx is that the main problems of society are no longer explained by injustices in social structure determined by the conditions of production. If one looks at the large masses of starving people who can not sufficiently satisfy their basic needs and have neither legal certainty nor political rights to speak or access education or health care, then-according to Niklas Luhmann-one cannot define this with terms such as 'exploitation' or 'oppression'. These concepts are simply traditional mythologies only used out of habit. Exploitation and oppression on the basis of an internationally imposed class rule indeed presented simple solutions, such as revolutions. However, similarly to the theories of modern individualism, they also ended up trivializing the problem (Luhmann 1995a: p. 147; Luhmann 1995c: p. 259). The main problem of modern society is that poor people in metropolitan areas-which Karl Marx called the 'lumpen proletariat' - were no longer needed for exploitation. In short, the problem of modern society could be better understood with the inside/outside scheme than with the top/bottom one. In the functionally differentiated society, the disadvantaged are better described with the concept of the 'excluded' than with the concept of 'proletariat' (for the debate, see Kronauer 1997).

A special problem of exclusion, according to the perspective of systems theory, is the formation of 'chains of exclusion'. According to the observation, the exclusion from a functional system can lead to a 'cumulative exclusion'. Families who live on the street and do not have a permanent address cannot register their children for school. Someone who does not have a passport or some form of ID is excluded from social benefits, cannot vote or legally marry. The exclusion from one functional system is a valid excuse for the exclusion from another: No work leads to no income, which leads to a restriction of the consumption possibilities, which leads to worse health care, which leads to an unstable intimate relationship, which leads to less favorable education opportunities for the children, which leads to hardly any access to legal protection and possibilities to take legal action and which leads to worse income opportunities for the children (Luhmann 1995c: p. 260, 1997: p. 630).

It only seems to be possible to survive the exclusion from a few functional areas unscathed. Withdrawal from the church - and, as a result, being largely ignored by religion-leads neither to a status of lawlessness nor to the exclusion of political co-determination rights or to a prohibition of work (even if depictions from fundamentalist Christian strongholds in the southern United States would partly suggest otherwise). Non-participation in social areas of culture and sport does not diminish the chances of winning a judicial process. Before an election, neither politicians, as service providers, nor voters are required to take a test in art or sports. In contrast to segmented and stratified societies, estranging yourself from your family remains largely inconsequential if you can nevertheless see yourself as part of a large 'single society' within a functionally differentiated society. 


\section{Economical Primacy \& functional differentiation}

The risk of a 'chain of exclusion' seems to be particularly high when one slips out of the functional systems of the economy, law, politics, health or education. There are dramatic cases of individual exclusion, in which the chain of exclusion originates in an exclusion from the economy; there are also followers of theories of functional differentiation which regard work as the medium of inclusion in a functionally differentiated society, and therefore see the 'beginning of the end' in the exclusion from the world of work and its resulting lower chances of consumerism. However, there is no empirical or theoretical suggestion that chains of exclusion are fundamentally attributed to the economy. Studies on migrants point out that the lack of a legal status is often the cause of this phenomenon, and often just by legalizing their residential status, the problem could be significantly reduced. The case of Indian and Chinese minorities in some East African states-as well as Jewish entrepreneurs and workers during the period of German National Socialism-shows that successful economic inclusion is also of little use if basic political and legal rights are denied and, consequently, chains of exclusion ensue.

The chains of exclusion raise problems first for the individual person and then also for the society. "What does it mean", asks Luhmann,

that the illiteracy rate does not decrease, but increases for reasons that can not be controlled educationally? What does it mean for the legal system if exclusion areas - as well as the police as a connecting organization between inclusion and exclusion and ultimately politics-are no longer bound by a constitutional state, but can be just as well and equally successful if they operate lawfully or unlawfully? What does it mean for the economic system if large parts of the population are excluded from the marketplace, but cannot support themselves in the manner of a subsistence economy either, so that it becomes obvious that the economy is not capable of delivering sufficient food where it is needed?

(Luhmann 1995c: p. 261)

The crisis scenario of the theory of functional differentiation is that - as is the case in some regions of Europe, America, Asia and Africa-the distinction between inclusion and exclusion is more important than the distinction between the functional systems. According to Luhmann (1997: p. 632), whether or not the distinction between right and wrong can be made depends on the previous filtering based on the distinction of inclusion and exclusion; this becomes clear when looking at the favelas and barrios of Latin America, the large refugee camps in Africa, as well as the 'hyperghettos' and 'banlieues' of the North American and European metropolises, respectively. There is no legal form in which a functionally differentiated society is not being replaced by another form of differentiation; which is why, for adherents of this theory, the discovery of the chain of exclusion may be disturbing but not surprising (cf. Kronauer 2002: 126ff.). 


\section{Open questions: how can it be explained that economy plays such an important role?}

The theory of functional differentiation assumes that societal subsets fulfill different functions that cannot be easily taken over by any other social subsystem. If politics 'doesn't take charge', the economy-embodied in the representatives of employees and employers - may complain, but it cannot take on the tasks of politicians. In the same way, however, politics cannot take over the functions of the economy whenever it doesn't fulfill its tasks in the eyes of political representatives.

It would be too easy to place all function systems at the same level and on equal terms. Although Luhmann points out that all subsystems tend to fulfill their function for society and one cannot simply forgo an individual subsystem, it would be naive if religion were granted a status of equal significance as politics. Art and sport may represent independent functional systems, but just a glance at several people active in these fields is enough to know that one can do just fine without their individual services.

Functional differentiation, according to Luhmann, in no way guarantees equal opportunities for all sectors of society. It is a question of social evolution, the focal points of development and the functional systems that are particularly active (cf. Luhmann 1997: 770f.). However, these abstract aspects are not by themselves sufficient. The theory of functional differentiation requires research that refer to different subsystems of modern society with the same questioning and with the same conceptions. Only in this way is it possible to compare the different areas of society with one another and to coordinate them within a societal theory (Beck et al., 2001: p. 79).

The theory gives only the first starting points as a 'functional primacy' of economics. In the sociology inspired by Marx, the primacy of economics is determined on the one hand by a particular role of the economy in the development of modern society, on the other by a stronger position of power of the economy compared to other societal subsets. In their-appropriately caricatural-version, one imagines how capital controls the mass media, how politicians are led by the economy, or why science is forced to follow economic guidelines. On the other hand, under the primacy of a functional system, Luhmann does not understand the rule of one functional system over another. On the contrary, for him, 'primacy' means that the development of a company "depends primarily on one of its functionally necessary subsystems" and the problems of the other functional systems are predefined by this functional system (Luhmann 1975e: p. 96). For the political system, for example, political success is all that matters - whether or not success is achieved by winning an election, the violent removal of a despot from office or a victorious global revolution. A population paralyzed in its religious devotion, a functioning legal system or economic prosperity for all are only interesting for politics insofar as they contribute to political 


\section{Economical Primacy \& functional differentiation}

success. Luhmann would speak of a functional primacy of a functional system if political success is decisively dependent on the functioning of this functional system.

From the point of view of systems theory, the prominence of a function system is not understood in terms of its strength, but in terms of its weakness. "The system with the highest failure rate dominates", says Luhmann, "because the failure of specific operating conditions cannot be compensated anywhere and can be accentuated everywhere". If money was no longer accepted or law no longer enforced, not only the economy or the legal system, but also all other areas of society would be faced with problems that could hardly be solved (Luhmann 1997: p. 769).

This explains why the economy becomes such a salient social subsystem in our field of vision whenever phenomena such as mass unemployment, diminishing purchasing power or inflation occur. It is precisely the failure of the capitalist economy that contributes to the rise in their interest. But in the functionally differentiated society, there is no legal measure which contributes to the fact that this role of the 'chronically sickly' has to be taken by the economy. Just as the Italian model of politics - that of a government in perpetual crisis - focuses on the necessary function of politics, great crises of value as a result of the dwindling significance of religion serve to ensure that this societal field receives greater attention. 


\section{Business vs. organization \\ Subsumising the company to the logic of profit maximization or stressing the self-logic of the organization}

In the early 1970s, writers Yaak Karsunke and Günter Wallraff published a 'questionnaire for workers'. In it, the worker was asked to provide information about their situation on the basis of 90 sets of questions: "Is the company you are working for privately owned or a stock company?" "How do foremen and master craftsmen behave towards their colleagues, their superiors?" "Are there any dismissals because of production change or adjustment?" "Are there punch-clocks?" "Can you set your own working speed?" "Who or what supervises work?" "Does an increase in the dividends for shareholders result in a rise in your wages, in other words, do you participate in the profits you have generated from the company?" "Are you aware of the assets of the owner or the majority shareholders of the company you are working for?" "Has there been a strike within the last five years?" "Are you aware of any abuse that might justify a strike or which could only be resolved through a strike?" (Karsunke/Wallraff 1970: 2ff.).

This questionnaire, distributed in companies, was based on a well-known model. In 1880, Karl Marx had developed a questionnaire for the Paris Socialist Review in order to launch a 'serious investigation' into the situation of the French working class. Marx's questions were also concerned with the working conditions in the factories, capital relations and the living conditions of the workers: "Is the workplace overfilled with machines?" "How many hours do you work daily and how many days a week?" "What is your contractual relationship with your employer?" "Do you get time or piece wages?" "How much is your wage per day or per week?" "From personal experience, have you seen an increase in prices for essential things higher than that which wages allow?" "Do you know of cases where workers have lost their jobs as a result of the introduction of machines or other advancements?" "Are there associations of employers to enforce pay cuts or extensions of the working day, to eliminate strikes and, in general, to force their will upon the working class?" "What is the general physical, mental, and moral condition of the workers employed in your profession?" (Marx 1962b: 230ff.).

This "Questionnaire for Workers" had a dual function in the Marxian sense, as did Karsunke's and Wallraff's later versions. On the one hand, it was a way of gathering data on the condition of the working class in the 


\section{Business vs. organization}

form of a social survey. On the other hand, when the questionnaire was read, the worker was to associate the "seemingly quite self-evident and everyday details discussed therein" to a "general picture of his situation". According to the assessment of the social scientist Hilde Weiss, by answering the questions they gained "insight into the nature of the capitalist economy and the state, and get to know ways and means of abolishing the wage labor conditions, towards his liberation" (Weiss 1936: p. 86).

Even though social scientists would probably not use such a questionnaire for an 'operational analysis' today (if only because the response rate to such an extensive catalogue of questions would be unsatisfactory), the questionnaire managed to address the central issues regularly dealt with by the sociology of work and industrial sociology focused on working conditions in businesses.

\subsection{Marx's basic notion: the increase of absolute and relative surplus value}

All capitalists, according to Marx, strive to increase profit in their own businesses. Their "ravenous appetite" for surplus value cannot be satiated (Marx 1962a: p. 249). For this reason, they not only try to get as much work as possible for their money, but also focus on technical, organizational and work-psychological innovations, which lead to increased work productivity. The capitalist can succeed in gaining advantage over the competition because the workload they put into a product is less than the average workload in their industry. According to Marx, they create an 'extra value'. But this extra value disappears because the 'compulsory law of the competition' drives the competitors to introduce innovations as well. Thus, the measures initially introduced in single cases become widespread (Marx 1962a: 336ff.).

The technical level of the means of production is thus improved further and further. As a result, less and less labor power is required for the production of a watering can, a grinding machine or a Mercedes-S-Class sedan. But this, according to Marx's idea, means that the share of capital expended for work wages (the variable capital ' $v$ '), as opposed to the capital spent on machines (the constant capital 'c'), consistently decreases. In Marx's terms, the "organic composition of capital"- the relation of constant and variable capital - is constantly changing to the detriment of the variable capital. As a result, profit rates - the relation of the value added by work alone to the total capital invested - are reduced. Marx refers to this as the law of the "progressive fall of the profit rate" (Marx 1964: 223ff.; see also Sweezy 1972: p. 177; Herkommer/Bierbaum 1979: 39ff.).

For the individual capitalist, this means that they are not able to get out of the 'rat race' of permanently increasing their surplus value under conditions of the capitalist "compulsory laws of competition". To increase surplus value, the capitalist has two strategies: either the extension of the working 
day of the worker (increase in absolute surplus value) or the intensification of work (increase in relative surplus value). Even the 'Enquete Ouvrière' by Marx (1962b: 230ff.) aimed at these basic strategies for surplus value production with questions regarding the shortening of lunch breaks, working overtime for the cleaning of machines, night work or seasonal overtime work on the one hand, and questions regarding the increase of work intensity on the other (cf. Weiss 1936: p. 89).

\section{Work as long as possible: the increase of absolute surplus value and the discussion on working time}

A first central strategy of the capitalist to draw the biggest possible value from the purchased labor power is to let the workers work as long as possible. The logic of the capitalist is easy to understand: "If I have secured the labor power of Mr. Jones or Mrs. Smith for a salary of 2,500 dollars, I try to let them work for this salary as long as possible". The more hours a day and the more days a month Mr. Jones or Mrs. Smith are present in the company for those 2,500 dollars, the higher the value for the capitalist. The "extension of the working day beyond the point at which the worker would have produced only one equivalent for the value of his labor power" is what Marx defines as the increase of absolute surplus value (Marx 1962a: p. 532).

The capitalist tries, wherever possible, to organize working hours in terms of the logic of capital utilization. If it seems necessary to the capitalist that expensive machines run around the clock, then the workers must come to the factory from ten o'clock at night to seven o'clock in the morning. If it's the holiday season, then the workforce in the mail order office must also work on Saturdays and Sundays.

In capitalism, workers increasingly lose the possibility to manage their own time. "Time for education, for intellectual development, for the fulfilling of social functions and for social intercourse, for the free-play of his bodily and mental activity, even the rest time of Sunday", seemed to the capitalist to be pure "moonshine!" (Marx 1962a: p. 280). The capitalist does not support the needs of their workers as values in and of their own, unless they help the worker improve the use of their labor power.

And yet, it is not possible to simply extend working hours to 24 hours a day. According to Marx, the "maximum barrier of a day of work" is determined by two factors. A human being needs time to rest, eat and drink every day. If this 'physical barrier' is not respected, the workers' ability to work is at risk. However, the extension of the working day also faces a 'moral barrier'. The worker needs time for the satisfaction of mental and cultural needs, whose circumstance and structure are determined by the cultural condition of the country in which they live (Marx 1962a: p. 246).

Yet both the physical as well as the moral barrier are "of a very elastic nature". It is true that a working day cannot last longer than 24 hours, but 
whether it is now 18, 16, 8 or 4 hours long is not determined by any natural law. Accordingly, there were also different views as to how long a workday should last. The capitalist bought the "labor power at its daily value". The time during which the "worker works is the time during which the capitalist consumes the work he has purchased of him. If the worker consumes his disposable time for himself, he robs the capitalist". The capitalist, like any other buyer of a commodity, can act against this unlawful appropriation (Marx 1962a: p. 247).

However, as Marx observed, the unrestricted attempts of the capital to increase absolute surplus value through the extension of the working day and the adjustment of the time to the needs of capital utilization ran into counter-strategies of the workers. The sale of labor power is ultimately subject to the same laws as the sale of other goods. Just as one can try to 'get' as much as possible from the sale of a record collection at the flea market, the worker can try to sell their labor power for as much as possible. And just as the buyer aims to reduce the price of a record collection, the capitalist as the buyer of the labor power as a commodity also tries to squeeze its price.

Thus, according to Marx, the negotiation of working time does not depend on the basic religious attitude or the attitude of heart of the capitalist, but is rather the result of an economic negotiation process. "Capital has", says Marx, "one single life impulse, the tendency to create value and surplus value, to make its constant factor", from the workers, to extract the greatest "possible amount of surplus". The worker insists on a working day which is justifiable for them: "I demand, therefore, a working day of normal length, and I demand it without any appeal to your heart, for in money matters sentiment is out of place". "I demand the normal working day because I, like every other seller, demand the value of my commodity" (Marx 1962a: 247ff.).

According to Marx, the history of capitalism is characterized by the workers' struggle for the determination of what a working day is "the result of a struggle, a struggle between collective capital, i.e., the class of capitalists, and collective labour, i.e., the working-class" (Marx 1962a: p. 249). It is only when the worker, as a free seller of their labor power in the form of the working class, faces the class of capitalists that they are no longer defenseless. According to Marx, "The creation of a normal working day is, therefore, the product of a protracted civil war, more or less dissembled, between the capitalist class and the working-class" (Marx 1962a: p. 316).

Three aspects regarding the regulation of the working day can be highlighted, all of which have established themselves in an increasing number of industrialized countries since the middle of the 19th century (cf. Altvater et al. 1999: 78f.): First, this regulation protects individual capitalists from the 'compulsory law of competition'. It creates roughly equal conditions for the purchase of labor power for all capitalists. In this way, it prevents the strategies of individual capitalists from increasing their competitiveness by 
extending the working time without restriction. Second, "state law" constitutes an "overriding societal obstacle" which prevents workers from selling "by voluntary contract with capital themselves and their families into death and slavery" (Marx 1962a: p. 320). The overarching regulation of working hours also prevents the competition among the workers as sellers of labor power as a commodity. Minimal standards would be developed which, for example, could not undercut the unemployed on their desperate search for a job (cf. Müller/Neusüss 1979: 37f.). Third, defining the working day increases the binding capacity of the capitalist system. An unrestricted working day would reveal the exploitation to the workers on a daily basis and could lead to a growing protest against the appropriation of surplus value by capital.

Industry and industry-wide safeguarded regulations hinder many strategies of the capital which aim to extend the working time and thus the absolute surplus value production. Capital is therefore forced to concentrate on a different strategy for surplus value production: The increase in the value that an employee produces during the non-extendable working hours. According to Marx, production must be circulated in such a way that the "productive power of work" can be increased. "In addition to a measure of its extension, i.e., duration, labour now acquires a measure of its intensity or of the degree of its condensation or density" (Marx 1962a: p. 334 and p. 432).

\section{Work as productively as possible: the increase of the relative surplus value}

The more effectively work equipment is used, the more work a worker can carry out in a working day. The faster a machine is operated by a worker, the higher the yield of work at the end of the working day. This process is defined by Marx as an increase in relative surplus value, an increase in the output of work through its 'better', 'more rational' use of machinery, equipment, or the more efficient arrangement of work steps.

For Marx, the transition from production in manufacturing businesses to industrial production is the decisive step towards the increase of relative surplus value. The capitalist production process in manufacturing businesses consisted mainly of craft-oriented production from the middle of the 16 th to the end of the 18th century. Individual craftsmen concentrated on certain activities in the production process and thus perfected their 'detailed skills', for instance in the operation of certain machines. The implementability of machines was, however, limited by the "muscular development, the keenness of sight, and the cunning of hand" (Marx 1962a: p. 359; see also Altvater et al. 1999: p. 96, whose overview I follow herein).

In manufacturing businesses, the individual worksteps and machines had not yet been systematically connected. It was only with the advent of industrial production that machines became increasingly interlinked. By means 


\section{0}

Business vs. organization

of 'machines of motion', such as conveyor belts, rails or slides, the individual production steps were combined in such a way that complex "organized system of machines" were created and the industrial production process functioned as a "huge automaton" (Marx 1962a: 402f.).

This "system of machinery" liberated the machine as the means of production par excellence from the dependence of the individual workers. It was no longer the skilled worker who dominated the machine; with industrialization, "the organized system of machines" came about, which the worker found to be an "existing material condition of production" as an entirely "objective production organism". "The cooperative character of the work process is", says Marx, "a technical necessity dictated by the instrument of the work itself" (Marx 1962a: p. 407).

What were the effects of machinery operation on the workers?

Compared to the activities in the manufacturing businesses, which were generally carried out by qualified craftsmen, no special qualification was required of the workers in the 'system of machinery' at many workplaces. According to Marx,

The labour of women and children was, therefore, the first thing sought for by capitalists who used machinery. That mighty substitute for labour and labourers was forthwith changed into a means for increasing the number of wage-labourers by enrolling, under the direct sway of capital, every member of the workman's family, without distinction of age or sex.

(Marx 1962a: p. 416)

The change from manufacturing production to industrial production fundamentally changed the relationship between the worker and the machine. In industrial production, the "capabilities of the tool are emancipated from the restraints that are inseparable from human labour-power". The "lifelong specialty of handling one and the same tool", which had still determined the role of the worker in the manufacturing businesses, became, in the industrial production, "the lifelong specialty of serving one and the same machine". "In handicrafts and manufacture, the workman makes use of a tool, in the factory, the machine makes use of him" (Marx 1962a: 442ff.).

This drastic change shifted control of the work process from the workers to the capitalists. In the manufacturing businesses, the workers were 'formally' separated from the means of production. Ultimately, it was the capitalists and not the workers who were the owners. But in the specific work process, the workers had great influential power because of their knowledge. The capitalist had the tools and materials, but they did not control the process of work as such. Marx calls this a mere "formal subsumption" of work under capital. By the introduction of the 'modern industrialists', the workers were deprived of control over the work process. The work process was now no longer governed by the workers, but by the capitalists themselves or 
by their delegates. The "formal subsumption" was extended to a "real subsumption" of the workers under capital. Even if the subordinate order of the worker under the conditions of production - the "real subsumption" - was never perfectly achieved and could never be achieved, the process of work had fundamentally changed (see Marx 1962a: 532ff.).

According to Karl Marx and Friedrich Engels, the trend towards "real subsumption" had devastating consequences for the workers. "Owing to the extensive use of machinery, and to the division of labour, the work of the proletarians has lost all individual character, and, consequently, all charm for the workman". The worker became "an appendage of the machine, and it is only the most simple, most monotonous, and most easily acquired knack, that is required of him" (Marx/Engels 1958b: p. 468). According to Marx,

At the same time that factory work exhausts the nervous system to the uttermost, it does away with the many-sided play of the muscles, and confiscates every atom of freedom, both in bodily and intellectual activity. The lightening of the labour, even, becomes a sort of torture, since the machine does not free the labourer from work, but deprives the work of all interest.

(Marx 1962a: 445f.)

"Economy of the social means of production, matured and forced as in a hothouse by the factory system, is turned, in the hands of capital, into systematic robbery of what is necessary for the life...". 'Factory' meaning:

Every organ of sense is injured in an equal degree by artificial elevation of the temperature, by the dust-laden atmosphere, by the deafening noise, not to mention danger to life and limb among the thickly crowded machinery, which, with the regularity of the seasons, issues its list of the killed and wounded in the industrial battle.

(Marx 1962a: 448ff.)

\subsection{The debate: Taylorist vs. Holistic forms of work}

There are, as shown, two strategies of capital according to the Marxian analysis to 'get more' out of the worker: The extension of working hours, without the capitalist having to pay for it, and the more effective use of bought-and-paid-for work time (rationalization as a continuous improvement of the work organization). These two strategies for enhancing surplus value are related. If the expansion of work hours is not possible due to legal provisions on work protection or collective agreements on work hours, 'capital' will increase the intensity of work. By improving the technology and the work organization, optimum performance is to be achieved. At the same time, however, an excessively high intensity and long working 
times can destroy the labor power. For this reason, an increase in the intensity of the work would inevitably lead to a reduction of working hours (cf. Marx 1962a: p. 440).

Because of their strong roots in the Marxist tradition, the rationalization measures for the intensification of work - in addition to the research on remuneration and working time-were the main focus of business-focused Marxist research. Particularly the 13th chapter of "Capital", in which the change from manual production to industrial production is portrayed, can be seen as the Marxian 'source' of industrial sociology. This chapter, according to a heretical outside view of Hans Paul Bahrdt, is to sociology what the epistle to the Romans is to Protestant theologians. The dispute about the 13th chapter - the dispute as to whether, more and more, the worker is being demoted to an appendage of the machine-will, as Bahrdt says, no more come to an end than the dispute between the theologians on the relationship between God and the state (cf. Bahrdt 1982: p. 14).

Even if nowadays a great deal of the research on work in the industrial and service sectors refrains from referring to Marx, one can understand the main discussions within the research direction focused on businesses merely as an examination of the profit maximization strategies developed by Karl Marx.

\section{Taylorist-Fordist work structures: the escalation of the debate on the work process}

It was only natural to update Marxian reflections about an ever-stronger dominance of machines over workers. Harry Braverman, the most prominent representative of a Marxian-based 'de-qualification theory' in the 1970s, argued that the increasingly accepted rationalization strategies served to transform the production process so that the experience, knowledge and traditions of the artisan skills could no longer be regarded as inseparable from the worker as a person. The knowledge that the workers had accumulated over decades and centuries would be systematically transferred to management. This would free the capitalist from the qualifications of the worker and allow them to subordinate workers to the goals, ideas and plans of management.

According to Braverman, capitalists are able to kill two birds with one stone thanks to their rationalization strategies: First, they have an efficient organizational structure that could be used to increase relative surplus value; second, the de-qualification of the workers and the strong dissection of the work process made it possible for them to have better control over the workers (cf. Braverman 1974: 124ff.).

With this combination of rationalization strategies and questions of management control strategies, Braverman concludes directly with a specific aspect of the employment contract which was already touched on by Marx. While in a simple purchase contract-for example, when purchasing 
a bicycle or Nutella-services and return services are exactly specified, the employer purchases labor power in a very abstract form with a contract of employment. The employee writes a 'blank cheque' by signing an employment contract and affirms their willingness to apply their work, their abilities and their creativity according to their assigned task. They forgo a detailed description of what their services consist of in detail (see Commons 1924: p. 284).

For the capitalist, however, this results in a problem of control: While the employment contract precisely specifies the services of the employer (namely the wage payment), the return services of the employees are not precisely defined. Thus, the employee can try to hold back on the provision of their services as much as possible. The purchase of work by the capitalist - the 'formal subsumption' of the worker - is therefore not the same as the real use of labor power by the capital - the 'real subsumption' (see Marx 1962a: 532f.). When the employer buys labor power, they cannot be certain that it can be arranged into the work process smoothly (as opposed to the buildings, machinery and materials they buy) (Braverman 1974: p. 57; Friedmann 1977: p. 78; Berger 1999: p. 155). The transformation of work capacity (i.e., what a worker could perform in the work time bought by the capitalist) into work service (i.e., what the worker actually does) is problematic. In this view, both a Marxist-influenced sociology and an institutional economy stemming from the study of business economics are in agreement.

It was only through the systematic de-qualification of the workers and their submission to a Taylorist-Fordist production regime that, according to Braverman's Marxist-influenced statement, capitalists would have gained control of this 'transformation problem' (Braverman 1974: 124ff.). In his analyses, Harry Braverman takes the rationalization strategies of Frederick Winslow Taylor and Henry Ford at their word when he assumes that, with the advance of industrialization, the reality of business will increasingly correspond to the production ideologies that Taylor and Ford promoted at the beginning of the 20th century. Braverman differs from Taylor and Ford solely in the assessment of new production processes for workers. $\mathrm{He}$ saw in Taylorism a systematic expropriation of workers by capital, while Taylor and Ford saw in the form of the work organization promoted by them not only the most efficient method of production for the capitalist, but also the guarantee of 'prosperity' for the workers (cf. Taylor 1967: p. 9; see also Bendix 1960: 363ff.). According to their assumption, both the employer and the workers would benefit from a Taylorist-Fordist production system-a situation that would later be glorified by management theory as a typical 'win-win situation'.

In science, the question of how widespread the Taylorist-Fordist mode of production was in businesses is still controversial (see Spencer 2000). Some scholars argue that the Taylorist and to some degree the Fordist production paradigm - particularly in its escalated state of 'Fordism' - were constructs of science rather than a hegemonic reality in businesses. Especially Taylor's 


\section{Business vs. organization}

ideas seem to have been part of a public hysteria in the United States at the beginning of the 20th century, which, with the exception of businesses, was apparently ubiquitous. There were courses for scientific housekeeping for housewives, committees for clerical efficiency were established in churches, universities and schools incorporated scientific management, but the 'Taylor Principle' was implemented in only a few business establishments (cf. Haber 1964: 51ff.; see also Moldasch1/Weber 1998: 347ff.).

But precisely as a dominating rationalization model with some quasipractical considerations, the Taylorist-Fordist production paradigm was well-suited to contrast with empirical researches and to delineate the contours of a production paradigm that transcended Taylor and Ford. Those who came up against this production ideology had to show that they were better than Taylorism or Fordism. Any successful refutation and correction had to be ultimately identified as an instrument for increasing productivity.

\section{More holistic forms of work}

Between the two world wars, work that explicitly refrained from Taylorist approaches was already being experimented with. For example, in the case of Mercedes Benz in Stuttgart, preliminary tests began with so-called 'group production' (cf. Lang/Hellpach 1922). In the post-war period, 'holistic work' was carried out at Fiat, in the southern Italian city of Termoli, with the aim of abolishing assembly line work (cf. Guidi et al. 1974). These, however, were only isolated attempts in the automotive industry, striving to take the lead in the production sector, to move away from assembly line production.

Only toward the end of the 1970s and early 1980s did forms of work become established that explicitly distanced themselves from the Taylorist-Fordist production dogma. While the farewell from Taylor and Ford was positively characterized in management literature by the concepts of 'modular factory' (Wildemann 1988), 'lean management' (Womack et al. 1990), 'learning organization' (Senge 1990), 'business reengineering' (Hammer/Champy 1993), 'fractal factory' (Warnecke 1993), 'multi-cell enterprise' (Landier 1987) - later 'holacratic organization' (Robertson 2015) — or 'agile system' (Holbeche 2015), social scientists in particular opted for more neutral descriptions. They talked about the formation of a 'responsible autonomy' (Wood/Kelly 1982), 'new production concepts' (Kern/Schumann 1984a), 'flexible specialization' (Piore/Sabel 1984) or a 'post-Fordist work organization' (Aglietta 1979).

Even if the concepts differed in their emphasis, there was broad agreement with respect to the central features (for an overview, see Kühl 2017). Under the label of decentralization, central competences were partially abandoned and decision-making competences were shifted to the lower levels of organization. Strategic issues were no longer decided upon at the top levels of the company, but in largely autonomous areas. In their most 
pronounced form, these 'business units', 'profit centers' or 'segments' were small 'companies within a company', with their own purchasing, research and development, and sales departments. In operational issues, the strict separation between planning and execution was reduced. The disposition over the work processes returned to value-adding areas. For this reason, individual workplaces were often closed down and the employees were subsumed into groups and teams. In these teams, there was often no supervisor; instead, one was jointly responsible for the accomplishment of a roughly defined task ('goal agreement'). The instruction competencies of the foremen and lower supervisors were curtailed and their roles redefined as that of a 'moderator' of self-organized groups. The rationalization measures were no longer made exclusively by specialized staff; the expert knowledge of employees organized in groups was elevated by 'continuous improvement processes' and 'quality circles'.

As the focus on the development of the means of production ultimately fell back on Marx, in addition to the availability and the use of new technologies, the 'saturation on the sales markets', the intensified 'national and international competition' and the 'growing cost pressure' were also seen as the main engine for the change of the employment process. Especially the development of microelectronics led to machines being able to carry out complex work steps. Although this rendered superfluous a lot of simple jobs in the industry, remaining positions had to deal with the increasingly complex tasks of 'machine operators' and 'system regulators'. In the terminology of Marx, it could be said that the investments in the means of production (the constant capital ' $c$ ') required a re-qualification of workers (ultimately investment in the variable capital ' $v$ ').

In the case of Harry Braverman, his theses for the further de-qualification of the workers were strongly modified, if not entirely rejected, especially in the work process debate carried out in the Anglo-American regions (see Thompson/O'Doherty 2009; Thompson/Van den Broek 2010). Andrew Friedman, for example, emphasizes that the 'direct control'-with very reduced responsibility of the workers and their strict monitoring by the management - is just a strategy to transform work capacity into work. Another possibility is to bind the workers to the company through stable employment and to grant them 'responsible autonomy' (Friedman 1977) in the framework of this basic loyalty. Craig R. Littler argues that neither the control structures and production processes in the factories nor the conditions on the labor market can be extrapolated from the relation between capital and work prevailing in society. There is a high degree of autonomy at the levels of the labor market, control structures and the production process. Thus, it is quite possible that Taylorist-bureaucratic forms of work preside at the level of the production process, while Post-Taylorist strategies dominate the control level of management (Littler 1982: 57ff.).

The 'project group automation and qualification' pointed out early on that the training of computer-aided production and service provision 
processes did not automatically lead to a transfer of production knowledge to management. It was not the extensive separation of mental and manual work prophesied by Braverman, but the use of comprehensive production knowledge of the worker which was to be observed in the concrete work process (cf. Projektgruppe Automation und Qualifikation 1976). This idea was generalized by Horst Kern and Michael Schumann. The two sociologists proclaimed a 'historic upheaval in the use of labor power' and a departure from the dominance of the Taylorist-Fordist form of production. "Living work" is no longer - as Marx predicted - a "barrier to production", which the capitalist seeks to overcome by an "as far-reaching automation of the production process" as possible and a "restrictive, 'Taylorized' work organization". Due to changes in capitalist exploitation conditions, further compression of work through technology would in many cases no longer represent the economic ideal, as the "restrictive access to labor power" would squander important productive potentials. For this reason, core economic sectors such as the automotive, mechanical engineering and chemical industries are experiencing a "re-professionalization of production" (Kern/ Schumann 1984a: p. 19 and p. 74).

The idea of 'contingency'- the notion that processes could go 'this way or that', but without any special preference-was strengthened in the rationalization discussion as a result of the 'work process debate' following the Braverman developments, early pioneering work on automation work and the research on new production concepts. Under capitalist exploitation conditions, according to the basic argumentation, a further increase in efficiency could not only be imagined in the form of an increasing separation of the worker from their experience, knowledge and traditions, but in an opposing process as well.

\section{The debate structure in the question of work organization}

The merit of this long-standing predominant reading mustn't be overlooked: The rationalization processes were under strict social-scientific observation, and an intensive, scientifically informed discussion about the assessment of the observed rationalization strategies took place. The heated debate about whether we are dealing with a Post-Fordist-Post-Taylorist work organization or a return of Fordism-Taylorism has ultimately provided the formulas for the controversy on rationalization strategies being implemented and the impact they have on the employees.

This debate structure, however, led to a strong conceptual 'narrowing' of the discussion in industrial sociology (cf. also Kern 1997: p. 29). Ultimately, the debate in work sociology — but also in large parts of business administration studies, work science and organizational psychology_can be fit in a relatively simple chart (Table 3.1).

On the one hand, the debate revolves around the question of which work structure - a highly collaborative, 'Re-Taylorised' one (cf. Springer 1999), 
Table 3.1 Debate about work structure and situation of the workers

\begin{tabular}{|c|c|c|}
\hline & $\begin{array}{l}\text { Stronger work-sharing } \\
\text { organization as an } \\
\text { efficient form of value } \\
\text { creation }\end{array}$ & $\begin{array}{l}\text { Holistic work forms as an } \\
\text { efficient form of value } \\
\text { creation }\end{array}$ \\
\hline $\begin{array}{l}\text { Highlighting the } \\
\text { advantages for } \\
\text { the workers }\end{array}$ & $\begin{array}{l}\text { Both capital and workers } \\
\text { benefit. The work may } \\
\text { be dull for the worker, } \\
\text { but they participate in } \\
\text { an increase of efficiency. } \\
\text { The argumentation can } \\
\text { be found with Taylor and } \\
\text { Ford }\end{array}$ & $\begin{array}{l}\text { There is a win-win } \\
\text { situation for work } \\
\text { and capital, because } \\
\text { the work becomes } \\
\text { more efficient and at } \\
\text { the same time more } \\
\text { satisfying for the } \\
\text { workers. The argument } \\
\text { can be found with Kern } \\
\text { and Schumann }\end{array}$ \\
\hline $\begin{array}{l}\text { Highlighting the } \\
\text { disadvantages for } \\
\text { the workers }\end{array}$ & $\begin{array}{l}\text { Capital profits at the } \\
\text { expense of workers. } \\
\text { Argumentation is } \\
\text { prominent in Braverman, } \\
\text { can ultimately be traced } \\
\text { back to Marx }\end{array}$ & $\begin{array}{l}\text { Holistic forms of work } \\
\text { are sold as liberation } \\
\text { for the workers, but } \\
\text { are ultimately just } \\
\text { more ingenious control } \\
\text { mechanisms in favor of } \\
\text { capital }\end{array}$ \\
\hline
\end{tabular}

or work based on holistic work forms (cf. Kern/Schumann 1984a; Kern/ Schumann 1984b) - is most likely to contribute to profit maximization. On the other hand, the question of what effect the shared or holistic forms of work - seen as rational for the capital - have on the employees: Do postbureaucratic strategies contribute to satisfaction, self-realization, and liberation? Horst Kern and Michael Schumann in particular have strong sympathy for the 'new production concepts' they identified. In view of the central significance of work, the aim was to 'grab the opportunity' and assist enlightened managers with the introduction of these new production concepts (Kern/Schumann 1984a: p. 327, with great sympathy for this approach). A 'subjectivization' of work establishes itself as a result of employees increasingly striving to bring their interests and abilities into the work process and thus perform challenging and ultimately meaningful work (cf. Baethge 1991). Another direction in sociology puts the "potential for liberation' of new production concepts into perspective, and exemplifies the paradoxical work requirements arising from the decentralized corporate structures (see Boltanski/Chiapello 1999; Alvesson/Willmott 2002). The focus of the discussion is a 'dissolution' of work that allows the boundaries between work and private life to erode and leads to the formation of a 'Post-Fordistic social character' (cf. Eichler 2013).

This simple four-panel scheme provided the basis for a now almost incalculable number of research projects that ask-on behalf of newly emerging industries, countries, and employee groups-how work processes are 
changing, and how workers are affected as a result. Thus the central discussion threads of sociology of work, work psychology and work science focused on businesses can be ultimately understood with this four-panel scheme.

In a first strand of the debate on industrial sociology, new management concepts are being examined to determine whether they were more likely to lead to 'Re-Taylorisation', or to allow for more holistic work designs. Thus, there is a strong debate about whether 'Lean Management' - popular in the $1990 \mathrm{~s}$ - is a departure from Taylorism or, ultimately, only its continuation under modified conditions (cf. Jürgens 1995). The 'group work' in companies is examined from the point of view of whether it was practiced in a limited form with low workload, a high integration into assembly line production and a low degree of self-coordination, or whether it leads to a far-reaching partial autonomy of the group — with heavier workloads, a tendency to detach from the assembly line and a high degree of self-coordination. The 'marketization' with which, on the one hand, companies enter the markets and, on the other, structure cooperation between their organizational units through internal market processes is taken into consideration.

In a second strand of the debate, the rationalization strategies are examined for national specifications. While initial comparisons between Western European countries were at the focus of research (Maurice et al. 1980, 1982), since the late 1980s, early 1990s, research has been concentrated on comparisons between Japanese, American and European production forms (cf., e.g., Cole 1989; Lincoln/Kalleberg 1990; Jürgens 1995). Due to the successes of the Japanese automotive, microelectronics and mechanical engineering industries in the 1980s, industrial sociology is interested in the way in which the production methods developed in Japan could be classified into the discussion about Taylorist versus holistic production forms, and which processes could be observed in the transference of the organizational forms developed in Japan (cf., e.g., Ackroyd, Stephen et al. 1988; Lillrank 1995). Ultimately, these studies focus on national differences in the context of a research direction, which aims to work out "Varieties of Capitalism" (Hall/Soskice 2001) in different countries.

A third strand of the debate takes different work groups into consideration. As the 'classical industrial worker' was, in the eyes of sociological and work sciences, male and white for a long time, it was obvious to claim 'gender blindness' or 'ethnicity blindness' (Glucksmann 1990). The concept of 'gendered organizations' was used to study the role women play in organizations in contrast to men (see Acker 1990; Martin 2003; Britton/Llogan 2008). At the same time, the aspect of ethnicity came to the attention of organizations, and it was found that the opportunities for promotion were markedly worse - particularly in North America and Europe-for non-whites than for whites (see Davis 1995; Wingfield/Alston 2014; Wilson/ Roscigno 2016). 
A fourth strand of the debate, which is linked to the discussion on gender and ethnicity, examines the question of whether the descriptions of Taylorist-Fordist or Post-Fordist forms of organization, which are primarily developed by means of investigations in large industrial businesses, can also be found in other sectors. Due to the close link between the disciplinary history of development of companies - particularly in the field of industrial sociology and work sciences - and the formation of 'industrial society', the focus on industrial production companies was considerably strong. For a long time, a large part of work sociology and work science did not feel responsible for addressing the situation of hairdressers, nurses and flight attendants. It was only when it was recognized that the number of industrial jobs was declining, and the number of jobs in the service sector and in science was growing steadily - which was dramatized in mass media by the proclamation of a change from an industrial economy (see Galbraith 2007) to a service economy (see Häußermann/Siebel 1996) or a science economy (see Drucker 1969) - that work structures found their way to the center of attention: The care industry (see, e.g., Abel/Nelson 1990; Duffy 2011; Stacey 2012); the service sector (see, e.g., Hochschild 1983); call centers (see, e.g., Callaghan/ Thompson 2001; Krishnamurthy 2004; Aneesh 2012); the telecommunications sector (e.g., Katz 1997; Sako/Jackson 2006); hospitals (see, e.g., Reich 2014) or the fast food industry (see, e.g., Leidner 1993), to name just a few.

\section{The half-hearted farewell from purposive rationality}

A common feature in the industrial-sociological discussion is striking: Whether a trend was observed towards further Taylorization or towards the formation of holistic forms of work, it was always assumed that the strategies of the capital were to increase the economic rationality of the company. The industrial enterprise appeared in Marx's tradition wholly as a product of modern capitalism, in which profitability and the prosperity principle were dominant as the "Ultima Ratio". A 'secret efficiency determinism' owed to the Marxian tradition was still dominant (Ortmann 1994: p. 94).

This form of the approach, in which the entire enterprise is reconstructed from the principle of profit orientation, can be described as a 'purposiverational' organizational understanding, in accordance with Max Weber. "One acts in a purposive-rational way", says Weber, "when one balances different purposes in one's actions, chooses the most favorable means for the attainment of the defined purposes, and takes into account possible undesirable side-effects in this selection process of purposes and means". To meet Weber's purposive rational criteria, the decision-makers must be aware of their interests, wishes and values. For example, the capitalist must be aware of the goal of transforming ' $\mathrm{M}$ ' into ' $\mathrm{M}$ '. They must collect information that is as comprehensive as possible, spanning all alternative courses of action and ponder their consequences (see Weber 1976: p. 13; see also March 1988). 


\section{Business vs. organization}

This end-means structure was then 'connected in parallel' to the hierarchical structure, similarly to the classical, purposive rational organizational theory. The management of the company defines how the company wants to make profits. Actions necessary as a means of achieving this end are thus "assigned to the subordinate as a task". They then "delegate sub-tasks to their subordinate entities" until the "ground floor of the hierarchy", the immediate execution level, has been reached (Luhmann 1971: 96f.).

By means of this 'parallel connection' of the end-means relation with the hierarchical top/bottom distinction, clear organizational analyses emerge. For example, the company's management decides to become the number one company in the world market for drill boxes: Containers in which small and large attachments for drilling machines can be arranged neatly. As a result, the means by which this overall objective can best be achieved are determined. It is stated that the US market must be 'conquered' in order to achieve this goal, and that the production times for a series of drill boxes must be reduced by half. The defined means for achieving the overall goal of 'world market leaders in drill boxes' are then subdivided into sub-targets, and means for achieving these sub-targets are determined. The company management, for example, states that the 'foreign sales manager' should recruit a certain marketing specialist for the conquest of the US market, and the factory manager should introduce 'partially autonomous group work' to reduce the production times in the production area. This creates a hierarchical chain of overall goals and sub-goals, with which every action in the organization can be thoroughly structured.

The appeal of this purposive-rational organizational understanding is that a purpose derived from the requirements of capitalism-namely the goal of profit maximization - is taken as a starting point, and the whole organization is subsequently analyzed on the basis of this aspect. One can look at the alternatives aimed at achieving a goal and - even as a scientistmake statements on whether the strategy of the company is the right one or not from an exterior perspective. In this way, a generally clear network of theses and hypotheses emerges, which - in the best of cases - can even be verified for accuracy.

With Frederick Taylor and Henry Ford, and then - albeit in opposition to them - with Harry Braverman, there was a 'tight package deal' between the purposive-rational decision-making in the organization and a bureaucraticTaylorist organization type based largely on the deconstruction of the work process (for more details, see Kühl 2018a). There was the conviction that there is no form of organization that can be integrated into the hierarchically structured and bureaucratically organized companies in terms of rationality and ultimately efficiency. Taylor, similar to Max Weber, assumed that the top of the hierarchy identified with the purposes of the organization and divided it into many small tasks. The division into precisely defined work tasks is organized using a multi-tiered hierarchy. The tasks are assigned to those who are best qualified to carry them out. As the upper level 
of the hierarchy would be overwhelmed if it had to give instructions to the lower levels for each individual task, it establishes programs that provide the recipients of the instructions with information on how to behave in a standard scenario. The level of leadership of the hierarchy can be concentrated on the compliance of regulations and dealing with special cases (see Weber, 1976: 128ff.; see Luhmann 1973: 55ff., 2000: 16f.).

In retrospect, the innovation of sociology of work and work science which focuses on business is that they broke the 'package deal' between purposive rationality and a Taylorist-Fordist organizational concept. For the understanding of an organization that can be organized in a purposive-rational way without looking to the Taylorist-Fordist production or even at the bureaucratic ideal type of Weber as a guiding concepts, the concept of "paradigm shift', that is, the basic change of a structural form-otherwise used sparingly in sociology_was evoked (see Kern/Schumann 1984a: p. 24).

But-and this aspect must not be overlooked - even after the supposed paradigm shift, this research direction, as well as the mainstream in the study of business economics, remained theoretically tied to a purposiverational organizational understanding. In a turbulent market environment, according to the reasoning behind the argument, it is rational to opt for a decentralized, flattened, ad hoc form of organization; while in a stable market environment, it can make economic sense to return to a form of organization more aligned to the Taylorist-Fordist production model or the bureaucratic ideal type of Weber. Just like the situational approach in organizational research, this understanding went beyond a more sophisticated version of the 'one best way' philosophy. There is a best way for each situation-but it depends on the situation in which the organization finds itself. Instead of a Taylorist-Fordist-bureaucratic 'one best way', there is now a 'situationally relative best way' which, depending on the market situation, technological development or political environment, provides either a Taylorist-Fordist-bureaucratic form of production, or a more holistic form of production (Pondy/Boje 1980: p. 96).

The dominance of the purposive-rational approach can explain why the company analyses of Marxist sociology are surprisingly similar to the analyses of classical business administration in their conception. In the end, the dominating strands of work sociology as well as business administration are understood by companies as the long arm of capital - and differ only in the political assessment. Both scientific viewpoints understand rationalization strategies of companies as attempts to increase their efficiency; the only difference is that business administration theory views these as legitimate (and scientifically sound) efforts to maximize profits, while industrial and work sociology tend to sense in them new, more subtle exploitation mechanisms. Both perspectives recognize employee strategies to restrain their own work, the difference being that business administration theory sees (understandable) attempts by employees to withhold the already paid services from the company as 'principal'; attempts which must be countered 


\section{Business vs. organization}

with appropriate measures, while work and industrial sociology describes this restraint of performance as a comprehensible resistance to capitalist exploitation processes.

The danger is that the sociology which is influenced by purposive rationality in its operational analyses may degenerate into a study of business economics which is reduced to the 'societal aspects' as soon as it —as has been increasingly happening in the last 30 years - abandons its predominantly critical evaluation of capitalism. The heated debate about whether work sociology is supposed to practically participate in rationalization projects not only as an accompanying researcher, but as a co-designer or consultant as well can only be understood in the light of this similarity in the analytical approach of work and industrial sociology, on the one hand, and business administration theory, on the other. As a problem of an increasing involvement of work and industrial sociologists in design projects, it is no longer reputable to become a 'minion of capital', merely operating a 'cow sociology' which allows employees to be more effectively 'milked' by management. The subconscious concern seems rather to be that with the abandonment of the distance to entrepreneurial practice-cultivated over decades, and based on Marx - it becomes difficult to discern where sociology of work ends and other disciplines begin.

The strength of sociology of work was that, in contrast to the mainstream of business economics studies, its own empiricism pointed to the fact that the reality of the companies can be described only to a limited extent in terms of the clear end-means-scheme relatively early on. Michael Burawoy observed that on the 'shopfloor' - the production area of the company - the workers themselves carry out their own 'games' under the conditions of a restrictive Taylorist organization, with which they try to have as much responsibility and fun as possible. By means of this 'self-acting' design of the work process, the workers would work together on the creation of a consensus on the 'shopfloor' and ultimately develop their own forms of exploitation (Burawoy 1979: 71ff.; Burawoy 1985: 10f.). Horst Kern and Michael Schumann emphasize that rationalization processes are not pre-set by capitalist exploitation imperatives. Depending on the constellations of power, "margins of political formability' which would shape the rationalization developments emerged in companies (Kern/Schumann 1984a: 324f.). It has been shown that organizational change cannot be understood solely from one functional perspective. Which organizational structures, methodologies and personnel deployment concepts apply as rational means for achieving the organizational purpose, which concrete forms of organization ultimately prevail to what extent, or whether the changes envisaged by the top level of the organization can be realized only partially, in modified form - or possibly even not at all—would depend on the business power relations.

On the whole, within the sociology of work, there was growing doubt as to whether the conditions in businesses could be derived from general social conditions of capital and labor, and whether companies could be understood 
from the starting point of profit maximization. 'Marxist Functionalism', in which the functioning of a business was derived from the general movement laws of capitalism, became the subject of rising criticism (cf. Littler/Salaman 1982: p. 256; Littler/Willmott 1990: p. 12; see also Littler 1990: 46ff.). The organization's own life has never been able to properly intersect with industrial sociology and sociology of work. Theoretically ambitious approaches, such as Burawoy's arguments (1979) within the framework of the 'Labour Process Debate', ultimately persisted in the objectivist framework of Marx's "Critique of the Political Economy" (1961a) and derived the acting rationales in businesses from the capitalist conditions of competition. The approaches which concentrated on the 'areas of formability' or on 'work and business politics' succeeded in capturing the autonomy of companies empirically, but_according to critics — while businesses were taken empirically seriously in their autonomy, they were not taken seriously from a theoretical standpoint.

\subsection{The approach of systems theory: the inherent rationale of the organization}

Considering processes of functional differentiation from the perspective of systems theory, one may not understand at first why a sociology that focuses on 'work' should limit itself to companies. Ultimately, companies are only just one special type of work organization. Even the sociologically untrained observer is aware of the fact that not only in companies do people work for payment, but that this is also the case in hospitals, courts, schools, universities, administrations, armies and even trade unions and professional lobbying organizations such as Greenpeace, and that nurses, judges, teachers, civil servants, trade union officials and managing directors of political lobbying organizations also describe their activities as work.

The long-standing focus, particularly of sociology of work and business administration theory, on core sectors such as the automotive, mechanical engineering and chemical industries, and the focus on their production areas, while neglecting sectors such as the service industry or knowledge-based work, can be understood when considering Marx's aphorism "work is where something is produced". From a systems theory perspective, there is no comprehensible reason for this initially slow-emerging, work-sociological restriction to trade-union-organized, predominantly male technical workers in the engineering, automotive or chemical industries.

Of course, it would be naive now to assume that companies, churches, universities, ministries, armies and police precincts are all identical organizational forms - if they were equal, then these different concepts would not exist. Financial companies are different from other organizations in that they pay employees (or suppliers) only because they assume that this leads to the immediate 'return' of their solvency as soon they sell their products or services. In contrast to government administrations, which spend 


\section{Business vs. organization}

money so that services can be provided to others (e.g., welfare recipients, road builders or consultants), or armies financed by looting or by the more modern alternative of taxes, companies spend money so that it flows back to them in excess when they sell their products and services (cf. Luhmann 1988b: 249ff.).

However, the criterion 'work for pay' is clearly not limited to companies and their particular form of refinancing. Contrary to Marxism, systems theory, in its 'analyses of work', deals therefore at the level of 'organizations', regardless of whether they are in the financial system (companies), in the health system (hospitals or small clinics), in the legal system (courts, law firms), in the scientific system (universities, large research facilities) or in the political system (ministries, municipal administrations, non-governmental organizations). With this focus on the whole range of organizations, systems theory - with an eye for processes of functional differentiation-finds itself following the tradition of Max Weber, who abandoned the Marxian focus on economic organizations in his studies on the formation of bureaucracies and the development of rational forms of rule and developed a sense for the similarity of rationalization processes in companies and public administrations (cf. Weber 1976).

What is the commonality of organizations from the perspective of systems theory? If the organizations of different functional systems are compared, it is striking that they are not only structurally similar, but that the principles of pre-modern societies can be identified within them. The fact that events such as business conglomerates, the dissolution of ministries or the closure of universities do not have a serious impact on the community shows that organizations are, similarly to tribes in segmented societies, independent from each other. The failure of a unit usually has no devastating consequences for the whole. Internally, organizations are differentiated according to the overall dominant pattern of 'top and bottom' in stratified societies. Despite frequently delivered management speeches regarding the 'abolition of hierarchies', the 'death blow' of hierarchies or 'hierarchies as an expiring model', which also regularly show up in sociology of work and industrial sociology (cf. Bahrdt 1974), there is no example of an organization too large to fit all their employees around the conference table forgoing some type of 'top-bottom' differentiation (see Dahrendorf 1962: p. 77).

Whereas-put very simply - the Marxist-influenced social sciences understand the top-bottom scheme of companies as an indicator for the structure of society as a whole (see Deppe 1971: 16f.) — therefore stylizing the factory regimes as a relation of social domination-systems theory high-

lights the difference between society and organization. Particularly Niklas Luhmann came to the conclusion that even though the significance on a societal level of first membership inclusions and exclusion, second purposes, and third hierarchies is diminishing, they remain nonetheless increasingly popular as attributes of organizational structures (cf. Luhmann 1975a: p. 39, 1997: p. 826). 
Regarding membership: The management of inclusion and exclusionthe determination of memberships - is handled by organizations differently to modern societies. The exclusion of members from societies through the death penalty, exile or expulsion constitutes the exception. The maintenance of the principle of exclusion immediately exposes a state (see the debate on the death penalty in the United States) to the charge of being 'antiquated'. In organizations, on the other hand, the management of the inclusion and exclusion of members is a central instrument. In determining membership, management can decide who belongs to a company, an administration or an association. This creates boundaries within which the members (and only the members) have to submit to the rules of the organization (Luhmann 1964: 44f.).

Regarding purposes: Functionally differentiated societies, in contrast to the societies of antiquity or the Middle Ages, hold back from prescribing higher purposes such as the religious realization of its citizens or the attainment of the socialist human ideal, and to subject citizens to these ends. It is completely different with organizations: Whether a government administration, a company or a trade union is concerned, only the determination of concrete purposes allows a certain kind of orientation for dealing with organizations. An organization which completely renounces the formulation of purposes would provoke a maximum degree of confusion among its own members, as well as with the external environment (cf. Luhmann 1973: 87ff.).

Regarding hierarchies: The concept of hierarchy is also losing its importance in society, but this form of governance is still the method of choice for structuring organizations (Luhmann 1997: p. 834). In modern societies, there is no longer a ruler who is able to regulate the various spheres of life of the population through orders and chains of command. As the example of Iraq shows during the Saddam Hussein era, or Afghanistan in the time of the Taliban, states with a hierarchical structure are considered unfashionable and even potentially dangerous. In modern society, no one, with the exception of the members of the presidential administration, accepts the president as the supreme leader of a commanding hierarchy. In contrast to modern societies, organizations are centrally structured using hierarchies. Ulrich Beck refers to this phenomenon with the concept of 'half a democracy'. Large sections of society were 'de-hierarchized', while the organizations in business, science, politics and art remained, for the most part, as hierarchically structured systems, free of democracy (Beck 1992).

The management of memberships, the formation of a variety of purposes, and the establishment of a hierarchy - in whichever way - are not only the key distinguishing features of societies and organizations, but they can also help explain why organizations have a 'life of their own', an 'autonomy' beyond the functioning of business, politics or law. Both systems theory and Marxist sociology have as their central figures of organizations the determination of purposes, hierarchy and membership. Systems theory arranges and interprets them differently, however. 


\section{Business vs. organization}

\section{Membership in organizations}

How do organizations manage to maintain their independence with respect to the rest of society? How do they make sure that a bank employee will don a suit and tie as a matter of course, although there is no such thing as a specific dress code in society (except for having to wear at least some form of clothing)? How is it possible that young professionals are willing to subordinate themselves to the behavioral expectations of an organization when they first start working at a company? Luhmann's answer is 'membership'. Unlike the tribes of the archaic societies, the aristocratic networks of premodern societies, or even the families of today's modern society, membership is not a quasi-natural fact, but falls within the decision-making sphere of the organization itself (cf. Luhmann 1964: 39ff.).

Organizations can stimulate completely different motivations in order to attract members (see in detail their limits and possibilities in Kühl 2013: p. 31ff.). Obviously, people can be motivated by remuneration to enter and remain in organizations. Because people have a chronic need for money, members can be tied to an organization not only for a limited period of time, but long-term as well. In all the advanced cultures of antiquity, the Middle Ages, and early modern times, compulsion is a tried and tested motivation still used by some organizations. With it, organizations use their own means of enforcement - such as police, jurisdiction, and prisons within the organization itself - to ensure the participation of members in organizational activities. The use of compulsion to recruit and retain members has lost popularity in modern society, but is still being used by government organizations - case in point: Compulsory military service. Another way to bind members to organizations is to offer them attractive purposes. As a rule, the more motivating the purposes are, the lower the payment of members can be. Attractive activities are therefore a further mean to motivate members to remain in the company. Consider the volunteer fire brigades or the Red Cross, which primarily bind their members through interesting tasks. Another way to establish membership ties is through the esprit de corps that forms among the members of an organization. Organizational researchers-especially representatives of the so-called 'human-relations approach'-have repeatedly tried to prove that members of an organization are both more satisfied and more efficient when they have a close relationship with their colleagues. As a rule, organizations use different means to motivate their members. But, with all the heterogeneity of membership motifs, one thing is central: Whatever moved individual members to join a company, an association or a political party, be it identification with the purpose or the prospect of money or a pleasant atmosphere among the other members of the organization, the organization can expect members to stick to the rules, so long as they wish to remain members of the organization.

With the more or less voluntary acceptance of membership, the employee of an organization agrees to submit to its rules, instructions and practices. 
Just by understanding yourself as a member of an organization, you start following a supervisor's instructions to check the links of a motor chain for imperfections; or as an employee of a call center, you are willing to treat even the rudest of customers in a friendly manner; or as a student, you subject yourself to attending a mind-numbing lecture on "Introduction to Statistics" at 8:15 in the morning.

This binding force is achieved, on the one hand, by the fact that it is clear to every member that there is no natural right to membership, and that it can therefore be revoked. Even if dismissals from companies, compulsorily de-matriculation of students and the exclusion from the bowling club are the exception rather than the rule, the mere possibility can lead to a high level of willingness to comply with the rules, instructions and practices in an organization. In most cases, it is not necessary to intimidate, often not even to openly threaten, in order to inspire willingness to comply. It is sufficient to casually imply that membership to the organization can be revoked.

On the other hand, the binding to the organization - and this force must not be underestimated-is also achieved by the self-commitment of the member. As Marx pointed out — even if only in respect to wageworkers - the 'liberation' of humans from the relation of state-feudal domination means that they, as autonomous legal individuals, can decide to perform activities in a company (see Marx 1962a: 99ff.). Because a member decided to work at the pharmaceutical company Bayer of their own volition, and was not coercively recruited by a slaveholder, they only have limited possibilities to convey their distance to this organization. While a school student can still openly express their dislike for the school, a university student has a lot more trouble showing their displeasure without being more or less directly reminded that, contrary to a school, attendance in universities is not compulsory (cf. Luhmann 1964: 37f.).

Through their self-commitment, employees can hardly escape two central expectations of organizations (cf. Luhmann 1964: 36f.). This concerns first the purpose of the organization. Whoever fails to affirm the guiding purpose of an organization and nonetheless remains in it is consequently perceived as acting inconsistently by other members. Whoever considers work for profit-making companies to be a reprehensible support of capitalism and proclaims this openly while being a member of such a company is acting contradictorily. This is what was experienced by the students influenced by the protests in Germany in 1968 who, for the purposes of the movement, hired themselves out as assembly workers at Opel, Renault or Citroën. The role of the 'revolutionary' in the organization leads to role conflicts which can only be suppressed - either short or long term - by the increasing adaptation to the membership expectations of the company, the retreat into the institutionalized resistance roles in the worker's council, or the fundamental change of the organizational purpose (cf. the portrayal of Linhart 1978). Second, it is difficult for members to escape the hierarchical management structure of the organization. As a member of a company, a political party, 
or a university institute, it is difficult to deny the management of the organization your loyalty without risking your membership. Openly contradicting your own boss is a risk only to be taken if you have the legitimate hope that, after the ensuing power struggle, you can take over their position.

Niklas Luhmann points out that the membership rule is already violated when a member of staff withdraws from a single requirement of the organization - this is the key point. Anyone who doesn't accept 'a directive from his superior' or refuses to recognize a regulation 'on principle', is rebelling 'against the system and against all formal expectations' (cf. Luhmann 1964: p. 63). The statement by a scientific colleague to the director of his research institute that they will not attend a coordination meeting because they consider this meeting to be unnecessary would be an example of a violation of the central membership rule. Forgetfulness, delays, illness are all accepted as reasons for absence; an explicit refusal to follow a directive from their supervisor, however, is not. It is not a question of the point which one refuses to carry out, but of how the rejection of even one directive or regulation calls into question the basic principle of 'organization'. Thus, when a clerk of the student administration office explicitly refuses to provide a requested file of a student to their boss, this does not trigger considerable organizational unrest because the file may be essential for the work of the office, but rather because the rejection of even this small direction must be interpreted as an act of rebellion against all the formalized expectations of the organization.

Despite the possibility of members losing their membership, organizations do not control their members like puppets. In companies, public administrations, universities and hospitals, employees can perform a variety of actions that are not safeguarded by rules, instructions or regulations without risking membership. Precisely because the decision of inclusion and exclusion is such a serious one, neither the organization nor the members of the organization dare to openly question membership status every time some form of subversion is identified. Supervisors would have to spend all day writing notice and dismissal letters, and members would only be concerned with the question of whether or not they'll be allowed to remain in the organization. This explains the many small everyday actions whichupon a closer look - might well contradict the guidelines of an organization but remain unaddressed.

What is the role of membership for companies, public administrations, universities or hospitals? Organizations have the possibility - and this can have severe consequences - to abstract from the motives of their members (see Kühl 2013: p. 24f.). You don't have to ask whether the motives of the members are identical with the goals of the organization, and if, for example, the new employee was already working on a six-ply, flowered toilet paper, or if the technical worker at BMW, Ford or Toyota would like to teach an intercultural awareness course. The organization can also forgo the difficult and time-consuming development of motivations for the actions of 
organization members for every decision made, as the membership itself already implies a generalized motivation regarding compliance. As Niklas Luhmann puts it in his famous sentence, "Soldiers march, clerks keep records, ministers of state govern, whether it pleases them in a certain situation or not" (Luhmann 1975b: p. 12).

Members, upon their entry, forgo the detailed definition of their activities. As shown above, they write a sort of 'blank cheque' to the work organization for the usage of their work as shown above (see Commons 1924: p. 284). The deal between employers and employees is designed in such a way that the employee submits to the corporate objectives, promises obedience to the hierarchical instructions and is rewarded by the employer with cash payments (see Barnard 1938: 167ff.). In the case of employees, an 'indifference zone' emerges, within which they cannot say no to the orders, requests, instructions and regulations of the superiors (see Simon 1957). The advantage for the management of the company is obvious: The employees vow a kind of general obedience to orders and directives not initially specified in further detail. They enable management to adapt the organization to changing requirements quickly and without the need for painstaking internal negotiation processes.

How can it be explained that more and more organizations are no longer solely motivating their employees by more or less openly threatening to withdraw their membership, but rather aim for their employees to identify with their company and with their products? How to understand the management strategy which designs various requirements, communication and learning opportunities so that employees find their work tasks interesting and meaningful - a strategy which is welcomed and endorsed by a number of sociologists of work and work scientists?

The idea of not only hiring employees to an organization via monetary payment is already present in management literature from the first half of the 20th century. Chester I. Barnard (1938: 149ff.) found that it was not enough to bind employees to the organization by offering them wages, career opportunities, or status symbols. On the contrary, in terms of purpose identification, it is important to influence the needs and benefits of employees in such a way that they feel that their own interests are aligned with the interests of the organization. If employees find their work interesting, the hope is that the work process will 'solidify' and 'stabilize'. It is believed that change processes work better with the approach of the employees recognizing the company as part of their personal interests, and not by offering them high salaries and bonuses, fancy company cars with teak wood interiors or incentive trips with celebrities. The assumption is that people are more motivated if they are fascinated by the thing itself and can therefore identify with the values and norms of the company.

At first glance, this approach offers advantages for organizations. If employees were only motivated by money, a suspicious supervisor would have to constantly control their actions. Supervisors benefit from the fact that 


\section{0}

Business vs. organization

norms, values and basic principles complement rewards in monetary form and promotions because they offer a more stable base for cooperation than the pure principle of exchange of labor power for money. The transformation problem of capital, the conversion of purchased work capital to real labor power, is reduced. But unlike Marxist sociology, which here merely detects subtler control strategies of capital, Luhmann refers to the dark side of organizations when employees identify with certain processes or products.

A company-and this may seem surprising at first sight-loses its ability to change. According to Luhmann, companies lose their organizational resilience when employees identify with a product or a process (cf. Luhmann 1964: 137ff.). Solidifying and stabilizing prevent the once established processes from being easily modified. The stonemason who defined himself as having been an active participant in the building of a cathedral could not have been as easily employed for the various other construction sites of the Middle Ages. An employee who draws a significant amount of their motivation from bringing a specific product to a customer will find it difficult to be enthusiastic about selling a different product. An employee who is responsible for the flexible handling of certain tasks within their group - and who strongly identifies with this group — can suffer from motivational problems when they are suddenly asked to work on different tasks in a completely different department.

The 'tragedy' here consists of the fact that a company that makes every effort to get its employees to identify with a particular product or process loses its ability to transform in regards to this product or process. Especially where employee motivation is particularly strong, change becomes particularly difficult. For a company that is dependent on constantly adapting to changes in the market and its environment, it would be a particular burden if it also tried to ensure that the employees personally identified with the respective state of the organization (cf. Kühl 2018b).

How far does the category of membership reach? Does it do justice to the discussion carried out in sociology on the 'dissolution of the company', the 'delimitation of companies' and 'networks as a structuring form beyond the market and hierarchy' (Powell 1990). Is the category of membership still relevant in the face of 'virtual networks', in which a large number of colleagues work together? Does the membership role also erode with the dwindling of normal working conditions?

According to the argument of the organizational approach presented here, the more contingent the membership of an organization, the harder all those involved will observe what exactly counts as a part of the organization and what doesn't. The technical workers in a production department of Siemens may tremble in front of Mr. Foreman, just as long as he is the principal 'member' responsible for the steam turbines at the factory. But as soon as Mr. Foreman leaves Siemens or is transferred to another department, his statements are suddenly the mere opinions of a private person 
(or of a member of another organization), and thus largely irrelevant to the technical workers. Students at the Institute of Sociology take note when their professors reveal their awareness of the possibility of downloading 'halffinished term papers' from the Internet, not because they have always been interested in the utterances of their professors, but rather because they know that those statements can assume the character of organizational decisions. If they are dealing with frequently changing professors, this observation becomes more difficult.

It may be that what is inside and what is outside is constantly being redefined in the strategic decision about the structures and functions of cross-company production and value chains. The permanent redefinition of what does and does not belong to an organization is not an indication of the criteria of membership losing significance. On the contrary, it is proof that the 'management of the memberships', the decision on how to draw the 'limits of membership', is increasingly becoming a central measure in the development of organizations.

\section{The purpose as an inherent construction of the organization}

There is no denying that organizations are capable of defining purposes and objectives, and do so on a daily basis. "We are increasing our market share in Bosnia from 7 to 8.5 percent", "Next year we are reducing our committee by 10,000 parts per year" or "Our management ensures that all employees are happy with us, and as a result we never lost more than one employee in a month"-such or similar purposes are formulated by companies in the same way work unions make statements such as " 800 new members hired in three months" or "Pay raises of at least 4.5 percent can be achieved by the strikes in Northern Mexico".

As shown above, the popularity of purpose formulations in organizations has led some areas of sociology to recognize organizations as 'purpose associations'. Especially the profit motive of companies can be seen as a main purpose from which the actions of this type of organization can be easily understood, and which allows for possible 'deviations' in the form of false market predictions, problems with the procurement of supplies and individual employees not performing services (positive or negative). At the same time, there was a tendency to understand political parties in terms of their supposed main purpose of winning elections, or to approach the functioning of churches through their central purpose of the successful recruitment and counseling of followers. Such analytically rather loosely knit organizational theories à la 'in the beginning there was purpose' nonetheless obscure the fact that the matter of 'purpose' is not a simple one.

Solely for this reason, purposes are not suitable as a central starting point for the analysis of organizations, because even the 'final', 'loftiest' purposes of an organization may be modified. Organizations that originally produced rubber boots can shift their purpose to the production of mobile phones. 


\section{2}

Business vs. organization

Companies producing mainly steel pipes can try to change their purpose in such a way that they operate mobile radio networks. Even profit maximization as a supposed main purpose can be modified. A printing company can transform itself into a 'charitable foundation' and claim the conversion of as many unbelievers as possible to Christianity as the new ultimate purpose of the distribution of their writings (Luhmann 1971: p. 95).

The ability of organizations to define their own purposes often leads to the formulation of contradictory goals. For example, companies often demand that business operations bring profits, develop new markets, develop innovative products, and treat employees excellently-all of this simultaneously. These goals may be compatible in a distant future, in the after-life, in a functioning market economy, or in a classless society. Short term, however, these goals are typically competing in organizations. Thus, an increase in operating profit can lead to the dismissal of employees, while long-term investments in innovations can often exclude the simultaneous conquest of new markets (Luhmann 1971: p. 95).

According to Luhmann's early observations, not all purposes are so instructive that they can be derived from correct means, let alone 'one correct' mean (1971: p. 94). Certainly, 'making profit' and 'selling cars' sounds plausible for companies; the issue, however, concerns the setting of purposes that don't provide guidelines for the means by which they can be achieved. Of course, decisions in companies are frequently justified with reference to the purpose of the company's profits. But since the purpose of profit maximization is not very instructive, it is difficult to determine whether or not a new marketing campaign, the purchase of a new machine or the dismissal of 35 employees contribute to the maximization of profits, despite a company's sophisticated cost calculation. However, the formulation of more abstract purposes such as 'profit maximization', 'humanization of the working world' or 'pacification of a war zone' does not often have the function of directing specific actions in organizations.

An important strand of organizational research, the so-called 'neoinstitutionalism', does not attribute the problem of unclear purpose formulation to the respective enterprise, university or administration in order to demand a clearer definition of the purpose in the style of a practical business management doctrine, but argues that many purpose-based commitments tend to have the function of generating legitimation towards the outside. A management in a capitalist economy which does not profess maximizing profits as its goal is likely to have the same difficulties with the company's shareholders as a trade union functionary with their colleagues if successful representation of the union members is not at least professed to be the goal (see, for neo-institutionalist perspective, Westphal/Zajac 1998 or Fiss/Zajac 2006). Because of this legitimization, companies cannot forgo the frequently monotonous avowal to increase profits, satisfy shareholders and workers, and retain their clientele (see Meyer/Rowan 1977; but for even more precise insights, see Luhmann 1964: 108ff.). 
So far, so good: All these limitations, identified by organizational research over the last 50 years, don't exclude the fact that organizations have presented themselves as if they largely succeeded in using a clear purpose as a guiding point and established their structure predominantly based on end-means chains, such as Ford after the introduction of the assembly line, the software company Oracle after the reorganization of their business by means of their own software, or the Bavarian state government after it was jointly 'whipped into shape' by the CSU Premier and the Roland Berger consulting company. Yet with newer organizational sociology it can be argued that precisely this supposed streamline form illustrates the problem of organizations.

Conflicts and competition-according to a possibly heretical observation for non-sociologists - fulfill an important function for the organization. Friction between departments can draw attention to new possibilities that would not have been recognized by a clear and conflict-free organization of all departments towards a general goal. The everyday clashes between departments, profit centers and teams counteract the impending reduction of the organization to a purpose which, while facilitating action in the organization, also has a blinding effect with regards to opportunities in the environment (cf. from the different theoretical perspectives, Luhmann 1973; Crozier/Friedberg 1977).

The strength of this concept is that purposes are no longer conceived as a category dictated by (capitalist) external relations, as in Marxist sociology or classical business economics studies, but rather as the inherent construction of an organization. Whether one speaks of a "dethronement of the concept of purpose" (Luhmann 1973: p. 86) or of a "disassembly of the classical notion of an instrumental and objective organization" (Friedberg 1995: p. 62), it is always about putting a more complex reading of organization-with their purposes, hierarchies and regulations - in place of the vacantly appearing illusion of order of an organization guided by a purpose that uses hierarchical structuring.

The core of Luhmann's ideas has so far been put to little use by researchers. It consists of the fact that the understanding of the organization as a link between hierarchically ordered end-means relations is dissolved, and purpose definitions, as a variable constructed by the organization itself, are reintroduced into the organization (see Luhmann 1973: p. 126). In other words, only by overcoming the central perspective on the purpose did it become possible to develop the construction of purposes in organizations as a research subject in organizational research.

\section{The debate on hierarchies}

Unlike sociology of work and industrial sociology primarily influenced by Marx, organizational sociology doesn't understand an in-house hierarchy as an expression of macro-social class relations between capital and work. Similarly to the concept of purpose, the category of hierarchy is not taken as the starting point for organizational analysis in the organizational theory of Niklas Luhmann. Instead, one asks about the function of hierarchy for 


\section{Business vs. organization}

organizations: Why does hierarchy play a role in organizations? Why do hierarchical top-bottom distinctions start to develop in self-governing businesses of a certain size? Why was the principle of hierarchy not rejected in the companies, public administrations, hospitals, or universities of Eastern European state socialism - which aimed to avoid the appearance of alienation of organizations in capitalism?

Luhmann's (1997: 834f.) concise answer to this is that organizations can communicate externally, primarily thanks to their hierarchical structure. The hierarchy - and James Coleman (1982) argues similarly as the most prominent representative of rational choice theory - is the 'instrument' which helps organizations ensure their ability to communicate externally. For example, if the head of a company and the chairman of a trade union agree to shorten (or lengthen) working hours by two hours a week because of current customer orders, both sides rely on the hierarchical protection of the other party in the other organization being stable enough so that the commitment made in that private conversation reflects not only the opinion of a single member of the organization, but also the attitude of the entire organization. It is only because of this principle that it is possible to speak of organizations as 'legal persons'.

But how can hierarchy ensure external communication? By means of membership rules, the organization establishes a generally accepted system of superiors and recipients of instructions. As a result, thanks to 'authority as hierarchy', the ability to decide can be guaranteed in the case of decisionmaking problems in organizations. Open decision-making situations can be solved by the 'hierarchs' simply by invoking their role as 'boss'. As a superior, it is possible for the boss to ask that other people perform work without them having the opportunity to question these requirements in principle. Because a hierarchical organizational chart clearly identifies who is subordinate to whom, contradictions, ambiguities or uncertainties can be moved upwards until they reach a level that restores things into (the right) order.

Through the hierarchical arrangement of givers and recipients of instructions, it is possible to generate decisions with comparatively low organizational costs. The organizational costs - one could also speak of "transaction costs' in the language of the institutional economy-are therefore low because cost-intensive negotiation processes are not necessary thanks to the company hierarchy. Hierarchies free the participants from the necessity of leading elaborate power struggles in order to resolve unclear relations when solving a problem. The search for decisions can be cut short with statements like: "Thank you for your opinion. As manager, I will now make the decision to proceed this way or that". In doing so, a supervisor can force his employees to follow the management's concepts of time when adopting this decision (cf. Luhmann 1975d: p. 52).

Hierarchy plays an important role in organizations. But, just as the cracks of the hierarchical order were worked out in Marxist sociology, the analysis of power in organizations is not primarily guided by a focus on hierarchy 
in the sociology of systems theory. The issue of power in organizations is in fact much more complicated than a first glance at the function of hierarchies would suggest.

First, the hierarchical command model suggests that rationalization takes place only from the standpoint of a single participant: That of the ruler, founder or entrepreneur. The organization appears as a quasi extension of its rationality of action. But just as the company boss, the other members of the organization also try to act as rationally as possible. Even though the 'hierarch' has better means of enforcement, there is no reason to grant them a 'higher' form of rationality than other members in organizations (cf. Luhmann 1971: p. 97; see similarly Crozier/Friedberg 1977: 41ff.).

Second, power in organizations is not determined solely by the hierarchical position. The need for specialized technical knowledge implies that subordinates often possess more expertise than their bosses. This expertise is their wild card in the 'power plays' with their superiors. External transactions cannot be controlled by the boss alone. Buyers, salespeople or product developers occupy the 'border posts' of the organization, and are thus able to use their privileged contacts in the organization's environment in 'power plays' with their superiors (or with other colleagues). In addition, the boss may be able to define the formal service routes in his area, but this does not mean that they can also handle the informal communication channels - on the contrary. The mastery of the informal, non-officially legitimated communication channels is a talent that can be made the most of in these "power plays' (Luhmann 1971: 97f.; see also Crozier/Friedberg 1977: 71ff.).

Third, hierarchy does not exclude an officially legitimate crosscommunication within the organization. Routine traffic between members of several departments is defined as an integral part of organizational planning with terms such as 'task force', 'project groups' or 'lateral leadership'. Thus, it is possible - and this is even seen as a praiseworthy case in management ideology - that the agreement of all subordinates involved makes the instruction of the superior superfluous. The function of the supervisor is often that of a 'stopgap', active in particularly difficult situations or in the case of unsolvable conflicts, or when the hierarchy is needed in the representation of external decisions. This means that hierarchy is not only top-bottom management; the leadership of the supervisor can also gain in significance through his subordinates, for example, via decision-making models or reporting channels (cf. Luhmann 1971: p. 98).

From this perspective, it becomes clear why organizations of a certain size cannot forgo hierarchy as a form of order, while being unable to elevate hierarchies to a central structuring medium. What position, then, can be assigned to hierarchies in organizations? How can these phenomenawhich hold the interest of sociology of work and industrial sociology-be explained from this theoretical perspective?

From the point of view of a science with a vested interest in clear categories, the strength of the systematic organizational sociology can be seen in the fact 


\section{Business vs. organization}

that-unlike other approaches such as micro-politics, neo-institutionalism, the institutional economy or a Marxist business analysis - it possesses a very precise concept of organizational structure from which the role of hierarchies in companies, public administrations, universities and churches can be determined.

Put simply: Luhmann starts from the banal consideration that one does not find exclusively simple decisions in organizations such as "We will buy this machine now.", "Ms. Miller is dismissed." or "The whole administrative team has the day off tomorrow." Rather, an organization only gains stability by making decisions that apply to a variety of individual decisions: "Whenever someone registers as unemployed at the employment office, you enter their personal data and arrange for the transfer of unemployment benefits". "You can give Mr. Jones instructions not only in this one case, but always". Following Herbert Simon, Luhmann describes the decisions that structure a large number of individual actions perhaps somewhat complexly as 'decision-premises'. But you can also simply refer to them as the structure of an organization.

The core of Luhmann's thought is based on distinguishing three types of organizational structures: 'Decision programs', 'communication channels' and 'personnel'. The differentiation of decision programs and individual decisions corresponds in the widest sense to the distinction between headwork and handwork, according to Taylor or his industrial-sociological critics. Managers wrack their own brains trying to figure out what the manufacturing process should look like ideally, and then program the switches and levers that the workers have to operate accordingly. This idea of determining what is to be seen as correct in organizations either by decision programs in the form of predetermined purposes or by if-then rules can be ultimately traced back to James March and Herbert Simon. If you do not follow the purpose directive of "Increase your sales by three percent in the next three months." or the conditional rule "If the paper from your colleague, Ms. Miller, reaches your desk, forward it to Mr. Smith within that very same day.", you are then faced with the pressure to justify yourself. On the other hand, an employee who follows these rules is on the 'safe side', even if their actions - in hindsight — did not contribute to the survival of the organization in any way (cf. March/Simon 1958: 141ff.; Luhmann 1964: p. 282). Furthermore, by defining communication channels, it can be determined who is allowed to officially communicate with whom. By means of hierarchical guidelines, signing rights and classification into project groups, a structure can be established which can be used to define responsibilities and handle unusual events. The suddenly occurring quality problem, the massive order that disrupts the normal flow of production, or the 'temper tantrum' of a foreman in the production area can then be handled by the hierarchy or by a project group, and subsequently assigned a decision. But also personnel can be of service in the structuring of organizations. Whether a position is occupied by a lawyer, a sociologist or 
an employee not yet spoiled by science can very well have an effect on the decisions made in this area of work (cf. very briefly Luhmann 1988d: 176ff.; comprehensively see Luhmann 2000: 222ff.).

With this instrument-expounded very briefly here-the debate on Taylorist-Fordist forms of work on the one hand and holistic working concepts on the other can be summed up, without having to derive work organization from capitalist exploitation conditions. For example, if structuring through communication channels in a company loses importance as a result of the flattening of hierarchies, it is to be expected that other forms of structuring will gain in significance. For example, the precise specification of purposes for each employee in the form of goal specifications, or the standardized and possibly engineered programming of work processes. The emphasis on the factor of personnel in Post-Fordist companies can be explained by the fact that hierarchies are flattened and programming of workflows is reduced. On the other hand, the 'complete Taylorization' of workflows makes it possible to reduce hierarchy levels because fixed if-then rules specify exactly how processes are to be executed (Kühl 2018a).

\section{Open questions-what part does work play in organizations?}

Just as there is a trend among economists to describe modern society as a 'work society', an 'industrial society' or simply a 'postindustrial society', and knowledge sociologists and science sociologists quickly resort to a sociological contemporary diagnosis by referring to a 'knowledge-based society', organizational scientists have an apparent tendency to define modern society as an 'organizational society'. The understanding that the functioning of businesses cannot be exclusively explained by capitalist production conditions, and that more attention has to paid to the individual life of organizations, can have the misleading effect of such a sociological diagnosis aggrandizing the central significance of organizations. Even in an area of sociology of work, the postulate of a transition from 'class society' to an 'organizational society' is becoming acceptable with a 'De-Marxization' on the rise.

From the point of view of systems theory, which emphasizes the idiosyncrasy of social subsets, this sociological contemporary diagnosis has no merit. Politics cannot be understood through political parties alone, just as science cannot be exhaustively understood through universities, because one cannot comprehend the phenomenon of political elections or the system of academic publication by narrowing one's focus on organizations. Similarly, it would be wrong to attempt to seek economic-sociological approaches only through business phenomena, just as phenomena such as stock exchanges, capital markets, labor markets, or networked production relations cannot be (fully) comprehended by an organizational-sociological intensification of the social diagnosis (cf. Luhmann 1997: 841f.).

The strength of systems theory's approach to organizations, which has only briefly been expounded here, is that it avoids the simplification 
of 'super-purposes' or 'hierarchical peaks' of both classical organization theory and Marxist-influenced business sociology. The organizational approach admits that purposes have important structuring and legitimation functions in organizations, but it does not take a single purpose (let alone several) as a starting point for organizational analysis. It recognizes that organizations depend on hierarchies as structuring forms, but concedes that it is possible for them to put in place functional equivalents to hierarchy when it comes to individual issues.

A central question is whether one can craft a more precise conflict sociology with this perspective than Marxist-influenced business analysts have. For a theory of sociology of work and industrial sociology to take Marx seriously, it must explain central disputes in business with the ultimately macro-social opposition between capital and labor. Thus, the strong focus of work and industrial sociology on the relationship between employer and employee representations can be explained by the fact that it was thought to be possible to comprehend the connection between internal and external conflicts between capital and labor through these 'industrial relations'.

A theory focused on an organization's idiosyncrasies reformulates this conflict as a question of membership commitment. What incentives are introduced to commit members to an organization? How do organizations deal with members' attempts to take advantage of regulatory loopholes of businesses as a way to protect their labor on a daily basis? What are the functions of trade unions, company and staff councils as collective interest groups of members of organizations? What functional equivalents to trade unions are conceivable when one considers the fact that protests, demands for a salary raise or requests for a lighter workload always implicitly threaten the membership status of an individual member of an organization and only collective interest groups seem to be able to abstract from this?

These conflicts pertaining to the question of membership — and Luhmann's view here is essential - cover but one part of the conflicts in organizations. Disputes between production and sales departments, conflicts on how to deal with suppliers or customers, and differences of opinion regarding the restructuring plans of a chairman of the board do not result from the contrast between capital and work; they come about because organizations cannot be structured by simple end-means schemes, and relationships of power in organizations do not result solely from hierarchical positions. The lacking integration effect of purposes and hierarchies shown above leads to a variety of conflicts in organizations that are misunderstood if one's analytical instruments are aimed at the conflict between capital and work.

Wherein lies the challenge for this approach developed from systems theory? As the autonomy of organizations is emphasized in the branch of systems theory influenced by Luhmann, this theory either sinks or swims with the question of whether, in spite of the emphasis on the autonomy of organizations, it can gauge the connection between society and organization. The challenge turns out to be exactly the opposite of that to Marxist theory, 
in which there is a clear connecting line as a result of the derivation of the business conditions from the overall concept of capital and work, despite, as shown above, its limited ability to theoretically manage and define the autonomy of enterprises.

The most crucial test case that the theory of functional differentiation has to stand is whether it succeeds in defining wage labor-that is, the concept by which the connecting line between society and business was decisively drawn in Marxism - in an equally fastidious manner. The starting point for an answer is Marx's question of "Why do workers work?" How do organizations succeed in moving people to membership-compliant activities without them - like one might do in a basketball team, a Marxist debate club or when picking fights with football fans of an opposing teaminherently drawing satisfaction from organizational activity? How does a company ensure that an employee sits at their desk at seven o'clock every workday, despite the weather outside making a day at the beach a more plausible choice? How are universities able to motivate an employee to hold an introductory lecture on the connection between structure and action if they would rather pursue their interest in the relation between formal and real subsumption, a topic which was regrettably not deemed a suitable part of the curriculum?

The argument from this theoretical perspective is greatly simplified as follows: It was only under the regime of functional differentiation that the creation of 'autonomous' organizations built upon 'voluntary membership' took place. The creation of wage labor seems to have played a central role because only through it was it possible to commit members in various types of organizations (cf. approaches with Luhmann 1997: p. 840). Wage labor seems to be the medium that allows organizations to make use of individuals for arbitrarily specifiable expectations under the viewpoints of organizations and disregarding the person as a whole.

Marx and Engels had already concluded that people in capitalist societies carry out activities they are 'forced' to perform. "He is a hunter, a fisherman, a shepherd, or a critical critic and must remain so if he does not wish to lose his means of livelihood" (Marx/Engels 1958a: p. 33). Out of all means of motivation, wage labor seems to be the one that allows organizations to largely neglect the interests of their employees, and yet always have access to a "potential of unbound available resources" (Luhmann 1964: p. 45). To put it theoretically, wage labor is the central means of binding members to organizations (cf. Bommes/Tacke 2001: p. 62).

It is possible to formulate convincing links between organizations and society because the possibilities for binding members depend on a wide range of inter-organizational frameworks: What are the alternatives on the labor market? How good is state social security, and how does it impinge on the willingness to allow oneself to be included? How do social movements (e.g., the workers' movement) change if they form themselves as organizations and rely on wage labor for the inclusion of people? 


\title{
4 Worker consciousness vs. worker essence as a role
}

\author{
Class as a binding link between \\ society and the individual
}

With the concept of 'flexible people', the sociologist Richard Sennett tries to grasp the effects of a 'radically changing economy' on the individual. Sennett asks: How can mutual loyalties and commitments be sustained in institutions that are constantly breaking apart or continually being redesigned? How can long-term goals be pursued in an economy devoted to the short term (Sennett 1998)?

The comparison of his ideas with a study-conducted with Jonathan Cobb in the early 1970s on the American working class-is fascinating. Some of the interviewees of the first study met Richard Sennett again 25 years later. Thus, Sennett describes the meeting with Rico, whose father (a janitor) and mother (a dry cleaner) he had interviewed in his first investigation. While his parents were rather poor, albeit of a certain continuity (cf. Sennett/Cobb 1972: 47ff.), Rico embodies the ideal type of a 'flexible man'. Although (or perhaps, more appropriately, because) Rico can be counted among the well-earning when compared to his parents - and even set up his own small consulting firm after working in various high-tech companies - he lives in constant fear of "losing control", fear that "his emotional, inner life" is set "adrift". For Sennett, the parents of Rico embody the era of Fordism. Their activities were characterized by a high degree of monotonous routine. But this routine guaranteed the certainty of a predictable life. The janitors' union and the integration into the working world provided a sense of community. On the other hand, Rico lives in a society that revolts against the "bureaucratic structure which rationalized the use of time" (Sennett 1998: 10ff.).

Sennett's essay is symptomatic of a change observed by social scientists, especially in the industrialized world. While the discussion of social sciences in the early 1970s was still determined by the integration of workers into a stable Fordistic arrangement of long-standing company affiliation, certainty of workers' union representation and clear life planning, the development in the late 20th century shows a 'new capitalism' in which, although the workers are more prosperous, human beings nevertheless lose their sense of community as a result of the 'dictates of the economy'. 


\subsection{The Marxian rationale: the imprint of work and the class concept}

"In the beginning there was work". Even if Marx would have opposed such an apodictic starting point for his theory, he does not completely rule out such a reading in his works. According to Marx (1962a: p. 57), work is an "eternal natural necessity which mediates the metabolism between man and nature, and therefore human life itself". According to Marx and Engels (1958a: p. 28), "The first historical act is thus the production of the means to satisfy these needs" - needs such as food and drink, housing and clothing. The "production of material life" is "a fundamental condition of all history, which today, as thousands of years ago, must daily and hourly be fulfilled merely in order to sustain human life". In the work process, following Marx's position, the working subjects not only create the conditions for their survival, but also, in their constant exploration of nature, for themselves.

With his emphasis on the significance of work, Marx found himself in the tradition of a Lutheran-Calvinist understanding of labor. Martin Luther proclaimed that man was born to work like a bird to fly. John Calvin, as clearly elaborated by Max Weber, claimed that one finds God through work (cf. Weber 1990: 20ff.).

That this popularity of the concept of work is anything but self-evident can be seen in the understanding of work in Greek antiquity. Aristotle claimed: "It is agreed that in a state which is to enjoy good order and administration, the citizens must be free from the necessary (lowly) work". According to Aristotle, artisans often work in a closed space or in the shadows, looking as pale as women, working seated (which was believed to weaken body and soul), and had no time to attend to friends or the city (cf. Aristoteles 1967: p. 89). The life of the artisan, as also stated by Plato, was "not a life worthy of a free man". Only the labor-free citizen, according to this view, could also be politically active. Whoever had to work was either not regarded as part of society, as in the case of slaves, or their contribution was scarcely appreciated, as in the case of artisans (see also Conze 1972: 155ff.; Applebaum 1992: 4ff.).

According to Marx, individuals have the possibility of finding themselves through work - to develop their identities as agents - so long as the conditions of production allow it. Capitalism on the other hand, according to Marx's conception, prevents self-liberation and life-fulfillment, which should otherwise be possible. The worker loses contact with the product of his work as a result of the exploitation by the capitalist and competition with other workers. There is a resulting alienation of workers from their work. The consequences of this are a "crippling of body and mind", "intellectual desolation" and "moral degradation" (Marx 1962a: p. 13, 281, 421; for an alternative explanation of 'alienation', see Luhmann 1964: 392ff.).

Background for this is the Hegelian philosophy with its dialectical conception of alienation and self-finding. For Hegel, a thing, a gestalt, an identity 


\section{Worker consciousness vs. worker essence}

of any kind must always 'alienate' itself, that is, step outside, confront the world, and return to itself strengthened and self-assured. Marx takes this concept and applies it to the working person. People divest themselves in the product of their work - they insert themselves into the product to a certain degree. The carpenter $i$ s to an extent the table they made, since they have poured their strength and abilities into this table. However, it is necessary for them to re-appropriate the table - for example, by using it - in order to enjoy the product of their work and benefit from it.

In capitalism the worker is denied the re-appropriation of their work. They work, but the product of their work does not belong to them; it belongs to the capitalist. That is why they are bound to remain alienated and are 'estranged' from themselves and the product of their work. With some pathos, one could even say that workers are denied their humanity. A human being is made human by working and then appropriating the product of their work. If the second part is missing, there is a lack of what constitutes or should constitute human existence (see Marx 1985: 465ff.).

The first reason for this alienation of the worker from their work lies in the degradation of work to wage labor. Just as in religion the "spontaneous activity of the human imagination, of the human brain and the human heart, operates on the individual independently of him", and is met in the form of an alien, divine or diabolical activity, the activity of the worker in capitalism is not their own activity. "It belongs to another, it is the loss of his self". In the form of wage labor, work is "external" to the worker. "The worker therefore only feels himself outside his work, and in his work feels outside himself. He feels at home when he is not working, and when he is working he does not feel at home". As soon as compulsion ceases to exist, the worker tries to shun "labor like the plague" (Marx 1985: p. 514).

The second reason for alienation is the understanding of the whole living world through the principles of economics. Capitalists are increasingly driven by how to accumulate even more capital.

The less you eat, drink and buy books; the less you go to the theater, the dance hall, the public house; the less you think, love, theorize, sing, paint, fence, etc., the more you save - the greater becomes your treasure which neither moths nor rust will devour-your capital. The less you are, the less you express your own life, the more you have, i.e., the greater is your alienated life, the greater is the store of your estranged being.

(Marx 1985: p. 549)

But a worker as well is increasingly defined by the principles of exchange. "The ideal worker is active around the clock in the service of the capitalist and can also live from air" (Deutschmann 2002: p. 190). It is thus the case that both capitalists and workers cooperate in all relations, as if they were at a market. Human relations in capitalism became relations of exchange. "The society of 
commodities has", according to the poignancy of the Marxian position by Konrad Liessmann (2000: p. 99), "the characteristic that everything we are, feel and want to recognize and perceive as specific human qualities, can only be attained through the exchange of goods".

But it is precisely in these experiences of alienation that, according to Marx, there is a possibility of the proletariat establishing itself as a class and overcoming the conditions responsible for alienation. "Objectively, the capitalist", according to the summary of Luhmann's Marxian position, "without wanting, is destined by his class position to ruin his own class. Objectively, the proletarian, without wanting, is destined by his class position to alienation". Luhmann argues that Marx had incorporated a "perspective on future and social change" in this form of argumentation: If the other class - the capitalist class - were to disappear, then, according to this line of argument, nothing would stand in the way of "transitioning to self-determination", and a "realization of individuality free of contradictions" (see Luhmann 1985: p. 126).

\section{The definition of the class concept in terms of the conditions of production and the escalation towards a two-class society}

The bracket Marx uses to bring together society and the individual is his class concept. Although this term was already used before Marx as a categorization scheme and Marx never worked out the class concept (similar to the concept of the state) in a theoretically coherent way (see Berger 1998: p. 31), the general direction of Marx's class concept can be nonetheless clearly indicated. All the inconsistencies in Marx's work notwithstanding, what is special about his class concept - to some extent his revolutionary expansion-is the combination of two characteristics of classes (Luhmann 1985: 121ff.).

The first central characteristic of the Marxian class theory is the derivation of class affiliation from the conditions of production based on David Ricardo. For Marx, there is only one relevant question regarding the class to which one belongs: Do you possess means of production and are you able to have others work for you, or do you not possess means of production and must therefore sell your labor power? What matters is that it all revolves around the private property of means of production, and nothing else. The question is not whether the worker owns a bicycle or has a dachshund-not even if they have a home to live in. The question is: Do they own machinery, factories and other means of production with which they can have others work for them? Or do they at least have an acre of land and one tractor to work on their own terms for their livelihood? While other factors such as family origin, gender, ethnicity, hair color or bank account may well correlate with the conditions of production derived from class conditions, they do not ultimately count when it comes to the affiliation to the one class or the other (cf. Marx/Engels 1958b: p. 469). 
Contrary to Max Weber, who referred to the 'inheritance' of status characteristics through generations with his concepts of social classes, only the position in the conditions of production was significant for Marx. The son of a factory owner who is forced to work at the assembly line because his father has driven the company into bankruptcy belongs to the proletariat, whereas the daughter of a proletarian who, as an entrepreneur, has built a small business with ten employees belongs to the capitalist class.

For Marx, the amount of money a person can dispose of plays no role in the determination of class affiliation. The highly indebted Internet entrepreneur who is close to bankruptcy belongs to the capitalists class because of their possession of means of production, while an employee in a company who has much more money in the bank than the capitalist because of their high qualifications is a proletarian. According to Karl Marx, the "size of one's purse" was a "purely quantitative distinction" and does not say anything about class membership. Difference in purse sizes merely results in "any two individuals of the same class" being "incited against one another at will” (Marx 1959b: p. 339).

The second central feature of Marx's class concept is its structure as a two-class model. According to Karl Marx and Friedrich Engels in the "Communist Manifesto", society as a whole "is more and more splitting up into two great hostile camps, into two great classes directly facing each other: Bourgeoisie and Proletariat" (Marx/Engels 1958b: p. 463). According to Marx and Engels, the small bourgeoisie, the lumpen-proletariat, or the landowners were only historical transitional phenomena that would dissolve into one class or the other. Here Marx moves away from considerations previously defined by the "Critique of Political Economy" (1961b). With his two-class model, Marx aligns himself with considerations of the political economist François Quesnay (1888), who had also derived his class model from the production conditions, yet went on to distinguish between three classes.

From this double construction form of the class concept, one can explain the political appeal of Marxian theory. The class society derived from the conditions of production can be contrasted with concepts of equality which developed with modern society. In the face of the 'discovery' of the natural equality of all people by Rousseau, of the French Revolution's values of "Liberty - Equality - Fraternity" and the promise of an egalitarian society in the "Communist Manifesto", a class society became the "embodiment of unfreedom, inequality and lack of fraternity" (Müller 1994: p. 120). The postulate of equality - with only class society with its structures of oppression, exploitation, and alienation still standing in its way-appeared on the horizon of the Marxist concept of society. However, Marx's theory only obtained its explosive revolutionary power with the concept of the two-class society. According to Niklas Luhmann, all stable hierarchies presuppose at least three levels. It is only the threefold nature that makes the ratio of the top and bottom resilient to the breaking out or the transformation of one of the levels and requires a semantics of the relations of rank which must 
be valid for not just one, but all relations of rank. The Marxian reduction of class conditions to a dichotomy and its oppositional interpretation torpedoed these safeguards. The two-class system transformed the semantics of order into a semantics of struggle. "The instability of the dichotomy is used", Luhmann says, "to stimulate change expectations". "If only one class disappeared, the other class would not be a class anymore". The proclaimed goal of "human equality" would be achieved (Luhmann 1985: p. 124).

\section{Class consistency as a starting point: from a 'class in itself' to a 'class for itself'}

In his theory, Karl Marx brings the concepts of 'class' and the 'individual' so closely together that they almost merge (cf. Luhmann 1985: p. 125). Even if the process is delayed and broken, Marx assumes a simple translation scheme in his model of social change. The further development of capitalism will lead to a further polarization of class opposition. The homeworkers, the artisans and the rural community are regarded as a remnant of precapitalist formations which will sooner or later be absorbed either in the class of the means of production or that of labor power. Therefore, Marx understands the classes not only as an analytical category for the definition of the conditions of production but also assumes that classes also develop a similar lifestyle, a similar 'consciousness'.

While in Marx's early writings one can almost read an automatism into the formation of classes with similar lifestyles and similar forms of consciousness (cf. Marx/Engels 1958b: 462ff.), it becomes increasingly clear in later writings that this transition from a 'class in itself'-characterized by the conditions of production - to a 'class for itself' - conscious of its own position as an exploited class - is not without problems (cf. Lukacs 1923).

A first reason is that capitalist society is not able to recognize the appropriation of surplus value by the capital owner. In feudal society, serfs were still directly aware that the surplus value produced by them passed into the possession of the feudal lords. They worked one or two days a week on their 'own' small field, from which they derived income ensured their personal survival. The products produced during the other days on the fields of the feudal lords had to be handed over to them. For example, the workers were very directly informed about how the surplus values produced by them were appropriated. In the case of the work done in factories, employees are not aware of the amount of work necessary for their own survival and the point at which value is created for the capitalist. Because of the complex work structures, the worker at the assembly line does not know how many hours are necessary in a working day for their self-preservation, and how many hours of their work exclusively benefit the shareholders through dividends or price increases (cf. Marx 1962a: p. 251). "The wage form", according to Marx, "thus extinguishes every trace of the division of the working day into necessary labour and surplus labour, into paid and unpaid labour" 
(Marx 1962a: p. 562). The relationship between capital and labor appears therefore in a mystified or fetishized form. The workers would get the impression of facing the capitalist as supposed equitable owners of goods in order to negotiate a "fair wage for honest work" with them.

A second reason is that the social awareness of wage laborers is characterized by contradictory aspects. On the one hand, a class identity could develop when employees find that they are in a weak negotiating position against the capital. While the capitalist can forgo purchasing labor when the price of the commodity is too high for them, the worker is dependent on offering their commodity of work at almost any price, lest they are unable to guarantee their own survival. After all, they have nothing else to sell but their work. On the other hand, workers as vendors of their labor power compete with each other for the rare commodity of jobs. Not unlike the way in which vendors of ice cream, baby food or steam turbines compete with each other, workers also compete for available work. "This organisation of the proletarians into a class" is continually at threat of "being upset again by the competition between the workers themselves" (Marx/Engels 1958b: p. 471).

A third reason is that the two-class scheme never develops in its pure form. According to Marx, even in the most developed capitalist societies the "stratification of classes does not appear in its pure form". "Middle and intermediate strata even here obliterate lines of demarcation everywhere" (Marx 1964: p. 892). The middle and transitional stages were formed both in the capitalist class and in the proletariat. Friedrich Engels stated that "The English proletariat is actually becoming more and more bourgeois, so that the ultimate aim of this most bourgeois of all nations would appear to be the possession, alongside the bourgeoisie, of a bourgeois aristocracy and a bourgeois proletariat" (Engels 1963: p. 358). In particular, the increase in profits made possible the formation of a privileged minority of workers who, because of their material privileges, experienced a tendency of 'bourgeoisization', while the greater mass of the workers continued to fall.

The challenge for the development of Marxian theory is that there are two concepts of classes which cannot be easily reconciled with each other. In the concept of 'class in itself', class is understood as an analytical unit. Class appears only on the 'radar of the proletarian avant-garde' or on the 'screen of science' (cf. Luhmann 1985: p. 128). It appears to be 'objective', but for the scientists or the proletarian avant-garde this does not mean that the subjects (the proletarians) also recognize their class position. Thus, the class situation can only be apparent to a political activist with profound insights into its circumstances, or a scientist with the ability to make detailed measurements of the social structure. In the unlikely event that the average man or woman manages to acquire the scientist's or activist's interpretations of an 'intensified class society', a 'class society without classes' or a 'classless society', they may not, as subjects, be able to make head or tails of their own supposedly objective position within the class structure. 
With the dictum of the 'class for itself', it is proclaimed that those who are in similar class positions would be able to notice it, especially in the case of attempting to fundamentally change this situation. Thus, class no longer exists merely objectively, but also reveals itself to its subjects. Thus, the 'objective class situation', or so it is assumed, ultimately leads to the formation of comparable and similar life experiences, and subsequently to an awareness of one's own class situation. The average man or woman becomes aware of their status as workers and their class situation, and develop a comparable situation of awareness (cf. Marx 1959a: p. 180; see also Kocka 1983: p. 26).

From this difference between 'class in itself' and 'class for itself', from the distinction between 'objective class position' and 'subjective processing' a comprehensive research program can be generated: how can one explain, from a Marxist perspective, that empirically — at least in developed industrialized countries - a 'class for itself' is barely recognizable, and workers develop a limited political consciousness in which they understand themselves as workers? Why does the average man or woman not develop a class consciousness? How is it that the child of a worker makes a career as a biochemistry entrepreneur? What becomes of the worker consciousness when Taylorism loses its strength? Why do workers in the east of Germany not vote the party of the proletariat, but for the conservative center-right CDU? Why does the 'class in itself' not become a 'class for itself', or at least to some extent? How is it, according to the everyday formulation of the question, that one cannot conclude on the basis of a person's life alone whether someone is a member of the proletariat?

The problematic transition from 'class in itself' to 'class for itself' is often explained by reference to the 'false consciousness' of the proletariat (see Decker/Hecker 2002: 253ff.). But this form of modern insult to the proletarian is difficult to reconcile with the cult of worker veneration, especially in academic Marxism, and is therefore the target of strong criticism. The postulate of 'false consciousness' has only a few connections to the general discussion in social science, to which the distinction between objective relations and the subjective, and therefore possibly false, perceptions of workers appears suspicious. This may not be an issue from an activist's point of view, but the permanently recurring verdict of 'false consciousness' is ultimately the 'admission of defeat' of every sociological explanation (see Popitz 1958: p. 100).

\subsection{The debate: formation and differentiation of class consciousness}

At least since the Second World War, sociology has increasingly questioned whether the class-building processes propagated by Marx were enough for an analysis of society (see Touraine 1966). With the terms 'class society in the melting pot' (Geiger 1949), 'leveled middle-class society' (Schelsky 1965), 'unified classless society' (Landshut 1956), the 'dissolution of proletarian 
milieus' (Mooser 1983) and the 'pluralization of living conditions and individualization of life courses' (Beck 1992), social scientists pointed out that new stratification lines were forming in society that were of far more significance than the unifying power of production.

The structure of modern industrial society, unlike the pyramidal corporate structure of the early capitalist phase, is being increasingly described in the form of the famous 'Bolte Onion'. According to Karl Martin Bolte (1966), there was only one small upper class and a small group of socially despised people facing a group in the middle-consisting of the members of the new and old middle class, as well as the members of the working class - which was becoming increasingly dominant. According to this line of reasoning, an 'elevator-effect' would raise almost all strata to a higher level of income (see Popitz 1958: p. 95). Since the mindset and the interests of people are more strongly influenced by the possibilities of consumption and living standards than by the conditions of production, the result, purportedly, was that of a general 'slump' of proletarian class consciousness. The class-specific demands on family life, vocational and educational wishes of children, forms of living, consumption and entertainment, as well as cultural, political and economic responses which had previously been strongly distinguishable, would become increasingly homogenized (Geiger 1949: p. 78; Schelsky 1965: p. 333).

Characteristic of this sociology — denounced by critics as 'bourgeois' - is that the class concept is reduced to one of many categories of social structure analysis and is increasingly being replaced by other patterns of order. While with Marx the concept of class could be determined analytically by means of the conditions of production and similarly, the concept of strata

Table 4.1 The 'class question' in social sciences

\begin{tabular}{|c|c|c|}
\hline & $\begin{array}{l}\text { Tendency: preservation of } \\
\text { two-class system }\end{array}$ & $\begin{array}{l}\text { Tendency: multiple-class } \\
\text { system or dissolution of classes }\end{array}$ \\
\hline $\begin{array}{l}\text { Conditions of } \\
\text { production } \\
\text { between capital } \\
\text { and work as a } \\
\text { starting point }\end{array}$ & $\begin{array}{l}\text { Class-blending approaches: } \\
\text { due to the development of } \\
\text { the financial market, it is } \\
\text { only partially possible to } \\
\text { derive social classes from } \\
\text { analytical classes. }\end{array}$ & $\begin{array}{l}\text { Class-differentiation } \\
\text { approaches: due to their } \\
\text { position in the production } \\
\text { process, there are } \\
\text { constantly intermediate } \\
\text { classes forming from both } \\
\text { main classes. }\end{array}$ \\
\hline $\begin{array}{l}\text { Independent } \\
\text { cultural } \\
\text { existence of } \\
\text { the classes as a } \\
\text { starting point }\end{array}$ & $\begin{array}{l}\text { Class-cultural approach: } \\
\text { both the capitalist as } \\
\text { well as the working class } \\
\text { do not primarily form } \\
\text { because of the conditions } \\
\text { of production, but are } \\
\text { rather reproduced through } \\
\text { cultural mechanisms. }\end{array}$ & $\begin{array}{l}\text { Sociocultural approach: the } \\
\text { concept of capital cannot } \\
\text { be reduced to economic } \\
\text { criteria. One cannot } \\
\text { assume just two classes. }\end{array}$ \\
\hline
\end{tabular}


developed by Theodor Geiger could theoretically grasp the economic and social situation of a group of people and its underlying mentality (cf. Geiger 1932), both concepts of class and stratum have threatened to become categories of empirical social research no longer theoretically safeguarded since the Second World War. One speaks no longer of 'stratum' or 'class', but only vaguely of 'social inequality' or 'social structure'. Against the backdrop of this development, one must understand the Marxist-influenced debate on the 'class question', which, despite having peaked in the 1970s, has managed to maintain its glow to this day. For the sake of simplicity, four strands of the discussion can be distinguished (Table 4.1).

\section{The class-blending approach: the difficulties of deriving social classes from conditions of production}

Within the concept of 'class for itself', as already stated above, it is assumed that the production conditions can be reproduced in real social classes. In this sense, one is either a capitalist or a worker. The 'class-blending' approach does not exclude the possibility that the formation of social classes is possible in a capitalist economy in which individuals are owners of companies and the workers, as sellers of their labor power, do not have the possibility to claim a part of the capital. The class-blending approach, however, raises doubts as to whether the current developments in capitalism, particularly in the financial sector of the European, Asian and American industrialized countries, still allow for this separation.

In the third volume of "Capital", Marx already elaborated that due to the increasing importance of stock corporations, the ownership situation among capitalist companies was undergoing changes: Fewer and fewer companies belong to individuals; conglomerates are formed by capital owners. According to Marx, the distribution of capital property often found in corporations "is the abolition of capital as private property within the framework of capitalist production itself" (Marx 1964: p. 452). The individual or family capitalism, still dominant in the late 19th century, became more and more relativistic, as Marx predicted, in the 20th century. The owners of large companies were often other companies, which in turn were owned by other companies. Particularly in Germany-but also in other European countries - large capital interrelations took place between companies, which was also reflected in personnel interrelations, for example, in the boards of directors and supervisory boards of large insurance companies, banks and industrial companies (cf. Zald 1969; Palmer 1983; Mizruchi/ Stearns 1988; Scott 1997; Windolf 2002).

Simultaneously, the diversification of company shares also gained in importance. Even those who earn their money through wage labor do not just hand over their savings as deposits in their bank accounts; they also invest their 'capital' in the form of shares or fund shares (ultimately, holdings in companies). This trend is reflected in the contemporary social diagnosis 
of a society of 'small limited liability companies' or a 'society of workercapitalists'. Matthias Horx, for example, notes a kind of 'people's capitalism' in which workers are increasingly invested in production assets. Linked to this is the transition from an 'employee culture' to a 'culture of small capitalists'. Trade unions are progressively losing their influence, and their former members can now be found in shareholder meetings (Horx 2001). Quite similarly, Richard Nadler proclaims the formation of a broad stratum of 'labor capitalists'. These are employees who themselves speculate as smallholders on the stock market, organize their pension insurance through pension funds and participate in the companies through their share programs (Nadler 1999). Even Michel Aglietta, a thinker of Marxist tradition, looks agreeably upon the idea of employee shareholding. The "control of company shareholding" was "the battle to be fought and won" in order to preserve and develop an own mode of continental European capitalism (Aglietta 2000: p. 68).

The problem of these often more populist approaches is that they take a correctly stated, selective dissolution of the constellation between 'owners of means of production', on the one hand, and 'propertyless pure-workers' (Sombart) on the other, and stylize it into political reform programs. The smallholder, who owns Siemens shares of $€ 1,000$, has no influence on the company's strategies, so long as a large number of shares are held by a few majority shareholders. The employees of a US-based cleaning company, whose savings are invested in a pension fund, are unlikely to feel that they are acting as actual 'investors'. They have nothing to do with the decisions of these pension funds that are becoming increasingly relevant for the economy. Employees in the risk management department of the German insurance company Allianz, bound to the company via a lucrative share portfolio, are a far cry from seeing themselves as the company's co-owners.

Regarding the question of class consciousness, two strands of this debate are still relevant.

The first strand points to the formation of 'institutional capitalism'. Capital funds play an increasingly important role in issues of capital ownership. They attract a more or less large number of shareholders and mobilize large sums of money for investments in companies. In particular, pension funds in which the pension reserves of the working population are located are now among the largest capital owners worldwide, so that one could even speak of a so-called 'pension fund capitalism' (cf. Mizruchi 2004; Davis 2009). The more centralized effect on the question of class formation is that, due to the diffusion of capital ownership, the right of disposal of the individual private entrepreneur is being increasingly transferred to a group of 'executives without ownership' of means of production (see Useem 1990, 1993; Fligstein 1996, 2001). In the 1930s, as the first ideas of a 'democratization' of financial capital were uttered, Adolf Berle and Gardiner Means pointed out that a spread of stock ownership to a large number of people did not lead to a broader control of capital, but rather to a strengthening of the management. In companies listed on the stock exchange, the manager-who is 
actually a 'dependent employee'-becomes the 'seemingly entrepreneurial' ruler when capital ownership is no longer in the hands of just one or two central equity owners, but in the hands of a large number of shareholders (cf. Berle/Means 1932; see also Burnham 1941).

The second strand emphasizes that in individual pioneering industries a collapse of capital investor logic and employee logic can be observed in the same (!) company. In high-growth companies in the IT, biotech and nanotech industries, it is a dominant goal not only for management, but also for employees to acquire company shares in exchange for work, in order to sell them on the capital market for a lot of money if the company (and thus also the value of the company shares) has grown strongly. This resulted in a type of labor power type which - in contrast to Nadler's type of 'worker capitalist', on the one hand, and Voß-Pongratz's (1998) 'labor power entrepreneur', on the other-could be described as a 'labor power capitalist'. Labor power capitalists are also paid a salary for the employment of their labor power, but the problem of the transformation of labor power into work is decisively solved by the fact that labor power capitalists acquire shares in a company through the implementation of labor power (and not with money) (cf. Kühl 2003: 56ff.).

The quintessence of both strands of discussion is that, precisely because of how dynamic the capitalist economy is, the polarity of the capitalist and the worker as two socially distinguishable groups dissolves, and as a result the formation of distinguishable social classes is no longer expected. Despite all the weight of an analytical distinction between capital and work, this difference is still not sufficient to fulfill scientifically or politically justified hopes for revolutionary upheavals.

\section{The class-differentiation approach: intermediary classes and the subsets of the working class}

Representatives of the class-differentiation approach take advantage of the possibility already suggested by Marx and Engels of the formation of intermediate class positions and further differentiation within the capitalist and the working class. As neo-Marxists, they are both separated from the leveling thesis of the area of sociology dismissed as 'bourgeois', on the one hand, and distanced from a simple distinction between a capitalist class and a working class, on the other.

The sociologist Serge Mallet, one of the most prominent representatives of the class-differentiation approach, observed the formation of a "new working class'. As a result of the development of the means of production, workers are no longer required to perform physical work. Instead, they must possess technological intelligence, the ability to control complex technical systems and the willingness to take on responsibility for the production process. The 'new working class' consisted of a highly specialized type of worker expected to have a high level of education. This class is characterized 
by a strong professional and political self-awareness. Yet their urge to control the production organization in the business more strongly impinges on the claims of dominance of the management of capitalist companies. From this contradiction, a pronounced class consciousness of the 'new working class' emerges (see Mallet 1969: 38ff.; see also Deppe 1971: p. 47).

The sociologists Horst Kern and Michael Schumann came to the conclusion that the majority of the workers lacked a class-based understanding of Marx as a guide. The two sociologists noted that an increasing degree of mechanization and automation tends to lead to a differentiation of the working class into subgroups. One group of workers performs challenging work that requires a high level of qualification, while another group performs simple tasks under very restrictive conditions. Since the work itself also has an impact on the consciousness of the workers, this polarization of industrial work also leads to different levels of worker consciousness in the subgroups. The validity of the 'collective characteristics of the objective social situation' pales when compared to the 'specific conditions of industrial work'. The differences in the work itself are more significant for the 'determination of the life situation of the workers and their social thinking and action' than the positioning of means of production, which is the same for all workers (Kern/Schumann 1970: p. 22).

The sociologist Erik Olin Wright assumes that although the means of production is still the main difference in a class society, the class situation of the production owners and the class situation of those who are wage-dependent should be further differentiated. Just as it was necessary in the case of owners of means of production to divide the bourgeoisie into small-size employers and the petit bourgeoisie, it was also necessary to differentiate in the case of the wage-dependent between managers, supervisors and workers because of the varying degrees of access to the resources of their organizations. Within the groups of managers, supervisors and workers, significant differences had to be made with regard to qualifications (Wright 1985; for the predecessor model, Wright 1978; Berger 1998: 34ff.).

The debate developing in the course of the class-differentiation approach has remained easy to follow. Since the question of whether the 'proletariat-turned-bourgeois' has a class consciousness and can develop an awareness as a revolutionary subject (rather in favor: Mallet 1969; rather against: Deppe 1971) hardly attracts any attention, the main debate is led by the representatives of the thesis of a 're-proletarization', on the one hand, and the observers of an intensified class differentiation on the other. The question is whether we are dealing with a trend towards the impoverishment of the working class and thus a 'return of the proletariat', a 'reproletarization' and a 'reestablishment of a working class' with a corresponding class consciousness, or whether the trend towards the formation of a 'proletariat-turned-bourgeois' will still radicalize and a 'class society without classes' will emerge as a consequence of a progressive fragmentation of the proletariat. 


\section{The class-culture approach: the cultural influence of the worker}

The class-culture approach moves away from a derivation of class consciousness from the production conditions and warns of the danger of a reductionist tendency of limiting consciousness to a mere derivative drawn from objective conditions. Workers, similarly to capitalists, are not the bearers of forms of consciousness which result from a simple derivation from economic relations. On the contrary, people develop interpretive patterns which they use to try to process the reality they experience. These patterns of interpretation are influenced by economic conditions, but are 'relatively autonomous' (Neuendorff/Sabel 1978). The emphasis on 'relative autonomy' results almost automatically when directing one's attention to the cultural reproduction of ways of thinking, lifestyles and attitudes of the working and capitalist classes.

A group led by the sociologist Heinrich Popitz, whose position is noticeably removed from Marx, provided an early example of how patterns of explanation and interpretation develop in the working class. In one of the first large studies in the sociology of work after the Second World War, they found that, in the 1950 s, the social image of the worker was still determined by a top-bottom dichotomy. Although the workers in their specific work practice showed a pragmatic, performance-oriented and not at all revolutionary attitude to work, there was nevertheless a collective notion that it was the working class who, thanks to their 'physical exertion', made the prosperity of others possible. Class conflicts, however, were not primarily determined, as thought by Marx, by the contrast between possession and non-possession of means of production; they were perceived by the contrast between physical and mental work. The conflict, according to Popitz's group, was not so much between work and capital as between industrial workers on one end and entrepreneurs, managers, work planners and functionaries on the other (cf. Popitz et al. 1957; Popitz 1958: 97ff.; Bahrdt 1962: 25ff.).

When a group led by sociologist John H. Goldthorpe looked at 'wealthy' workers, they were able to determine that their attitudes were influenced by work, careers, colleagues, superiors, employers and trade unions, but above all by their specific life situation. The attitudes toward work could not be deduced from the simple contrast between wage labor and capital, but were based on everyday life and work experiences. According to these sociologists, not only did the 'objective' working conditions play a role, but also, in particular, whether or not the workers perceived their work as subjectively interesting. Work, especially among well-earning workers, is often no longer at the center of life, the source of self-realization or the center of social relations. Rather, work just aided their self-fulfillment during their free time. Their membership in the worker's union or in the British Labor Party is not an expression of a philosophy of life; it merely serves as a mean of securing their material and legal status. According 


\section{Worker consciousness vs. worker essence}

to the research, despite comparatively good income and living standards, this does not lead to a 'bourgeoisization' of the wealthy workers. Ultimately, a worker's consciousness emerged not so much from the fact that workers had a similar standard of living as employees, but rather because they were hired for worse jobs due to their lower qualifications (Goldthorpe et al. 1967: 23ff.; Goldthorpe et al. 1968: p. 162; see also Kern/ Schumann 1970: 30f.).

The sociologist Paul Willis assumes that there is a considerable degree of self-determination in modern democratic society, yet "working class kids" nonetheless usually take on "working class jobs" after school. Willis does not refer to the economic situation of working-class children as an explanation for the fact that working-class children very likely remain in the working class in later life; instead, he refers to the cultural reproduction of classes. Still in school, working-class children create their own culture by 'hanging out' and 'fooling around', by emphasizing physicality and by displaying competitive masculine behavior. This culture serves as resistance to the teachers' attempts to "to get them to do mental work". Working-class children are "masters of disguised subversion", who always stop just short of open confrontation. According to Willis, the forms of expression of resistance are quite similar to those of the work culture with which the workers, under partially restrictive control structures, also try to informally control the work process. Both schools and companies, with their attempts to directly control workers (children), contribute to the formation of a working culture as counterculture. This counterculture awakens an understanding of the uniqueness of labor power as the only commodity that can produce more than what it costs. After their school career, working-class children look for jobs that best match the counterculture practiced at school-and these are, as a rule, working-class jobs. Thus-according to the argumentation of Willis (1977) — broadly speaking, working-class children become workers.

The authors clearly differ in how strongly they link their approaches to Marx's distinction between possessing and not possessing means of production. In categories such as the 'double constitution of consciousness' (Hack 1977), which refer to the necessary distinction between 'objective' production conditions and 'subjective' processing mechanisms workers rely on, Marxian roots of a class contrast determined by the conditions of production shine when it comes to more culturalistic approaches. However, the commonality of these culturalistic approaches is that, while they explicitly or implicitly cling to Marx's two-class contrast between capital and work as a possible analytical category for social scientists, they tend to minimize the effects the conditions of production have on the formation of class consciousness. In this way, they shift their interest away from the 'objective' economic conditions of Marx and Engels to the rather Weberian question of how proletarian-typical (or capitalist-typical) attitudes, positions and behaviors are passed on over generations. 


\section{The sociocultural approach: on the economy of the social world}

The sociocultural approach, like the class-culture approach, no longer derives class categories primarily from production conditions. In addition, it pushes the escalation to a two-class juxtaposition. Pierre Bourdieu, the most prominent representative of this approach, rejects - in clear contrast to Marx - the escalation of the concept of capital to 'economic capital'. According to Bourdieu, the 'economic capital', expressed in the form of money, does play a significant role, but both relationship-based 'social capital' and knowledge-based 'cultural capital' are two further salient forms of capital. The point is 'to comprehend capital and profit in all its forms' and 'establish the laws whereby the different kinds of capital change into one another'. The 'economic capital' continues to play a central role, but 'social capital' and 'cultural capital' cannot be understood merely as an extension of 'economic capital' (Bourdieu 1983: p. 184). Bourdieu uses the three varieties of capital to show how status is inherited over several generations in a society characterized by the principle of achievement, a society in which the level of education and the position in a profession is primarily determined by income. He explains, in other words, why it is highly likely that the son or the daughter of a university professor will also reach a similar social status. According to Bourdieu, generational classes are no longer primarily based on the inheritance of production capital, for example, machines or factories. Rather, money can be translated into knowledge and a general cultural capacity; into 'habitus'. Say a family goes to classical concerts, reads the "New York Times" together or spends their holidays in Florence; in the next generations, this cultural capacity can then be translated into improved education and, in the long run, into higher income (cf. Bourdieu et al. 1981: 23ff.; Bourdieu 1983: p. 195).

In the approach of 'socialization of everyday life', a group led by the sociologist Thomas Leithäuser assumed that an increasing number of areas of life and relationships are under the influence of capital exploitation interests (see also Leithäuser et al. 1977). Not only paid work, but also leisure, family and friendships are becoming more and more influenced by the 'stamp of capital'. This also means that the social consciousness of workers can no longer be derived from the work process; that the sphere of non-work progressively gained influence. Mass media plays a special role by taking the 'production of consciousness' into the 'planning direction of industrialized superstructure' (Herkommer/Bierbaum 1979: p. 203).

The views of the group led by sociologist Günter G. Voß are quite similar. The concept of 'everyday life-management' refers to the dissolution or disintegration of work and life spheres, which are generally separated from each other by capitalism. The sellers of the commodity of labor power are forced by the capitalistic competition conditions to design their life-management in an increasingly efficiency-oriented manner, and to subject their everyday life to highly rationalized self-organization. The separation of work and 


\section{Worker consciousness vs. worker essence}

life was no longer exclusively predetermined by the dictates of the capitalist enterprise. On the contrary, daily working-time arrangements, as well as break-time regulations, these integral starting points of professional activity would increasingly become an employee's own personal task. The result is an intensified 'self-rationalization' and ultimately an increased self-control of the actors (cf. Voß 1991).

These discussion threads find their commonality in the fact that they no longer adhere to the two-class system and are only very loosely linked to production conditions. The Marxian idea that one can determine class membership over a single criterion-namely, the conditions of production-is rejected. Rather, as the basic assumption of the sociocultural approach, social classes were formed as groups of actors with similar 'conditions and conditioning' and therefore 'similar dispositions and interests' from a variety of criteria (Bourdieu 1985: 12f.). In the end, a Weberian class concept is used which is no longer primarily interested in the production conditions in a class analysis, but is aimed at the generational 'inheritance' of behaviors specific to a stratum, status symbols and social orientations.

\section{The slow retreat from Marx}

All four approaches undermine the equation of the analytical 'class' (as a shorthand for the relation between capital and work) and the social classes (as a relation of two actually existing large groups with similar ranges of experience, lifestyles and ways of thinking). The class-blending approach shows that the derivation of social classes from the production conditions is hardly possible anymore due to the formation of corporations. The differentiation approach observes the strong differentiation within the working class and the formation of intermediate class positions. The class-culture approach works out how social classes do not reproduce themselves on the basis of the production conditions, but instead because of their cultural integration. The sociocultural approach emphasizes the cultural reproduction mechanisms in classes, but also distances itself from a reduction to a two-class system.

It cannot be overlooked how far these Neo-Marxist class concepts have moved away from Marx's original provisions. If - as Luhmann elaboratedthe Marxian class concept is read, on the one hand, as an escalation of the three- or multi-class concept to a two-class concept, and, on the other hand, as an escalation of the classes to the position in the objective conditions of production, one tends to observe a reversal of precisely these two intensifications in class research. Apart from a few purists who claim to recognize a renaissance of the proletariat as a social class, the Marxian-influenced class research seems to have undermined the combination of the two-class concept with the conditions of production. There was no systematic place for the 'explosive revolutionary force' of Marx's class theory. 
The question is whether class research in this formulation can still provide support against the thesis of 'class society in the melting pot', the 'leveled middle-class society', the 'unified classless society', the 'dissolution of proletarian milieus' or the 'pluralization of living conditions and individualization of life courses'.

\subsection{The approach of a theory of functional differentiation: roles}

At first sight, the attitude of sociological system theory to the class question is relatively simple. It does not fundamentally reject the consistency assumptions associated with a class concept, but considers them to be historically relevant. According to the assumption of this theory, the typical feature of pre-modern societies is that one could infer a person's chances of life in all social parts of society from their positioning in the social structure. In tribal societies the position of chieftain often meant-aside from religious authority - better access to economic resources and greater political decision-making power. Both in societies of pre-modern advanced civilization and medieval societies, it was assumed that a person of nobility had a political 'say'; that the produced economic goods by his peasants could be appropriated; and that jurisdiction ultimately governed. In this respect, it was possible to make a precise statement about the position of a person in society, both in segmentally differentiated tribal societies and in stratified societies. In modern society, however, according to the basic idea of the theory of functional differentiation, it is no longer possible to directly infer the life chances of a person in other social areas from their positioning in a specific functional area. A person's 'liberation' from the constraints of a small tribal society, and later from the conditions of slavery and feudal lordship, led to the delegitimization of strata-dependent status positions (cf. Luhmann 1997: 634ff.).

This 'liberation', however, does not mean that a person is able do whatever they want; that is, be quasi virtually free from society. Put simply, when the Marxist theory speaks of 'class' in order to formulate the connection between society and the person, systems theory can resort to a suggestion of structural functionalism and implement the concept of 'role' in its place. Instead of referring to behavior or even ways of thinking of individuals, the 'role' is now placed at the intersection where social conditions and individual modes of action meet. The function of roles in modern society is that they create expectation certainties that do not presuppose any knowledgeor perhaps only little knowledge - of a person. We can assume that the beverage shop "Sammy's" in New York's Tribeca neighborhood will sell us a crate of beer provided we hand over the right amount of money, regardless of whether we know Sammy personally or not.

With the formation of social subsets, according to Luhmann's explanation, specific performance and public roles are created. Either one is 
involved in the provision of services in a subsystem or one is the recipient of services of a subsystem. One is either a doctor or a patient, a judge or a defendant, a governor or one who is governed, a producer of goods or a consumer, a university professor or a student (cf. Luhmann 1997: 739f.). In contrast to tribal or aristocratic society, the role in one context cannot be arbitrarily transferred into another context. The chairman of the board of directors of Daimler is obliged to blow into the breathalyzer of an Italian police officer to determine the level of alcohol in the blood. The parliamentary deputy does not have any privileges over one of his electors when awaiting their turn at the local brothel. The professor has to wait patiently for their turn until the hairdresser is done cutting the hair of a student (cf. Collins 2000).

A central reason why the old-fashioned understanding of class and strata no longer applies is the increasing spread of organizations in modern society. Organizations deprive their members of the opportunity to rely on their 'position in society' during their activities for this organization. The economist that comes from an aristocratic family cannot use their various 'of' and 'de' nobiliary name particles to accelerate their in-company career at a corporate consulting firm. The son of a professor is ill-equipped in his doctoral procedure when he demands a summa cum laude by referring to his academic heritage. The organizational status can, as we are able to experience first-hand, deviate from external status aspects. It happens again and again that 'someone who feels superior because of personal characteristics, abilities, traditions, life-style culture and interests will be subordinated in the organization' (see Luhmann 1964: 165f.).

This means that indications of intellectuality, bourgeoisie, or even aristocratic descent cannot justify any priority treatment in whatever form of organization. The subtle hints of intellectualism evidenced in publications such as "New York Times" or "New Yorker") may bring about recognition from their peers, but no priority treatment can be derived from it in court. A direct lineage to the former Archduke of Austria, Otto von Habsburg, may perhaps be beneficial to a noble bachelor on the aristocratic marriage market, but it does not grant him the advantage to ignore the instructions of his superiors in his function as a bank clerk and justify this with a reference to noble parentage.

Nowadays, not only being a member of an organization for a lifetime but also operating within the sphere of influence of different organizations results in a considerable ranking 'hodgepodge' in modern society. Today one finds, according to a well-known bon mot of Luhmann, "Knight's Cross Bearers buried in registry offices and lance-corporals in top government positions" (Luhmann 1964: p. 161). It is no longer an exception that the CEO of a Swiss food company only made it to private first class at the peak of his military career, whereas the group leader responsible for the marketing of chocolate eggs was a field major of the Swiss Army. We can assume that the people in question can 'manage' this complexity in a specific case. 
The person responsible for the marketing of chocolate eggs would not dream of giving orders to the CEO regarding the repositioning of the company in the market, nor would the private-by referring to his position in the food company - be able to ignore the commands of the field major in the case of a military attack of Switzerland. This means, however, that modern societycharacterized by its organizations - can only be very narrowly understood with the help of classes and strata.

How does the erosion of classes and strata come about in modern society? If a person who considers themselves to be special because of their origin, their sophistication or their lifestyle is given a low status in a company-or realizes that their 'big-city bourgeoisie' grants them no status-related advantage in their statistics examination - this would not only impair their chances of performing in the company or in university, but also in all other areas of life. In a painful conversation with their perhaps much less sophisticated boss or lecturer, they experience the feeling that they cannot transfer their sense of superiority anywhere they would like. Their selfunderstanding, and therefore their self-portrayal, in different interactions become 'problematic and unstable' (see Luhmann 1964: p. 166).

Nevertheless, the resulting tensions, dissatisfactions and behavioral difficulties can be defused - according Luhmann's view - by the fact that, in modern society, status is almost exclusively conferred by organizations, and organizations take on the status decisions of other organizations 'through a kind of diplomatic recognition' (see Luhmann 1964: p. 166). Put simply, status is no longer primarily a matter of family origins, position in relation to the means of production, or ethnic or religious affiliation, but rather of one's career in an organization, as it can provide an advantage of status in other organizations. If you are looking for a conversation partner for a visiting business unit manager of a cooperating company, you can be fairly certain that someone in a position of similar managerial hierarchy is not only professionally suitable, they would also be suitable in terms of their status. If an administration is looking for a new head of department, it is assumed that a person who has already held such a position in another organization is also suitable in terms of status.

\section{Worker and capitalist as a role}

Where does class consciousness factor into this theory based on the formation of organizations? How can such a theory explain why proletarians prefer to vote along social democratic lines or claim their class affiliation at trade union meetings?

At first glance, for systems theorists, there is no reason why sociology should be overly concerned with research on class consciousness. For their sociological research, there are no grounds to examine the social image of the worker in more depth than the social image of the consumer of mineral oil or taxpayers (see also, similarly, Offe 1984: p. 22). 


\section{Worker consciousness vs. worker essence}

At second glance, however, there are possibilities to at least find some relevance for the age-old Marxist question. From the perspective of the theory of functional differentiation, one could point out that class reality is not (or no longer) reflected in the 'economic class', but that it is very conceivable to regard 'class consciousness' as part of a social role. In a functionally differentiated society, 'class affiliation' could become a role that one would choose more or less in the same way one were to become chairman of the sports club, a member of a fraternity or a parent.

According to early role theory arguments by Theodor Geiger and later by Helmut Schelsky, the worker only behaves as a proletarian when it is expected of them to do so. They assume their role as more or less classconscious workers when the interests of the workers' council are to be carried out in the company; when higher wages are to be achieved in collective negotiations with the employer; when they go with their children to the protest marches on Labur Day; or when they are surveyed by industrial sociologists about their worker consciousness. Beyond these areas-for instance, in family life, consumption and leisure, in religious or cultural behavioral forms, but also when selecting their individual company affiliation or individual career expectations-, 'class roles', according to Schelsky, are largely set aside. In short, for the social status of an industrial worker, a geriatric nurse or a call center employee, 'class behavior' only exists as a 'partially social role', but not as a general 'behavior of social status' (see Schelsky 1965: p. 365; see also Geiger 1949: p. 176).

Schelsky argues that class conceptions are maintained and further developed only by "large lobby organizations" such as trade unions, workers" parties and welfare organizations because the "preservation of the remains of class consciousness' plays an important role in their legitimation. With this argument, Schelsky aligns himself to an idea of the social psychologist Peter R. Hofstätter. Hofstätter poses the thesis that in many societies, conflicts of interest are 'preserved' after having been overcome, so that they can continue to be displayed as a matter of form. Although the contrast between capital and labor is not a central conflict in modern societies, this conflict is continuously played on with 'traditional roles'. Through this 'ceremonial character' both sides signal their distance to these conflicts and confirm how they have actually overcome them (Hofstätter 1963: p. 103). In this form of 'ceremonialization', according to Schelsky (1965: p. 367), it is especially those actors who lead the arguments on subjects of classical class struggle who perish. The current conflicts over pay, working time and work safety are carried out in an institutionalized framework, which has little in common with the image of a class struggle. However, the negotiation meetings, 'round tables', and other meetings of employers and employee representatives designed to overcome class struggles and what accompanies them, are bound to the rhetoric of class struggle for both the public as well as for the members of the organization. Interest groups purport 'obsolete models' inwardly and outwardly as 'legends of their legitimacy'. However, these 
models are justified by the fact that organizations might be able to successfully represent the present interests of their members under this 'ceremonial ideology of communication' (for a small 'approach' of a trade union sociology, see Luhmann 1988c: p. 172).

With this perspective of 'being a worker' as a role, Schelsky turns the debate on worker consciousness 180 degrees. It's not 'being that determines consciousness', as the short formula for the Marxian thesis claims; rather, it's 'consciousness that determines the way in which one presents one's being'. In other words, it's not the case that 'work leads to socialist sentiment', but that 'whoever is a socialist is a worker in the sense of the expression of their opinions determined by class'. The concept of a proletarian gains the significance of a 'party badge' that is bestowed when one has the right socialist attitude. From this perspective it is also understandable that the 'proletarian consciousness' and 'class identification' are sometimes more pronounced in the utterances of students and intellectuals who have dealt with the history of labor power, than with the workers themselves (cf. early investigation of Kluth 1995: 148f.).

\section{Beyond stratum and class: the explanatory power of role theory for the thesis of individualization}

One should not push the focus on role theory too far. Even Luhmann-in the perception of his critics, certainly the embodiment of all the evils in functionalist role theory-has always warned against overestimating the ordering capacity of roles as factual behavior. Early sociological roles-which people conceived almost as 'puppets' of their roles-were, according to Luhmann's remark, limited in their ability to explain the diversity of human behavior (cf., e.g., Luhmann 1984: p. 430).

Just as the class concept was increasingly differentiated in Marxist theory, the concept of role was also increasingly modified, adapted, and extended, so that its critique - mainly based on Parson's concept-only has limited bearing today. The adoption of a role concept does not mean that the "personal' loses its significance in society. On the contrary, it is only through role attitudes that it is possible to grasp ideas such as 'personality', 'individualization' or 'individuation'. It is only because of the variety of combinations of roles that has developed through the transition to the functionally differentiated society that individuality is produced as an increasingly self-defined uniqueness of people (cf. also Simmel's early theory of social circles).

According to the fundamental idea, one can only establish oneself as an 'individual', or even as a 'personality', once the difference between person and role is clear. It is only when one knows what is expected of a worker that one is able to identify, say, Celine Petersen, Peter Collins or Kate Harvey as key players. It is only when one understands the extent to which work organizations encourage their members to adopt role-appropriate behavior that the subversiveness of workers' council member Anne Ibscher can be 
personally attributed. It is only when you know what the normal requirements are for the role-bearer of 'manager' or 'revolutionary' that one can identify them as a 'real winner' or 'loser'.

In the internal life of organizations, in expert-client relations, or in negotiations between representatives of lobby groups, it is always necessary to reflect on the expectations that can be achieved by the personal situation and what expectations are directed to a particular person. In a wage negotiation, the employer's representative tries to gauge exactly how his counterpart is able to make a compromise with the trade union in their role of designated negotiator, and the extent to which their counterpart's authority depends on the fact that they are the newly designated negotiator (for instance, Mr. Peters) and not the former negotiator (Ms. Huber). It is only in the context of the difference between role and person that one can observe the performance of the role assuming a 'personal style' (cf. Luhmann 1997: 771f.).

In addition to the formation of 'personality', 'individualization' or 'individuation', roles in the functionally differentiated society can be selected to a certain extent. It is true that in modern society there are also rolessuch as 'pupils', 'draftee' or 'prisoner' - which are not necessarily voluntary. However, most of the roles are assumed of one's own accord: one makes the decision to study sociology and not business administration; one works in Brussels as a lobbyist for a socialist non-governmental organization and not as a corporate consultant for McKinsey; one becomes a member of a knitting club and not a boxing club; one's spouse or life partner is a personal choice, and not pre-selected or suggested by a parental arrangement. As roles can (largely) be chosen in modern society, they become an expression of personal self-portrayal (cf. Goffman 1956).

In addition, it is also possible to perform roles with different levels of commitment. A fundamental notion of the interaction sociologist Erving Goffman is that the assumption of a role does not necessarily require $100 \%$ enthusiasm when it is carried out. A seven-year-old girl can ride a carousel, while simultaneously showing that she is actually already too old for such banal forms of leisure. A student can perform their internship tasks at the photocopier, while at the same time conveying how under-appreciated he feels as a future member of the German elite. Role-distancing makes it possible to embody a role while at the same time (and even: as a result) expressing one's own personality. The stronger the compulsion to take on a role, the easier it is to display this role-distancing. Someone who is forced to work on the assembly line because of capitalist conditions (or poor parents) can show their role-distancing better than someone who has worked for five years to become junior partner at a corporate consulting firm. It is easier for the draftee to display his role-distance when performing than it is for the professional soldiers, who have committed themselves to twelve years of defending their country (cf. Goffman 1971).

The discussion on individualization in modern society - which already played a major role with Durkheim and Simmel, and which also found its 
way into sociology through the emphasis of Ulrich Beck-can be interpreted in a role-theoretical manner. When Ulrich Beck speaks of an 'institutionalized individualism' with recourse to Talcott Parsons, he ultimately resorts to the combination of different roles. The conception of roles provides enough space to push the construction of unique individuals to the center, and prevents the concept of 'individualization' from degenerating into a complex, evidence-avoiding shorthand (cf. Beck 2000a: p. 87).

\section{Open questions: approaches for a class and strata conception of theory of functional differentiation}

The strength of the theory of functional differentiation is that, unlike Marxist class theory, it has no problems explaining status inconsistencies. The academic cab driver, the leading economist who loses a court proceeding and the top politician with an unsuccessful love life do not surprise us from this theoretical perspective. It can be drawn from this theory that someone who may well have a prominent role in one social section does not necessarily have much to say in another.

From this theoretical perspective, status consistencies - in other words, the transference of a high (or low) rank occupied in one functional area by someone into all other areas in which they are active-appear only as 'perception aids' which can be reached for as an initial guide during interactions. It is assumed that well-dressed business people have a university degree, or at least an MBA, and can therefore discuss the economic theory of Milton Friedman. One does not expect a truck driver to either be a fan of twelve-tone music, nor to recite the Song of Mary Magdalene from the Benediktbeuern Easter Drama (cf. Moers 1993). But because these assumptions are nothing more than perception aids for conversations while hitchhiking, chatting after mass or during parties, one is quickly able to adapt to a status-inconsistent conversation partner.

The risk of such a role concept based on the theory of functional differentiation is that - consciously or unconsciously - the subject class and stratification will be 'defined away' in sociology. Because role theory emphasizes the idea that people behave differently (i.e., according to their role) in different situations, it is difficult to observe any coherence across different roles.

Therefore, the approach of functional differentiation represented by the systems theorists always seems to run into explanation problems whenever there are status consistencies beyond social subsets in modern society: How can one explain that a multimillionaire company founder is treated more leniently when pulled over for speeding than an assembly line worker who's barely making ends meet? How do you explain that the practicing lawyer son of a congressman successfully avoids standing trial for tax evasion for years? Or that in organizations, public administrations and universities, organization-specific status criteria such as gender, ethnicity or sexual orientation, still play a role (cf. Tilly 1998)? 


\section{Worker consciousness vs. worker essence}

In order to find an answer to such questions from this theoretical perspective, one must take a step back. It is striking that functionally differentiated societies are capable of not only producing but also tolerating extremely 'unequal distribution of public and private goods' (Luhmann 1995b: p. 249). It is widely accepted that murderers are sentenced to life imprisonment - which has extreme consequences with regards to access to public and private goods. The majority of the population tolerates that Tony Blair has more to say politically than a simple voter, even if one is not sympathetic towards his policies. Similarly, Mexican billionaire Carlos Slim's Fifth Avenue residence does not cause any kind of social unrest among the denizens of Manhattan.

The - at first glance-surprising tolerance of the extremely unequal distribution of public and private goods can only be explained by the fact that all subsystems of modern society are based on the fundamental inclusion of all human beings. In functionally differentiated societies, everyone can, in principle, run for political office, regardless of economic standing, gender or ethnicity - which, as history shows, is anything but obvious. In principle, everyone in modern society can stand in front of a judge and demand that a criminal offense be prosecuted. Academic tenure at a US university is no longer reserved exclusively for white male Anglo-American heterosexual Protestants, but can also be granted to a homosexual female Muslim of Asian descent. In line with this 'principle of full-inclusiveness', functional systems themselves decide how far someone is to 'being right or wrong, whether their knowledge is recognized as true or not' (cf. Luhmann 1995a: p. 142).

Hyperbolically speaking, social inequalities can grow in a functionally differentiated society because social sectors such as the economic system, education system or the scientific system use 'equality or inequality' for their own operations (Luhmann 1997: p. 776). When the sales manager dismisses her employee with the argument that he did not generate enough sales last year, it is only necessary for them to point to the 'No admittance except on business' sign - already described by Marx - , which hangs symbolically on the threshold of every production site, and is hardly protested by anyone (see Marx 1962a: p. 190). The expert at the "German Research Association" rejects the research project of a colleague, because the project application was far worse than other submitted applications. The university professor denies a student her PhD because her thesis was simply not good enough compared to those of other candidates.

It is difficult to protest against this form of inequality in a functionally differentiated society. The student who considers it unfair that the clever and well-read fellow student gets better marks is similarly ill-equipped as the employee who asks her boss to ignore the criterion of the turnover generated when negotiating new wages. As a result, the protest of the 'hard done by' in modern society focuses on the argument that unequal treatment has nothing to do with the requirements of the respective functional system. 
The philosopher Michael Walzer (1983) has pointed out that 'injustice' is always felt when the 'fences' between social divisions do not work, and someone can use the benefits from one social area as an advantage in another field. One feels unjustly treated when, after being denied a promotion, one learns that the recipient of the promotion has close family ties with the boss. It is worth noting that it is usually acceptable for managers of a company, as a result of their higher monetary earnings, to drive bigger cars than the average person at the hierarchical base. What is actually perceived as unfair is when socially acknowledged achievements from one area can be linked to advantages in other areas; for example, when the managing director of a company only has a better chance of a happy relationship because of their influential position in the economy.

From the perspective of systems theory, which is characterized by the view on the process of functional differentiation, it would seem wise to reserve the stratification and class concept for this form of cross-system inequalities. From this point of view, the identification of strata and class is no argument against the notion of a functionally differentiated society. On the contrary, it is striking that, unlike in pre-modern advanced civilizations and societies of early industrialization, stratification and class get a 'bad rap' nowadays. Today — as opposed to a hundred years ago - it is seen as completely illegitimate that a farmer's daughter should have worse chances of getting a university degree than the son of a senator from New York. Even populist conservative parties have legitimacy issues when a member of the upper echelons enjoys privileged treatment in legal proceedings because of their politically prominent role. In short, the fact that one feels the need for justification when one transfers an advantage from one social field into another can be regarded as an indication that we live in a functionally differentiated society whose basic structure no longer consists of classes and strata.

The difference between this kind of class and stratification approach to Marxist class theory is easy to spot. The numerous varieties of Marxist class theory, as well as most social structural analysts who distance themselves from Marx, seek to pinpoint the central criterion for the definition of a strata or class in the economy (Berger 1998: p. 32). The theory of functional differentiation abandons this over one-hundred-year-old sociological tradition of the economic categorization of classes, reserving the class and stratification concept for the ordering patterns that have an effect across such diverse social segments as economics, politics, law, science and religion. 


\section{In favor of a renaissance of grand theories}

The strength of Marxist theory was that, in the fundamental formulations of Karl Marx and Friedrich Engels, it could satisfy a large part of the demands of a theory of society. Marxist theory, with its idea of class struggle, has a concept that could be used to explain conflicts in global society, national states, factories, universities or television networks, as well as in interactions between people. This conception of conflicts-rooted in the idea of class opposition - also serves to describe social changes within Marxist theory. Better than almost any other sociological theory, Marxism has a sophisticated understanding of the capitalist economy and is able to define the relationship between the economy and other social sectors by distinguishing between the economic 'base' and the ideological 'superstructure'.

It is a particular merit of Marx-influenced social sciences that they break down Marxist theory_rather focused on larger social spectrumsto the level of organizational analysis, and partly to the level of specific face-to-face interactions (see, e.g., Burawoy 1979, and also Willis 1977). Furthermore, Marxism, with its consideration that a person's consciousness can be derived from their class situation, has a concept with which knowledge and ways of thinking can be reconstructed. For many social scientists, class situation may seem too blunt an explanation for the manner in which people think and what knowledge is evident to them. However, it cannot be denied that, with this idea, Marxism had its own sociology of knowledge at its disposal.

The popularity of Marxism as a theory of society can be seen in the fact that all classic sociologists - from Simmel to Durkheim to Weber-worked on Marxian theory. In the end, it was not so much scientific controversies which forced Marx away from the general focus of theoreticians, but rather the collapse of 'real life' state socialism. This is understandable from a historical point of view, but it is certainly paradoxical (see Haug 2002: p. 229). Perhaps it is true when it is stated that sociologists, political scientists and educators whose work follows Marx's have-for some time-been suffering from 'shortness of breath', and the evidence that has been added to scientific explanations of class theory has grown less and less empirical. The question, however, is whether Marx was perhaps not too hastily dismissed as a 
sociological theorist. The strengths of Marx's theory lie less in a Marxistinfluenced organizational theory, or a sociological class consciousness research, than in the description of the expansive power of a capitalist economic order.

Aside from rational choice theory-which, with its economic theorem, is much more similar to Marxism than it may care to admit-there is at present only one other theory of society which is as completely developed as Marxism: systems theory. In contrast to the theories that raise either individual phenomena such as organizations (e.g., neo-institutionalism with its focus on the diffusion process of organizational patterns) or the relationship of structure and action (e.g., the actor-structure relation in structuring theory) to a theory of society, systems theory claims to include all (!) aspects of the social.

Aspects that are interesting to Marxist social scientists can be more accurately observed in systems theory, as it does not derive them from the causal yet relatively simplistic assumptions about the effect of the conditions of production. Only when one follows the assumption of the differentiation of modern society in largely autonomous social subsystems is one able to determine the role of 'economy' in society; only when one considers the individual life of organizations does the question about the function of 'profit' for companies arise; only when 'role'-rather than 'class'-is conceived as a nexus between the individual and society can the interplay between them be more closely observed.

Which (and if at all one) of the two sociological-theoretical perspectives presented here can be applied depends on whether one of the two succeeds in integrating the other perspective. The claim to a 'super-theory' of social sciences consists not only of being able to grasp all aspects of the social as a 'grand theory', but also to classify the explanatory approaches of other theories (Luhmann 1984: p. 19). The theoretical schism between Marxist theory and systems theory leads, in the worst-case scenario, to a silent standoff or a continued general rejection; in the best-case scenario, to productive attempts to integrate the other's respective observational perspective.

\section{Regarding the 'critical potential' of sociology}

It seems to be particularly worrisome that the 'critical potential' of social science could be lost. But what kind of criticism is referred to when speaking of the 'critical potential' of sociology, politics or pedagogy? Is it a social science that does not allow itself to be blinded by the bourgeois entitlement? Is it a social science that the proletarian recognizes as a 'natural' ally, which attempts to collaboratively revolutionize — or at least reform - the capitalist conditions of production? Is it concerned with a sociology, a political science, a pedagogy, or a science of work not solely limited to the role of 'companion researcher' regarding the 'humanization of the working world', but decidedly standing shoulder to shoulder with the worker? 


\section{Renaissance of grand theories}

From the perspective of systems theory - and, more broadly, all the theories of functional differentiation-one would argue that sociology, as a differentiated and theoretically safeguarded science, has an inherently critical distance to its subject (Luhmann 1991). It is characteristic of a differentiated science to be primarily interested in the opinions of one's own academic colleagues, and not so much in whether the staff manager, union functionary or even the assembly line worker deems one's research particularly good or insightful. Scientists read the bibliography of their colleagues' essays with intent to determine whether their own more or less innovative ideas have also been duly recognized. Of course, one can also infer their reputation from their popularity in the upper echelons of political parties, employer associations, trade unions and mass media corporations. However, it is worth noting that this type of reputation does not translate easily into scientific renown within a differentiated scientific field. In fact, any kind of popularity outside of science can be regarded as a sign of scientific unreliability.

Sociology in particular gains its strength as the science of society precisely because it can produce descriptions that do not need to take into account the logics of action of social subsets, the interests of organizations or even of people (Bourdieu 1993: p. 20). Indeed, it draws the justification for its existence as a social science precisely from contrasting systemic selfdescriptions with extraneous descriptions, which may seem 'heretical' for the described functional systems, organizations and interactions. Sociology, for example, may refer to religion as the "opiate of the masses" (as opposed to theology), or proclaim that when people worship God, they actually worship the functioning of society (Durkheim 1981). In contrast to business economics, it can characterize the profiteering of companies as a "myth", or even see the "beginning of all ends" in it (Marx 1962a). Precisely because sociology focuses on society as a whole, it does not-as is the case with other disciplines, such as business economics, but also political science or pedagogy - need to be characterized by a minimum degree of 'loyalty' with regards to the described social subsets (cf. Kieserling 2000: 45ff. and $77 \mathrm{ff}$.). In view of this ability to make heretically extraneous descriptions, the demand for a 'critical sociology' is, in fact, inherently redundant-a pleonasm.

For a long time, however, the 'critique concept' of most social sciences was more narrowly defined than the critical understanding derived from the differentiation of sociology. It dealt with the criticism of the 'dominant conditions' with simultaneous (and, of course, also critical) loyalty to 'society-transforming' groups of society. The famous eleventh Marxian thesis on Feuerbach clearly showed that it was not only a matter of interpreting society, but also of changing it (see Marx 1958: p. 535). Since the contrast between capital and work was the central differentiation scheme in order to determine who one should be critical about, Marxist social scientists had a faltering connection to the representatives of the workforce; in the boom 
phases of the early 1970 s, this was partly propagated under the label of 'employee orientation' and by occupying corresponding university posts with people who had a dual qualification as both skilled workers and a scientists (cf. the early observation of Hoefnagels 1966: 48ff.).

This militant social science, as propagated by Pierre Bourdieu, Michel Foucault, Zygmunt Bauman, Judith Butler and Ulrich Beck, gained sympathy with great ease. It is tempting for social scientists to stylize themselves in debates as independent political intellectuals, as critics of circumstances. Yet the bid towards neutrality was tainted with the often haphazardly formulated criticism of the dominant 'military-industrial complex', 'heteronormative patriarchy' or, to borrow Luc Boltanski's formulation (2010), 'white colonial mainstream'.

The challenge for sociology is not so much to avoid the positive references to the status quo. Unlike business economics, pedagogy or political science - all of which have a strong sympathy for a system-affirming perspective - the social sciences always tend to hastily take on the perspective of the victims of a system. If we look at such diverse fields of research as work sociology, gender research or political sociology, we can recognize a meticulously controlled sympathy for the oppressed, the injured and the subversive. By taking on exactly this underdog perspective, however, special areas lose their necessary critical distance. Good social scientists can be recognized by the fact that they do not focus on just one subject, even if it happens to be a good subject.

Certainly, if a discipline is ready to forgo the claim of being a science, there is nothing to say against a developmental path towards an affirmative reflection theory of a trade union, a nongovernmental organization or a suppressed minority, seeing as management (with their dominating business economics) and politicians (with the normative political science) also follow their own reflection theory, which, because of its practical orientation, is nevertheless exposed to the criticism of lacking scientific neutrality. But just as business economics and political science have to allow the question whether their affirmative approach is a means to educate companies or parties about themselves, a critically behaving social science must allow the question whether it is actually useful for trade unions, nongovernmental organizations or the movement organizations as their 'natural' contact partners to generate descriptions compatible with the programs of these organizations. Just as in parts of company and party management a trend can be observed whereby, under the premise of "Please, torture me", they demand more than just 'socially acceptable descriptions' from the organizational sciences, the question also arises for workforce representatives as to whether it would not be more useful for sociology to not only produce heretically dissociative descriptions of capitalist companies, but of trade unions, nongovernmental organizations or activist organizations as well. This question can confidently be left to the companies, trade unions and activist organizations as consumers of social science knowledge. 


\section{Renaissance of grand theories}

Especially for social sciences as sciences (!), the limitation of a point of view is problematic. The contrast between capital and work as a guiding difference makes it possible for hierarchically structured power relations in companies to be described, but it does not recognize that trade unions and nongovernmental organizations form similar hierarchical principles in their professionalized core. Along the contrast between capital and work, one comes across the alienation phenomena in Taylorized and Non-Taylorized businesses; however, the understanding that comparable alienation phenomena can also emerge in lobbies whenever they finance members with wage labor tends to wear down. According to Niklas Luhmann (1996: p. 200), a 'conceptualized theory of society' can thus appear much more radical and much more unsettling than individual criticisms - such as criticism of capitalism or patriarchy_could have ever depicted.

The charm of a sociology bolstered by systems theory lies in the fact that such a theoretically well-founded sociology is, in the best sense, an 'impractical science' (Bergmann 1982). The strength of sociology can be especially recognized in how heretical its descriptions are seen to be by the field that is being described. It is an attribute of a theoretically safeguarded social science that their findings cannot be easily transferred into the practice of a company, a trade union or even a social movement, but are perceived there as a confusing clarification of themselves (and not only of their environment). The scientific appeal of systems theory is that, unlike Marxism, it is 'impractical' and 'heretical' for companies and trade unions, capital and work, economy and politics. What better basis for scientific criticism could there be? 


\section{References}

Abel, E. K., \& Nelson, M. K. 1990. Circles of Care: Work and Identity in Women's Lives. Albany: State University of New York Press.

Acker, J. 1990. Hierarchies, Jobs, Bodies: A Theory of Gendered Organizations. Gender \& Society, 4: 139-158.

Ackroyd, S., Burrell, G., Hughes, M., \& Whitaker, A. 1988. The Japanisation of British Industry? Industrial Relations Journal, 19: 11-23.

Adorno, T. W. 1969. Einleitungsvortrag zum 16. Deutschen Soziologen Tag. In T. W. Adorno (Ed.), Spätkapitalismus oder Industriegesellschaft?: 12-28. Stuttgart: Ferdinand Enke.

Aglietta, M. 1979. A Theory of Capitalist Regulation. London: NLB.

Aglietta, M. 2000. Ein neues Akkumulationsregime: Die Regulationstheorie auf dem Prüfstand. Hamburg: VSA.

Aglietta, M. 2002. Mutationen des Kapitalismus. Eine schizophrene Lohnarbeitsgesellschaft? Sozialismus, 29(4): 13-19.

Almeling, R. 2007. Selling Genes, Selling Gender: Egg Agencies, Sperm Banks, and the Medical Market in Genetic Material. American Sociological Review, 72: 319-340.

Althusser, L. 1977. Ideologie und ideologische Staatsapparate: Aufsätze zur marxistischen Theorie. Hamburg: VSA.

Altvater, E., Hecker, R., Heinrich, M., \& Schaper-Rinkel, P. 1999. Kapital.doc. Münster: Westfälisches Dampfboot.

Alvesson, M., \& Willmott, H. 2002. Identity Regulation as Organizational Control: Producing the Appropriate Individual. Journal of Management Studies, 39: 619-644.

Amin, A. (Ed.). 1994. Post-Fordism: A Reader. Oxford: Blackwell.

Aneesh, A. 2012. Negotiating Globalization: Men and Women of India's Call Centers. Journal of Social Issues, 68: 514-533.

Applebaum, H. 1992. The Concept of Work: Ancient, Medieval, and Modern. Albany: State University of New York Press.

Aristoteles. 1967. Aufzeichnungen zur Staatstheorie (Politik). Köln: Hegner.

Baethge, M. 1991. Arbeit, Vergesellschaftung, Identität: Zur zunehmenden normativen Subjektivierung der Arbeit. Soziale Welt, 42: 6-19.

Bahrdt, H. P. 1962. Die Industriearbeiter. In H. P. Bahrdt \& M. Feuersenger (Eds.), Gibt es noch ein Proletariat?: 25-33. Frankfurt a.M.: EVA.

Bahrdt, H. P. 1974. Die Krise der Hierarchie im Wandel der Kooperationsformen. In F. Fürstenberg (Ed.), Industriesoziologie II: 111-132. Darmstadt, Neuwied: Luchterhand. 
Bahrdt, H. P. 1982. Die Industriesoziologie - eine "spezielle Soziologie"? In G. Schmidt, H. J. Bracyzk, \& J. v. d. Knesebeck (Eds.), Materialien zur Industriesoziologie: Kölner Zeitschrift für Soziologie und Sozialpsychologie, Sonderband 24: 11-15. Opladen: WDV.

Barnard, C. I. 1938. The Functions of the Executive. Cambridge: Harvard University Press.

Beck, U. 1992. Risk Society: Towards a New Modernity. London: Sage.

Beck, U. 1999. Die Zukunft der Arbeit. Frankfurt a.M., New York: Campus.

Beck, U. 2000a. Freiheit oder Kapitalismus. Frankfurt a.M.: Suhrkamp.

Beck, U. 2000b. Wohin führt der Weg, der mit dem Ende der Vollbeschäftigungsgesellschaft beginnt? In U. Beck (Ed.), Die Zukunft von Arbeit und Demokratie: 7-66. Frankfurt a.M., New York: Campus.

Beck, U., Holzer, B., \& Kieserling, A. 2001. Nebenfolgen als Problem soziologischer Theoriebildung. In U. Beck \& W. Bonß (Eds.), Modernisierung der Moderne: 63-81. Frankfurt a.M.: Suhrkamp.

Beckenbach, N. 1991. Industriesoziologie. Berlin, New York: de Gruyter.

Beckenbach, N., Braczyk, H.-J., Herkommer, S., Malsch, T., Seltz, R., \& Stück, H. 1973. Klassenlage und Bewußtseinsformen technisch-wissenschaftlicher Lohnarbeiter: Zur Diskussion über die "Technische Intelligenz". Frankfurt a.M.: EVA.

Bendix, R. 1960. Herrschaft und Industriearbeit: Untersuchungen über Liberalismus und Autokratie in der Geschichte der Industrialisierung. Frankfurt a.M.: EVA.

Berger, J. 1995. Warum arbeiten die Arbeiter?: Neomarxistische und neodurkheimianische Erklärungen. Zeitschrift für Soziologie, 24: 407-421.

Berger, J. 1998. Was behauptet die Marxsche Klassentheorie - und was ist davon haltbar? In H.-J. Giegel (Ed.), Konflikt in modernen Gesellschaften: 29-60. Frankfurt a.M.: Suhrkamp.

Berger, J. 1999. Der Konsensbedarf der Wirtschaft. In J. Berger (Ed.), Die Wirtschaft der modernen Gesellschaft: 155-194. Frankfurt a.M., New York: Campus.

Bergmann, J. 1982. Industriesoziologie - eine unpraktische Wissenschaft? In U. Beck (Ed.), Soziologie und Praxis: 397-416. Göttingen. Soziale Welt Sonderband 1.

Berle, A. A., \& Means, G. C. 1932. The Modern Corporation and Private Property. New York: Macmillan.

Boltanski, L. 2010. Soziologie und Sozialkritik. Frankfurt a.M.: Suhrkamp.

Boltanski, L., \& Chiapello, È. 1999. Le nouvel esprit du capitalisme. Paris: Gallimard.

Bolte, K. M. 1966. Entwicklungen und Probleme der Berufsstruktur. In K. M. Bolte, F. Neidhardt, \& H. Holzer (Eds.), Deutsche Gesellschaft im Wandel: Band 2: 279-449. Opladen. Leske.

Bommes, M., \& Tacke, V. 2001. Arbeit als Inklusionsmedium moderner Organisationen. Eine differenzierungstheoretische Perspektive. In V. Tacke (Ed.), Organisation und gesellschaftliche Differenzierung: 61-83. Opladen: WDV.

Borrus, M., \& Zysman, J. 1998. Globalization with Borders: The Rise of "Wintelism" as the Future of Industrial Competition. In J. Zysman \& A. Schwartz (Eds.), Enlarging Europe: The Industrial Foundations of a New Political Reality: 27-62. Berkeley: University of California Press.

Bourdieu, P. 1979. La distinction: Critique social du jugement. Paris: Les Éditions de Minuit.

Bourdieu, P. 1983. Ökonomisches Kapital, kulturelles Kapital, soziales Kapital. In R. Kreckel (Ed.), Soziale Ungleichheiten: Sonderband 2 der Sozialen Welt: 183-198. Göttingen: Nomos. 
Bourdieu, P. 1985. Sozialer Raum und 'Klassen': Zwei Vorlesungen. Frankfurt a.M.: Suhrkamp.

Bourdieu, P. 1993. Soziologische Fragen. Frankfurt a.M.: Suhrkamp.

Bourdieu, P. 2003. Interventionen 1961-2001: Band 1. Hamburg: VSA.

Bourdieu, P., Boltanski, L., Saint Martin, M. de, \& Maldidier, P. 1981. Titel und Stelle: Über die Reproduktion sozialer Macht. Frankfurt a.M.: Suhrkamp.

Boyer, R., \& Saillard, Y. (Eds.). 2002. Théorie de la régulation: L'état des savoirs. Paris: Découverte.

Braverman, H. 1974. Labor and Monopoly Capital: The Degradation of Work in the Twentieth Century. New York, London: Monthly Review Press.

Britton, D., \& Llogan, L. 2008. Gendered Organizations: Progress and Prospects. Sociological Compass, 2: 107-121.

Bromley, P., \& Meyer, J. W. 2015. Hyper-organization: Global Organizational Expansion. Oxford: Oxford University Press.

Budd, J. W. 2011. The Thought of Work. Ithaca: Cornell University Press.

Budd, J. W. 2013. Work, Definitional. In V. Smith (Ed.), Sociology of Work: An Encyclopedia: 985-987. Los Angeles, London, New Delhi: Sage.

Bungum, B., \& Kvande, E. 2013. The Rise and Fall of Cash for Care in Norway: Changes in the Use of Child-care Policies. Nordic Journal of Social Research, 4: 31-54.

Burawoy, M. 1979. Manufacturing Consent. Chicago, London: University of Chicago Press.

Burawoy, M. 1985. The Politics of Production: Factory Regimes under Capitalism and Socialism. London: Verso.

Búriková, Z., \& Miller, D. 2010. Au pair. Cambridge, Malden: Polity.

Burnham, J. 1941. The Managerial Revolution. New York: Day.

Callaghan, G., \& Thompson, P. 2001. Edwards Revisited: Technical Control and Call Centres. Economic and Industrial Democracy, 22: 13-37.

Carruthers, B. G., \& Ariovich, L. 2004. The Sociology of Property Rights. Annual Review of Sociology, 30: 23-46.

Castel, R. 1995. Les métamorphoses de la question sociale: Une chronique du salariat. Paris: Fayard.

Cole, R. E. 1989. Strategies for Learning: Small Group Activities in American, Japanese, and Swedish Industry. Berkely: University of California Press.

Coleman, J. S. 1982. The Asymmetric Society. New York: Syracuse University Press.

Collins, R. 1990. Market Dynamics as the Engine of Historical Change. Sociological Theory, 8: 111-135.

Collins, R. 2000. Situational Stratification: A Micro-Macro Theory of Inequality. Sociological Theory, 18: 17-43.

Collins, R. 2010. Conflict Sociology. London: Routledge.

Commons, J. R. 1924. Legal Foundation of Capitalism. New York: Macmillan.

Conze, W. 1972. Arbeit. In O. Brunner, W. Conze, \& R. Koselleck (Eds.), Geschichtliche Grundbegriffe: Band 1: 154-215. Stuttgart. Ernst Klett Verlag.

Crouch, D., \& Ward, C. 1997. The Allotment: Its Landscape and Culture. Nottingham: Five Leaves.

Crozier, M., \& Friedberg, E. 1977. L'acteur et le système. Paris: Seuil.

Cummings, T., \& Srivastva, S. (1977). Management of Work. A Socio-Technical Systems Approach. Kent: Ohio State University.

Dahrendorf, R. 1957. Soziale Klassen und Klassenkonflikt in der industriellen Gesellschaft. Stuttgart: Ferdinand Enke. 


\section{References}

Dahrendorf, R. 1962. Industrie und Betriebssoziologie (2nd edn.). Berlin: Walter de Gruyter.

Davis, G. F. 2009. Managed by the Markets. New York: Oxford University Press.

Davis, T. J. 1995. The Occupational Mobility of Black Males Revisited: Does Race Matter? The Social Science Journal, 32: 121-135.

Decker, P., \& Hecker, K. 2002. Das Proletariat. München: Gegenstandpunkt.

Deppe, F. 1971. Das Bewußtsein der Arbeiter: Studien zur politischen Soziologie des Arbeiterbewußtseins. Köln: Pahl-Rugenstein.

Deutschmann, C. 2002. Postindustrielle Industriesoziologie. Theoretische Grundlagen, Arbeitsverhältnisse und soziale Identitäten. Weinheim, München: Juventa.

Drucker, P. F. 1969. The Age of Discontinuity: Guidelines to our Changing Society. New York: Harper \& Row.

Duffy, M. 2011. Making Care Count: A Century of Gender, Race, and Paid Care Work. New Brunswick: Rutgers University Press.

Durkheim, É. 1981. Die elementaren Formen des religiösen Lebens. Frankfurt a.M.: Suhrkamp.

Durkheim, É. 1984. Die Regeln der soziologischen Methode. Frankfurt a.M.: Suhrkamp.

Durkheim, É. 1988. Über soziale Arbeitsteilung: Studie über die Organisation höherer Gesellschaften. Frankfurt a.M.: Suhrkamp.

Eichler, L. 2013. System und Selbst: Arbeit und Subjektivität im Zeitalter ihrer strategischen Anerkennung. Bielefeld: transcript.

Engels, F. 1962. Der Anteil der Arbeit an der Menschwerdung des Affen. In K. Marx \& F. Engels (Eds.), Marx-Engels-Werke: Band 23: 444-455. Berlin: Dietz.

Engels, F. 1963. Brief von Engels an Marx vom 7.10.1858. In K. Marx \& F. Engels (Eds.), Marx-Engels-Werke: Band 29: 357-358. Berlin: Dietz.

Engels, F. 1969. Der Ursprung der Familie, des Privateigentums und des Staates. In K. Marx \& F. Engels (Eds.), Marx-Engels-Werke: Band 21: 30-173. Berlin: Dietz.

Fiss, P. C., \& Zajac, E. J. 2006. The Symbolic Management of Strategic Change: Sensegiving via Framing and Decoupling. The Academy of Management Journal, 49: 1173-1193.

Fligstein, N. 1996. Markets as Politics. A Political and Cultural Approach to Market Institutions. American Sociological Review, 61: 656-673.

Fligstein, N. 2001. The Architecture of Markets. An Economic Sociology of Twenty-First-Century Capitalist Societies. Princeton: Princeton University Press.

Ford, H. 1923. Mein Leben und Werk. Leipzig: List.

Forrester, V. 2001. Die Diktatur des Profits. München: Carl Hanser.

Fourcade, M. 2011. Cents and Sensibility: Economic Valuation and the Nature of "Nature". American Journal of Sociology, 116: 1721-1777.

Friedberg, E. 1995. Ordnung und Macht. Frankfurt a.M., New York: Campus.

Friedman, A. 1977. Industry and Labour. London: Macmillan.

Friedmann, G. 1959. Grenzen der Arbeitsteilung. Frankfurt a.M.: EVA.

Galbraith, J. K. 2007. The New Industrial State. Princeton: Princeton University Press.

Geiger, T. 1929. Zur Soziologie der Industriearbeit und des Betriebes. Die Arbeit, 6: 673-689 und 766-781.

Geiger, T. 1932. Die soziale Schichtung des deutschen Volkes: Soziographischer Versuch auf statistischer Grundlage. Stuttgart: Ferdinand Enke.

Geiger, T. 1949. Die Klassengesellschaft im Schmelztiegel. Köln, Hagen: Gustav Kiepenheuer. 
Georgeou, N. 2012. Neoliberalism, Development, and Aid Volunteering. New York: Routledge.

Gershuny, J. 1978. After Industrial Society? The Emerging Self Service Economy. London, Basingstoke: Macmillan.

Glick, M., \& Brenner, R. 1999. Der Regulationsansatz: Theorie und Geschichte. In Arbeitsgruppe Marxismus (Ed.), Kapitalistische Entwicklung und Krisen: Einemarxistische Kritik der "Regulationstheorie": 37-130. Wien: Arbeitsgruppe Marxismus.

Glucksmann, M. 1990. Women Assemble: Women Workers and the New Industries in Inter-war Britain. London, New York: Routledge.

Goffman, E. 1956. The Presentation of Self in Everyday Life. New York: Doubleday.

Goffman, E. 1971. Role Distance. In E. Goffman (Ed.), Encounters: Two Studies in the Sociology of Interaction: 73-134. London: Allen Lane.

Goldthorpe, J. H., Lockwood, D., Bechhofer, F., \& Platt, J. 1967. The Affluent Worker and the Thesis of Embourgeoisement. Some Preliminary Research Findings. Sociology, 1: 11-31.

Goldthorpe, J. H., Lockwood, D., Bechhofer, F., \& Platt, J. 1968. The Affluent Worker: Industrial Attitudes and Behaviour. London: Cambridge University Press.

Graeber, D. 2011. Debt: The First 5000 Years. New York: Melville House.

Gramsci, A. 1967. Philosophie der Praxis. Frankfurt a.M.: Fischer.

Gramsci, A. 1999. Amerikanismus und Fordismus. In A. Gramsci (Ed.), Gefängnishefte: Band 9: 2061-2101. Hamburg: Argument Verlag.

Guidi, G., Bronzino, A., \& Germanetto, L. 1974. Fiat: Struttura aziendale e organizzazione della sfruttamento. Mailand: Mazotta.

Gurland, A. R. L. 1969. Zur Theorie der sozial-ökonomischen Entwicklung der gegenwärtigen Gesellschaft. In T. W. Adorno (Ed.), Spätkapitalismus oder Industriegesellschaft? Stuttgart: Ferdinand Enke: 48-62. Stuttgart: Ferdinand Enke.

Haber, S. 1964. Efficiency and Uplift: Scientific Management in the Progressive Era 1890-1920. Chicago, London: University of Chicago Press.

Habermas, J. 1981. Theorie des kommunikativen Handelns. Frankfurt a.M.: Suhrkamp.

Hack, L. 1977. Subjektivität im Alltagsleben: Zur Konstitution sozialer Relevanzstrukturen. Frankfurt a.M., New York: Campus.

Hall, P., \& Soskice, D. 2001. An Introduction to Varieties of Capitalism. In P. Hall \& D. Soskice (Eds.), Varieties of Capitalism: The Institutional Foundations of Comparative Advantage: 1-68. Oxford: Oxford University Press.

Hammer, M., \& Champy, J. 1993. Reengineering the Corporation: A Manifesto for Business Revolution. New York: HarperBusiness.

Häußermann, H., \& Siebel, W. 1996. Dienstleistungsgesellschaften. Frankfurt a.M.: Suhrkamp.

Haug, W. F. 2002. Karl Marx - der Kritiker des Kapitalismus. Das Argument, 245: 229-240.

Healy, K. 2006. Last Best Gifts: Altruism and the Market for Human Blood and Organs. Chicago: University of Chicago Press.

Herkommer, S., \& Bierbaum, H. 1979. Industriesoziologie: Bestandsaufnahme, Kritik, Weiterentwicklung. Stuttgart: Ferdinand Enke.

Hirsch, J. 1995. Der nationale Wettbewerbsstaat: Staat, Demokratie und Politik im globalen Kapitalismus. Berlin: Edition ID Archiv.

Hirsch, J., \& Roth, R. 1986. Das neue Gesicht des Kapitalismus: Vom Fordismus zum Post-Fordismus. Hamburg: VSA.

Hochschild, A. R. 1983. The Managed Heart: Commercialization of Human Feeling. Berkeley: University of California Press. 
Hoefnagels, H. 1966. Soziologie des Sozialen: Einführung in das soziologische Denken. Essen: Hans Driewer.

Hofstätter, P. R. 1963. Einführung in die Sozialpsychologie. Stuttgart, Wien: Kröner.

Holbeche, L. 2015. The Agile Organization: How to Build an Innovative, Sustainable and Resilient Business. London: Kogan Page.

Holloway, J., \& Piciotto, S. 1979. Introduction: Towards a Materialist Theory of the State. In J. Holloway \& S. Picciotto (Eds.), State and Capital: A Marxist Debate: 1-31. Austin. University of Texas Press.

Horx, M. 2001. Smart Capitalism. Das Ende der Ausbeutung. Frankfurt a.M.: Eichborn.

Hounshell, D. A. 1985. From the American System to Mass Production: 1800-1932. Baltimore: Johns Hopkins University Press.

Illich, I. 1979. Entmündigende Expertenherrschaft. In I. Illich (Ed.), Entmündigung durch Experten: Zur Kritik der Dienstleistungsberufe: 7-35. Reinbek: Rowohlt.

Jakob, M. 1999. Die Regulationstheorie. In Arbeitsgruppe Marxismus (Ed.), Kapitalistische Entwicklung und Krisen: Eine marxistische Kritik der "Regulationstheorie": 7-36. Wien. Arbeitsgruppe Marxismus.

Jessop, B. 2003. Postfordismus und wissensbasierte Ökonomie. Eine Reinterpretation des Regulationsansatzes. In U. Brand \& W. Raza (Eds.), Fit für den Postfordismus?: Theoretisch-politische Perspektiven des Regulationsansatzes: 89-113. Münster: Westfälisches Dampfboot.

Jessop, B., \& Sum, N.-L. 2006. Beyond the Regulation Approach: Putting Capitalist Economies in their Place. Cheltenham, Northampton: Edward Elgar.

Jochum, G. 2010. Zur historischen Entwicklung des Verständnisses von Arbeit. In F. Böhle, G. G. Voß, \& G. Wachtler (Eds.), Handbuch Arbeitssoziologie: 81-125. Wiesbaden: VS Verlag für Sozialwissenschaften.

Jürgens, U. 1995. Lean Production in Japan. Myth and Reality. In W. Littek \& T. Charles (Eds.), The New Division of Labour: Emerging Forms of Work Organisation in International Perspective: 349-466. Berlin: de Gruyter.

Karlsson, J. 2004. The Ontology of Work. Social Relations and Doing in the Sphere of Necessity. In S. Fleetwood \& S. Ackroyd (Eds.), Critical Realist Applications in Organisation and Management Studies: 84-104. London, New York: Routledge.

Karsunke, Y., \& Wallraff, G. 1970. Fragebogen für Arbeiter. Kursbuch, 21: 2-8.

Katz, H. (Ed.). 1997. Telecommunications: Restructuring Work and Employment Relations Worldwide. Ithaca: Cornell University Press.

Kern, H. 1997. Industriesoziologie weit gedacht. In D. Bieber (Ed.), Technikentwicklung und Industriearbeit: 29-44. Frankfurt a.M., New York: Campus.

Kern, H., \& Schumann, M. 1970. Industriearbeit und Arbeiterbewußtsein. Frankfurt a.M.: Suhrkamp.

Kern, H., \& Schumann, M. 1984a. Das Ende der Arbeitsteilung?: Rationalisierung in der industriellen Produktion. München: Beck.

Kern, H., \& Schumann, M. 1984b. Vers une déprofessionnalisation du travail industriel. Sociologie du travail, 26: 398-406.

Kieserling, A. 2000. Die Soziologie der Selbstbeschreibung. In H. d. Berg \& J. F. Schmidt (Eds.), Rezeption und Reflexion: Zur Resonanz der Systemtheorie Niklas Luhmanns außerhalb der Soziologie: 38-92. Frankfurt a.M.: Suhrkamp.

Kieserling, A. 2003. Makropolitik, Mikropolitik, Politik der Protestbewegungen. In A. Nassehi \& M. Schroer (Eds.), Der Begriff des Politischen: 419-439. BadenBaden: Sonderband 14 der Sozialen Welt. 
Kluth, H. 1995. Arbeiterjugend: Begriff und Wirklichkeit. In H. Schelsky (Ed.), Arbeiterjugend gestern und heute: 16-174. Heidelberg: Quelle und Meyer.

Kocka, J. 1983. Lohnarbeit und Klassenbildung: Arbeiter und Arbeiterbewegung in Deutschland 1800-1975. Berlin: J.H.W. Dietz Nachfolger.

Kocka, J. 1990. Arbeitsverhältnisse und Arbeiterexistenzen: Grundlage der Klassenbildung im 19. Jahrhundert. Bonn: J.H.W. Dietz Nachfolger.

Krippner, G. R. 2011. Capitalizing on Crisis: The Political Origins of the Rise of Finance. Cambridge, London: Harvard University Press.

Krishnamurthy, M. 2004. Resources and Rebels: A Study of Identity Management in Indian Call Centers. Anthropology of Work Review, 25: 9-18.

Kronauer, M. 1997. "Soziale Ausgrenzung" und "Underclass": Über neue Formen der gesellschaftlichen Spaltung. Leviathan, 25: 28-49.

Kronauer, M. 2002. Exklusion: Die Gefährdung des Sozialen im hoch entwickelten Kapitalismus. Frankfurt a.M., New York: Campus.

Kühl, S. 2002. Vom Arbeitskraftunternehmer zum Arbeitskraftkapitalisten. In E. Kuda \& J. Strauß (Eds.), Arbeitnehmer als Unternehmer?: Herausforderungen für Gewerkschaften und berufliche Bildung: 81-99. Hamburg: VSA.

Küh1, S. 2003. Exit: Wie Risikokapital die Regeln der Wirtschaft verändert. Frankfurt a.M., New York: Campus.

Kühl, S. 2013. Organizations. A Systems Approach. Farnham: Gower.

Kühl, S. 2014. The Sudoku-Effect: Universities in the Vicious Circle of Bureaucracy. Amsterdam: Springer International.

Küh1, S. 2017. When the Monkeys Run the Zoo: The Pitfalls of Flat Hierarchies. Princeton, Hamburg, Shanghai, Singapore, Versailles: Organizational Dialogue Press.

Kühl, S. 2018a. Sisyphus in Management: The Futile Search for the Optimal Organizational Structure. Princeton, Hamburg, Shanghai, Singapore, Versailles: Organizational Dialogue Press.

Kühl, S. 2018b. The Rainmaker Effect: Contradictions of the Learning Organization. Princeton, Hamburg, Shanghai, Singapore, Versailles: Organizational Dialogue Press.

Kurbjuweit, D. 2003. Unser effizientes Leben. Die Diktatur der Ökonomie und ihre Folgen. Hamburg: Rowohlt.

Landier, H. 1987. L'entreprise polycellulaire: Pour penser l'entreprise de demain. Paris: Éditions Entreprise moderne.

Landshut, S. 1956. Die Gegenwart im Lichte der Marxschen Lehre. Hamburger Jahrbuch für Wirtschafts- und Gesellschaftspolitik, 1: 42-55.

Lang, R., \& Hellpach, W. 1922. Gruppenfabrikation. Berlin: Springer.

Leidner, R. 1993. Fast Food, Fast Talk: Service Work and the Routinization of Everyday Life. Berkeley: University of California Press.

Leithäuser, T., Volmerg, B., Salje, G., Volmerg, U., \& Wutka, B. 1977. Entwurf zu einer Theorie des Alltagsbewußtseins. Frankfurt a.M.: Suhrkamp.

Liessmann, K. P. 2000. Im Schweiße deines Angesichts. Zum Begriff der Arbeit in den anthropologischen Konzepten der Moderne. In U. Beck (Ed.), Die Zukunft von Arbeit und Demokratie: 85-107. Frankfurt a.M., New York: Campus.

Lillrank, P. 1995. The Transfer of Management Innovation from Japan. Organization Studies, 16: 971-989.

Lincoln, J. R., \& Kalleberg, A. L. 1990. Culture, Control and Commitment: A Study of Work Organization and Work Attitudes in the United States and Japan. Cambridge: Cambridge University Press. 
Linhart, R. 1978. L'Établi. Paris: Edition de Minuit.

Lipietz, A. 1985. Akkumulation, Krisen und Auswege aus der Krise. Einige methodologische Anmerkungen zum Begriff der "Regulation". Prokla, 58: 109-137.

Lipietz, A. 1998. Nach dem Ende des "goldenen Zeitalters". Regulation und Transformation kapitalistischer Gesellschaften. Berlin, Hamburg: Argument Verlag.

Littler, C. R. 1982. The Development of the Labour Process in Capitalist Societies: A Comparative Study of Transformation of Work in Britain, Japan and the USA. London: Heinemann.

Littler, C. R. 1990. The Labour Process Debate. A Theoretical Review 1974-1988. In D. Knights \& H. Willmott (Eds.), Labour Process Theory: 46-94. London: Macmillan.

Littler, C. R., \& Salaman, G. 1982. Bravermania and Beyond: Recent Theories of the Labour Process. Sociology, 16: 251-269.

Littler, C. R., \& Willmott, H. 1990. Introduction. In D. Knights \& H. Willmott (Eds.), Labour Process Theory: 1-45. London: Macmillan.

Luhmann, N. 1964. Funktionen und Folgen Formaler Organisation. Berlin: Duncker \& Humblot.

Luhmann, N. 1965. Grundrechte als Institution. Berlin: Duncker \& Humblot.

Luhmann, N. 1971. Zweck - Herrschaft - System: Grundbegriffe und Prämissen Max Webers. In N. Luhmann (Ed.), Politische Planung: 90-112. Opladen: WDV.

Luhmann, N. 1973. Zweckbegriff und Systemrationalität. Frankfurt a.M.: Suhrkamp.

Luhmann, N. 1975a. Allgemeine Theorie organisierter Sozialsysteme. In N. Luhmann (Ed.), Soziologische Aufklärung 2: 39-50. Opladen: WDV.

Luhmann, N. 1975b. Interaktion, Organisation, Gesellschaft. In N. Luhmann (Ed.), Soziologische Aufklärung 2: 9-20. Opladen: Westdeutscher Verlag.

Luhmann, N. 1975c. Legitimation durch Verfahren. Frankfurt a.M.: Suhrkamp.

Luhmann, N. 1975d. Macht. Stuttgart: Enke.

Luhmann, N. 1975e. Selbst-Thematisierungen des Gesellschaftssystems. In N. Luhmann (Ed.), Soziologische Aufklärung 2: 72-102. Opladen: WDV.

Luhmann, N. 1984. Soziale Systeme: Grundriß einer allgemeinen Theorie. Frankfurt a.M.: Suhrkamp.

Luhmann, N. 1985. Zum Begriff der sozialen Klasse. In N. Luhmann (Ed.), Soziale Differenzierung: Zur Geschichte einer Idee: 119-163. Opladen: WDV.

Luhmann, N. 1988a. Die Wirtschaft der Gesellschaft. Frankfurt a.M.: Suhrkamp.

Luhmann, N. 1988b. Geld als Kommunikationsmedium: Über symbolische und diabolische Generalisierungen. In N. Luhmann (Ed.), Die Wirtschaft der Gesellschaft: 230-271. Frankfurt a.M.: Suhrkamp.

Luhmann, N. 1988c. Kapital und Arbeit. In N. Luhmann (Ed.), Die Wirtschaft der Gesellschaft: 151-176. Frankfurt a.M.: Suhrkamp.

Luhmann, N. 1988d. Organisation. In W. Küpper \& G. Ortmann (Eds.), Mikropolitik: Rationalität, Macht und Spiele in Organisationen: 165-186. Opladen: WDV.

Luhmann, N. 1991. Am Ende der kritischen Soziologie. Zeitschrift für Soziologie, 20: $147-152$.

Luhmann, N. 1995a. Die Form "Person". In N. Luhmann (Ed.), Soziologische Aufklärung 6: 142-154. Opladen: WDV.

Luhmann, N. 1995b. Inklusion und Exklusion. In N. Luhmann (Ed.), Soziologische Aufklärung 6: 237-265. Opladen: WDV.

Luhmann, N. 1996. Systemtheorie und Protestbewegungen. Ein Interview. In K.-U. Hellmann (Ed.), Protest: Systemtheorie und soziale Bewegungen: 175-200. Frankfurt a.M.: Suhrkamp. 
Luhmann, N. 1997. Die Gesellschaft der Gesellschaft. Frankfurt a.M.: Suhrkamp.

Luhmann, N. 2000. Organisation und Entscheidung. Opladen: WDV.

Lukacs, G. 1923. Geschichte und Klassenbewußtsein. Berlin: Malik-Verlag.

Lutz, B. 1989. Der kurze Traum immerwährende Prosperität. Eine Neuinterpretation der industriell-kapitalistischen Entwicklung im Europa des 20. Jahrhunderts. Frankfurt a.M., New York: Campus.

Mallet, S. 1969. La nouvelle classe ouvrière. Paris: Seuil.

March, J. G. 1988. Introduction: A Chronicle of Speculations about DecisionMaking in Organizaitons. In J. G. March (Ed.), Decisions and Organizations: 1-21. Oxford: Blackwell.

March, J. G., \& Simon, H. A. 1958. Organizations. New York: John Wiley.

Marcuse, H. 1973. On the Philosophical Foundation of the Concept of Labor in Economics. Telos, 16: 9-37.

Martin, P. Y. 2003. "Said and Done" Versus "Saying and Doing": Gendering Practices, Practicing Gender at Work. Gender \& Society, 17: 342-366.

Marx, K. 1958. Thesen über Feuerbach. In K. Marx \& F. Engels (Eds.), MarxEngels-Werke: Band 3: 533-535. Berlin: Dietz.

Marx, K. 1959a. Das Elend der Philosophie. In K. Marx \& F. Engels (Eds.), MarxEngels-Werke: Band 4: 63-182. Berlin: Dietz.

Marx, K. 1959b. Die moralisierende Kritik und die kritisierende Moral. In K. Marx \& F. Engels (Eds.), Marx-Engels-Werke: Band 4: 331-360. Berlin: Dietz.

Marx, K. 1960. Der achtzehnte Brumaire des Louis Bonaparte. In K. Marx \& F. Engels (Eds.), Marx-Engels-Werke: Band 8: 111-207. Berlin: Dietz.

Marx, K. 1961a. Einleitung (zur Kritik der politischen Ökonomie). In K. Marx \& F. Engels (Eds.), Marx-Engels-Werke: Band 13: 615-641. Berlin: Dietz.

Marx, K. 1961b. Zur Kritik der Politischen Ökonomie. In K. Marx \& F. Engels (Eds.), Marx-Engels-Werke: Band 13: 3-160. Berlin: Dietz.

Marx, K. 1962a. Das Kapital: Erstes Buch. In K. Marx (Ed.), Marx-Engels-Werke: Band 23: 11-955. Berlin: Dietz.

Marx, K. 1962b. Fragebogen für Arbeiter. In K. Marx \& F. Engels (Eds.), MarxEngels-Werke: Band 19: 230-237. Berlin: Dietz.

Marx, K. 1964. Das Kapital. Drittes Buch. In K. Marx \& F. Engels (Eds.), MarxEngels-Werke: Band 25: 7-930. Berlin: Dietz.

Marx, K. 1985. Ökonomisch-Philosophische Manuskripte. In K. Marx \& F. Engels (Eds.), Marx-Engels-Werke: Band 40: 465-588. Berlin: Dietz.

Marx, K., \& Engels, F. 1958a. Die deutsche Ideologie. In K. Marx \& F. Engels (Eds.), Marx-Engels-Werke: Band 3: 9-33. Berlin: Dietz.

Marx, K., \& Engels, F. 1958b. Manifest der kommunistischen Partei. In K. Marx \& F. Engels (Eds.), Marx-Engels-Werke: Band 3: 459-493. Berlin: Dietz.

Maurice, M., Sellier, F., \& Silvestre, J. J. 1982. Politique d'éducation et organisation industrielle en France et en Allemagne. Paris: Presses Universitaires de France.

Maurice, M., Sorge, A., \& Warner, M. 1980. Societal Differences in Organizing Manufacturing Units: A Comparison of France, West Germany, and Great Britain. Organization Studies, 1: 59-86.

Mayer, T. 1994. Analytical Marxism. Thousand Oaks, London, New Delhi: Sage.

Meyer, J. W., \& Rowan, B. 1977. Institutionalized Organizations: Formal Structure as Myth and Ceremony. American Journal of Sociology, 83: 340-363.

Mizruchi, M. S. 2004. Berle and Means Revisited: The Governance and Power of Large U.S. Corporations. Theory and Society, 33: 579-617. 
Mizruchi, M. S., \& Stearns, L. B. 1988. A Longitudinal Study of the Formation of Interlocking Directorates. Administrative Science Quarterly, 33: 194-210.

Moers, W. 1993. On the Road. Frankfurt a.M.: Eichborn.

Moldaschl, M., \& Weber, W. G. 1998. The "Three Waves" of Industrial Group Work: Historical Reflections on Current Research on Group Work. Human Relations, 51: 347-388.

Mooser, J. 1983. Auflösung der proletarischen Milieus. Klassenbindung und Individualisierung in der Arbeiterschaft vom Kaiserreich bis in die Bundesrepublik Deutschland. Soziale Welt, 34: 270-306.

Morf, O. 1970. Geschichte und Dialektik in der politischen Ökonomie: Zum Verhältnis von Wirtschaftstheorie und Wirtschaftsgeschichte bei Karl Marx (2nd edn.). Frankfurt a.M.: EVA.

Müller, H. P. 1994. Abschied von der Klassengesellschaft? Über ein "Menetekel" im Spiegel der soziologischen Diskussion. In C. Görg (Ed.), Gesellschaft im Übergang: Perspektiven kritischer Soziologie: 120-140. Darmstadt: Wissenschaftliche Buchgesellschaft.

Müller, W., \& Neusüss, C. 1979. The "Welfare State Illusion" and the Contradiction between Wage Labour and Capital. In J. Holloway \& S. Picciotto (Eds.), State and Capital. A Marxist Debate: 32-39. Austin: University of Texas Press.

Nadler, R. 1999. The Rise of Worker Capitalism. Washington, DC: Cato Policy Analysis No. 359.

Neuendorff, H., \& Sabel, C. 1978. Zur relativen Autonomie der Deutungsmuster. In K. M. Bolte (Ed.), Materialien aus der soziologischen Forschung: 842-863. Darmstadt, Neuwied: Luchterhand.

Oakley, A. 1985. The Sociology of Housework. Oxford: Blackwell.

Oakley, A. 1990. Housewife (2nd edn.). London: Pinguin.

Offe, C. 1984. Arbeit als soziologische Schlüsselkategorie? In C. Offe (Ed.), Arbeitsgesellschaft: Strukturprobleme und Zukunftsperspektiven: 13-43. Frankfurt a.M., New York: Campus.

Offe, C. 1985. Disorganized Capitalism: Contemporary Transformation of Work and Politics. Cambridge: Polity Press.

Ortmann, G. 1994. Dark Stars - Institutionelles Vergessen in der Industriesoziologie. In N. Beckenbach \& W. van Treek (Eds.), Umbrüche gesellschaftlicher Arbeit: 85-118. Göttingen: Soziale Welt Sonderband 9.

Palmer, D. 1983. Broken Ties: Interlocking Directorates and Intercorporate Coordination. Administrative Science Quarterly, 28: 40-55.

Parsons, T. 1971. The System of Modern Society. Englewood Cliffs: Prentice-Hall.

Piore, M. J., \& Sabel, C. F. 1984. The Second Industrial Divide: Possibilities for Prosperity. New York: Basic Books.

Polanyi, K. 1977. The Great Transformation: Politische und ökonomische Ursprünge von Gesellschaften und Wirtschaftssystemen. Wien: Europa Verlag.

Pondy, L. R., \& Boje, D. M. 1980. Bringing Mind Back In. In W. M. Evan (Ed.), Frontiers in Organization and Management: 83-101. New York: Praeger.

Popitz, H. 1958. Zum Begriff der Klassengesellschaft. Hamburger Jahrbuch für Wirtschafts und Gesellschaftspolitik, 3: 93-102.

Popitz, H., Bahrdt, H. P., Jüres, E. A., \& Kesting, H. 1957. Das Gesellschaftsbild des Arbeiters: Soziologische Untersuchungen in der Hüttenindustrie. Tübingen: J.C.B. Mohr.

Poulantzas, N. 1973. Political Power and Social Classes. London: New Left Books. 
Powell, W. W. 1990. Neither Market Nor Hierarchy: Network Forms of Organization. Research in Organizational Behavior, 12: 295-336.

Projektgruppe Automation und Qualifikation. 1976. Entwicklung der Arbeitstätigkeiten und die Methode ihrer Erfassung. Berlin: Argument Verlag.

Provis, C. 2009. On the Definition of Work. Labour \& Industry, 20: 123-137.

Quesnay, F. 1888. Oeuvres économiques et philosophiques. Frankfurt a.M.: Baer Peelman.

Ransome, P. 1996. The Work Paradigm. A Theoretical Investigation of Concepts of Work. Aldershot: Avebury.

Reich, A. D. 2014. Contradictions in the Commodification of Hospital Care. American Journal of Sociology, 119: 1576-1628.

Robertson, B. J. 2015. Holacracy: The New Management System for a Rapidly Changing World. New York: Holt.

Saint-Simon, C.-H. d. 1964. Du système industriel. Aalen: Reprografischer Nachdruck Oevres des Saint-Simon et d'Enfantin.

Sako, M., \& Jackson, G. 2006. Strategy Meets Indsitutions: The Transformation of Management-Labor Relations at Deutsche Telekom and NTT. Industrial and Labor Relations Review, 59: 347-366.

Savage, M. 2009. Against Epochalism: An Analysis of Conceptions of Change in British Sociology. Cultural Sociology, 3: 217-238.

Schelsky, H. 1965. Auf der Suche nach Wirklichkeit: Gesammelte Aufsätze. Köln, Düsseldorf: Eugen Diederichs Verlag.

Scott, J. 1997. Corporate Business and Capitalist Classes. Oxford: Oxford University Press.

Scott, W. R. 2001. Institutions and Organizations (2nd edn.). Thousand Oaks: Sage.

Senge, P. M. 1990. The Fifth Discipline: The Art and Practice of the Learning Organization. New York: Doubleday.

Sennett, R. 1998. The Corrosion of Character: The Personal Consequences of Work in the New Capitalism. New York; London: Norton.

Sennett, R., \& Cobb, J. 1972. The Hidden Injuries of Class. New York: Knopf.

Simon, H. A. 1957. Models of Man. New York: John Wiley.

Spencer, D. A. 2000. Braverman and the Contribution of Labour Process Analysis to the Critique of Capitalist Production - Twenty-Five Years on. Work, Employment \& Society, 14: 223-243.

Spencer, H. 1969. Principles of Sociology (3rd edn.). London: Macmillan.

Springer, R. 1999. Rückkehr zum Taylorimus? Arbeitspolitik in der Automobilindustrie am Scheideweg. Frankfurt a.M., New York: Campus.

Stacey, C. 2012. The Caring Self: The Work Experiences of Home Care Aides. Ithaca: Cornell University Press.

Strangleman, T. 2016. The Disciplinary Career of the Sociology of Work. In S. Edgell, H. Gottfried, \& E. Granter (Eds.), The SAGE Handbook of the Sociology of Work and Employment: 17-33. London: Sage.

Sweezy, P. M. 1972. Theorie der kapitalistischen Entwicklung. Frankfurt a.M.: Suhrkamp.

Taylor, F. W. 1967. The Principles of Scientific Management. London: Norton.

Thompson, P., \& O'Doherty, D. P. 2009. Perspectives on Labor Process Theory. In M. Alvesson, T. Bridgman, \& H. Willmott (Eds.), The Oxford Handbook of Critical Management Studies: 99-121. Oxford, New York: Oxford University Press. 


\section{References}

Thompson, P., \& van den Broek, D. 2010. Managerial Control and Workplace Regimes: An Introduction. Work, Employment \& Society, 24: 1-12.

Tilly, C. 1998. Durable Inequality. Berkeley, Los Angeles, London: University of California Press.

Tönnies, F. 2010. Geist der Neuzeit. Wien: Profil-Verlag.

Touraine, A. 1966. La conscience ouvrière. Paris: Seuil.

Useem, M. 1990. Business Restructuring, Management Control, and Corporate Organization. Theory and Society, 19: 681-707.

Useem, M. 1993. Executive Defense. Shareholder Power and Corporate Reorganization. Cambridge: Harvard University Press.

Velthuis, O. 2005. Talking Prices. Symbolic Meanings of Prices on the Market for Contemporary Art. Princeton: Princeton University Press.

Voß, G. G. 1991. Lebensführung als Arbeit: Über die Autonomie der Person im Alltag der Gesellschaft. Stuttgart: Enke.

Voß, G. G. 2010. Was ist Arbeit? Zum Problem eines allgemeinen Arbeitsbegriffs. In F. Böhle, G. G. Voß, \& G. Wachtler (Eds.), Handbuch Arbeitssoziologie: 23-80. Wiesbaden: VS Verlag für Sozialwissenschaften.

Voß, G. G., \& Pongratz, H. J. 1998. Der Arbeitskraftunternehmer. Eine neue Grundform der Ware Arbeitskraft? Kölner Zeitschrift für Soziologie und Sozialpsychologie, 50: 131-158.

Walzer, M. 1983. Spheres of Justice. A Defence of Pluralism and Equality. Oxford: Robertson.

Waring, M. 1999. Counting for Nothing. What Men Value and What Women are Worth (2nd edn.). Toronto, Buffalo: University of Toronto Press.

Wark, M. 1991. From Fordism to Sonyism. New Formations, 15: 43-54.

Warnecke, H.-J. 1993. The Fractal Company: A Revolution in Corporate Culture. Berlin; Heidelberg: Springer.

Weber, M. 1976. Wirtschaft und Gesellschaft. Tübingen: J.C.B. Mohr.

Weber, M. 1990. Gesammelte Aufsätze zur Religionssoziologie: Band 1 (10th edn.). Tübingen: Mohr.

Weiss, H. 1936. Die "Enquête Ouvrière" von Karl Marx. Zeitschrift für Sozialforschung, 5: 76-98.

Westphal, J. D., \& Zajac, E. J. 1998. Symbolic Management of Stockholders: Corporate Governance Reforms and Shareholder Reactions. Administrative Science Quarterly, 43: 127-153.

Wildemann, H. 1988. Die modulare Fabrik: Kundennahe Produktion durch Fertigungssegmentierung. München: TCW.

Willes, M. 2014. The Gardens of the British Working Class. New Haven: Yale University Press.

Willis, P. 1977. Learning to Labor: How Working Class Kids Get Working Class Jobs. Farnborough: Taylor \& Francis.

Wilson, G., \& Roscigno, V. J. 2016. Public Sector Reform and Racial Occupational Mobility. Work and Occupations, 43: 259-293.

Windolf, P. 2002. Corporate Networks in Europe and the United States. Oxford, New York: Oxford University Press.

Wingfield, A. H., \& Alston, R. S. 2014. Maintaining Hierarchies in Predominantly White Organizations: A Theory of Racial Tasks. American Behavioral Scientist, 58: 274-287.

Womack, J. P., Jones, D. T., \& Ross, D. 1990. The Machine that Changed the World. New York: Maxwell Macmillan International. 
Wood, S., \& Kelly, J. 1982. Taylorism, Responsible Autonomy and Management Strategy. In S. Wood (Ed.), The Degradation of Work? Skill, Deskilling and the Labour Process: Skill, Deskilling and the Labour Process: 74-89. London: Hutchinson.

Wright, E. O. 1978. Class, Crisis and the State. London: New Left Books.

Wright, E. O. 1985. Classes. London: Verso.

Zald, M. N. 1969. The Power and Function of Boards of Directors: A Theoretical Synthesis. American Journal of Sociology, 75: 97-111.

Zelizer, V. A. 1985. Pricing the Priceless Child. The Changing Social Value of Children. New York: Basic Books. 
